\title{
Next Generation Nuclear Plant Materials Selection and Qualification Program Plan
}

G. O. Hayner

E. L. Shaber

R. E. Mizia

P. A. Lessing

$R$ L. Bratton

J. S. Morton

W. K. Sowder

T. C. Totemeier

W. E. Windes

R. N. Wright

November 7, 2003

Idaho National Engineering and Environmental Laboratory Bechtel BWXT Idaho, LLC 


\title{
Next Generation Nuclear Plant Materials Selection and Qualification Program Plan
}

\author{
G. O. Hayner, E. L. Shaber, R. E. Mizia, P. A. Lessing,
}

R. L. Bratton, J. S. Morton, W. K. Sowder, T. C. Totemeier,

W. E. Windes, R. N. Wright

$\frac{\text { National Technical Director and Staff }}{W . R . C o r w i n, ~}$

W. R. Corwin, Director

T. D. Burchell, J. M. Corum, J. W. Klett, R. K. Nanstad, L. L. Snead, R. E. Stoller, P. L. Rittenhouse, R. W. Swindeman, D. F. Wilson

Other DOE Laboratory Contractors

R. Jones, F. Gardner

November 7, 2003

Idaho National Engineering and Environmental Laboratory Idaho Falls, Idaho 83415

Prepared for the

U.S. Department of Energy

Assistant Secretary For Office of Nuclear Energy

Under DOE Idaho Operations Office

Contract DE-AC07-99ID13727 
This page intentionally left blank. 


\section{SIGNATURES OF APPROVAL}

Originator:

George O. Hayner

NGNP Materials Selection and Qualification Program Lead

Reviewer:

Russell Jones

Chair, NGNP Materials Review Committee

Approval:

Finis H. Southworth

NGNP Program Manager
Date

Date

Date 
This page intentionally left blank. 


\section{ACKNOWLEDGMENTS}

This report is based on the results from the NGNP Materials Meetings held at the Idaho National Engineering and Environmental Laboratory in Idaho Falls, Idaho on July 8-9, 2003, and at the Oak Ridge National Laboratory (ORNL) in Oak Ridge, Tennessee, on July 29, 2003. These meetings were attended by staff from the national laboratories and the nuclear industry. Additional input was received from the ORNL Metals and Ceramics Division. A list of attendees from the July 8-9 meeting appears in Appendix A. 
This page intentionally left blank. 


\section{EXECUTIVE SUMMARY}

The U.S. Department of Energy (DOE) has selected the Very High Temperature Reactor (VHTR) design for the Next Generation Nuclear Plant (NGNP) Project. The NGNP will demonstrate the use of nuclear power for electricity and hydrogen production without greenhouse gas emissions. The reactor design is a graphite-moderated, helium-cooled, prismatic or pebble bed thermal neutron spectrum reactor with an average reactor outlet temperature of at least $1000^{\circ} \mathrm{C}$. The NGNP will use very high burn up, lowenriched uranium, TRISO-Coated fuel in a once-through fuel cycle. The design service life of the NGNP is 60 years.

The VHTR concept is considered to be the nearest-term reactor design that has the capability to efficiently produce hydrogen. The plant size, reactor thermal power, and core configuration will ensure passive decay heat removal without fuel damage or radioactive material releases during accidents. The NGNP Project design incorporates the following high-level functions:

- Develop and demonstrate a commercial-scale VHTR

- Develop and demonstrate high-efficiency power conversion

- Obtain licenses and permits to construct/operate the NGNP

- Develop and demonstrate hydrogen production

- Include provisions for future testing

- Enable demonstration of energy products and processes.

The goal of the Generation IV NGNP Reactor Project is deployment of a full-scale Nuclear Regulatory Commission (NRC)-licensed demonstration reactor, capable of producing electricity and low-cost hydrogen in the 2015 to 2017 timeframe. The pre-conceptual and conceptual design of the NGNP will be completed during the first three years of the project. The preliminary design, which will be completed by FY-09, will define the final materials requirements for the reactor design. These materials must be fully qualified for the final design process, which is expected to begin in late FY-09.

The objective of the NGNP Reactor Materials Program is to provide the essential materials selection and qualification activities needed to support the design of the reactor and balance of plant. The materials program is being initiated prior to the design effort to ensure that materials test irradiations, long-term testing (e.g., creep), and materials codification activities are initiated early enough to support the design process. A direct relationship exists between component materials feasibility and reactor system design requirements. An additional objective of the materials program is to provide the preliminary materials information required to support initial reactor design/materials selection trade-off studies that will be used to establish reactor system requirements. The Materials Selection and Qualification Program Plan will describe the needs, rationale, and content of the NGNP Materials Program activities.

The thermal, environmental, and service life conditions of the NGNP will make selection and qualification of some high-temperature materials a significant challenge. ; thus, new materials and approaches may be required. Some materials will be exposed to temperatures beyond what is currently allowed in the American Society for Mechanical Engineers (ASME) Boiler and Pressure Vessel (B\&PV) Code for nuclear construction. Numerous areas of the Code will have to be modified or expanded to address these new design conditions.

Some important materials issues that are addressed in this plan are:

- High-temperature mechanical properties (e.g., tensile, creep, creep fatigue, stress-rupture, high and low-cycle fatigue, fracture toughness) in air and impure helium environments 
- Environmental degradation processes from exposure to high-temperature helium with contaminants such as $\mathrm{CO}, \mathrm{CO}_{2}, \mathrm{H}_{2}, \mathrm{H}_{2} \mathrm{O}$, and $\mathrm{CH}_{4}$

- Long-term irradiation effects on mechanical properties (e.g., tensile, creep, creep fatigue, stressrupture, high and low cycle fatigue, fracture toughness)

- High-temperature metallurgical stability (thermal aging effects)

- Development and validation of new sources of graphite materials

- Extension of ASME Code approval for metallic materials at the higher NGNP operating temperatures

- Development and ASME Code approval for graphite, composite, and ceramic materials

- Development of component fabrication technologies for critical components such as the reactor pressure vessel (RPV) and control rods

- Emissivity of the RPV external surface for cool-down under accident conditions.

The NGNP materials program will perform all material identification, selection, testing, and qualification activities required to support the NGNP Project. These include:

- Development of a specific program plan for managing the selection and qualification of all component materials required for the NGNP

- Identification of specific materials for each system component

- Evaluation of the needed testing, ASME B\&PV code and related materials standards work, and analysis required to qualify each identified material

- Preliminary down-selection of component materials based on known requirements, manufacturability, and feasibility of achieving needed code licenseability

- Specification and purchase of representative materials for testing

- Design and construction of capsules and vehicles for irradiation of materials where irradiation test data is required

- Irradiation of needed sample materials

- Materials testing and evaluation, as required, for materials qualification to support the design of the NGNP.

This plan will be updated annually to reflect adjustments in the design requirements basis and their effect on the scope of the materials selection and qualification activities. Funding levels for the identified work are summarized in Section 6.2. 


\section{CONTENTS}

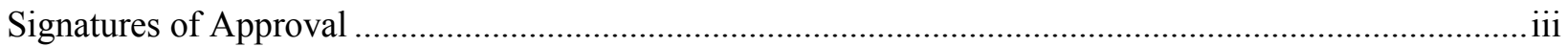

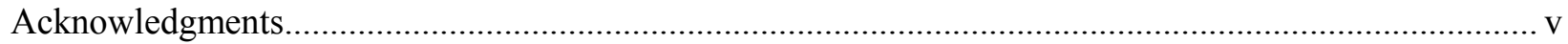

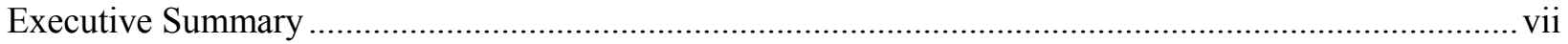

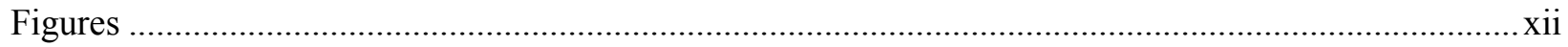

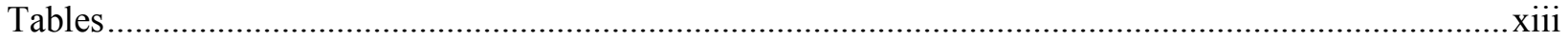

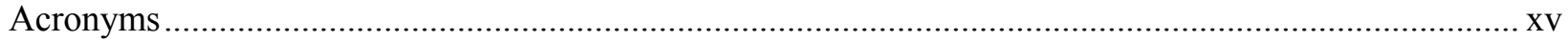

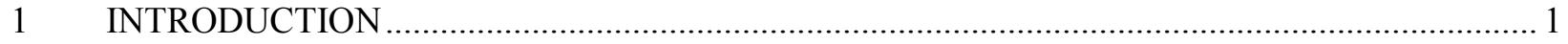

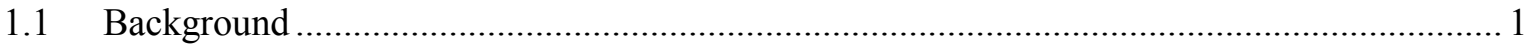

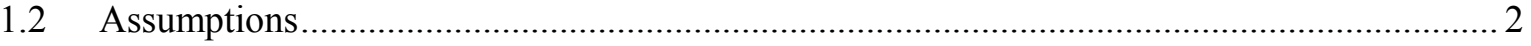

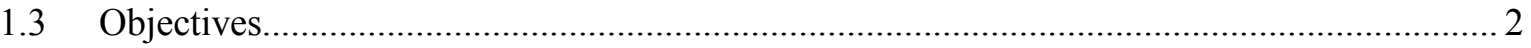

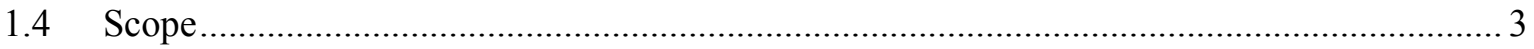

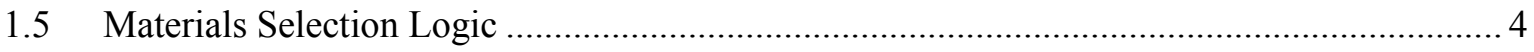



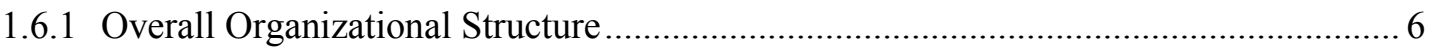

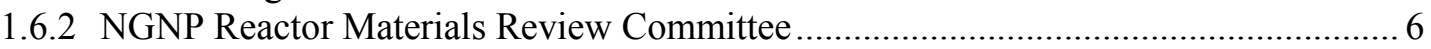

1.6.3 Generation IV Materials Crosscut Interface ................................................................. 6

1.7 Program Interface with Other Design Organizations ...................................................... 7

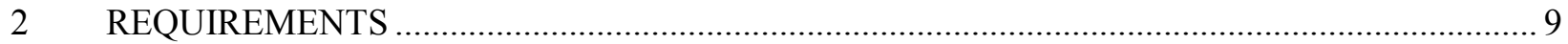

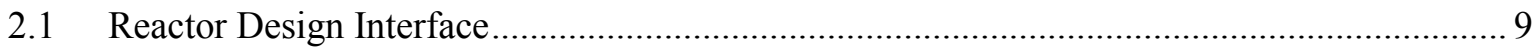

2.1.1 Requirements for High-temperature Materials Structural Design Methodology .......... 9

2.1.2 Formal Materials Design Data Inputs.......................................................................... 9

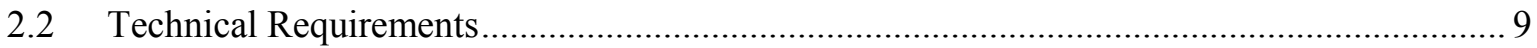



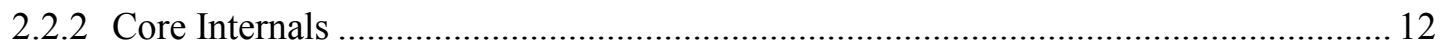

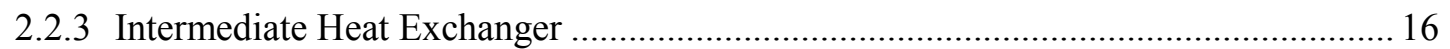

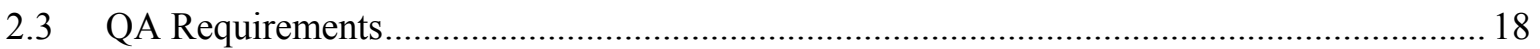

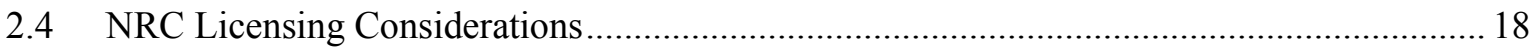

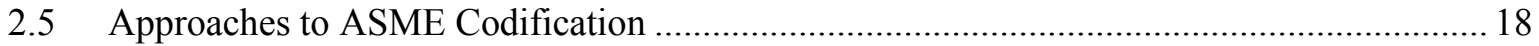






2.5.2 Current ASME B\&PV Code Material Acceptance Criteria ...................................... 19

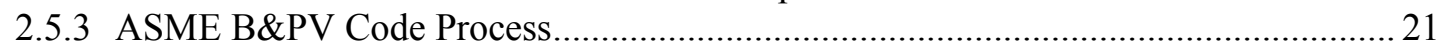

2.5.4 Beyond ASME B\&PV Code Material Acceptance ..................................................... 21

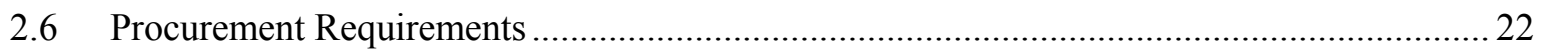

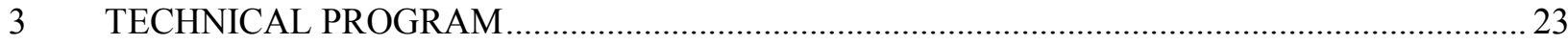

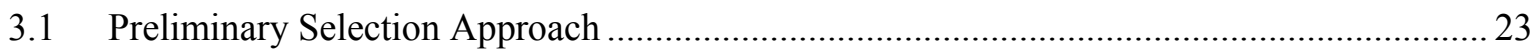

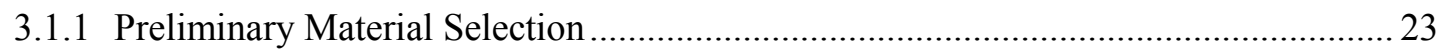

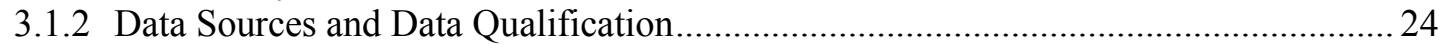

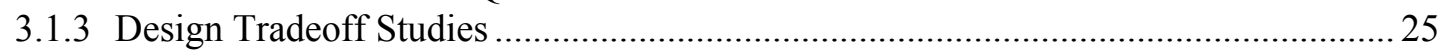

3.2 Candidate Materials Identified for NGNP Components ................................................. 25

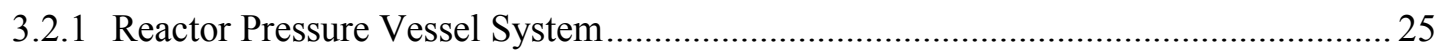

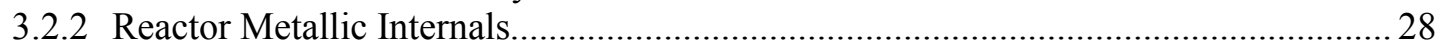

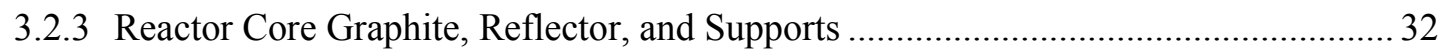

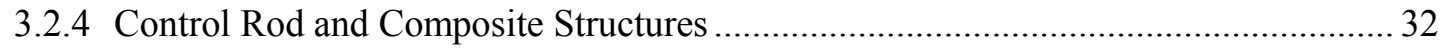

3.2.5 Intermediate Heat Exchanger and Piping .............................................................. 37

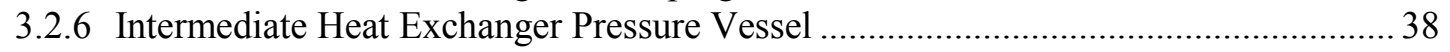



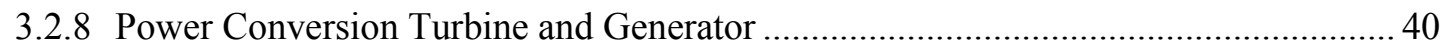

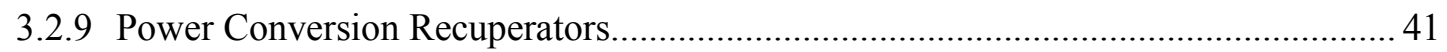



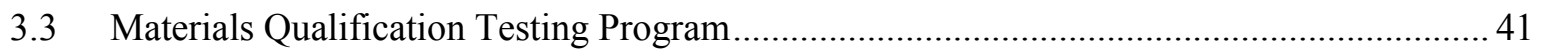

3.3.1 Qualification Testing Facility for Helium Environmental Effects ............................ 41

3.3.2 Considerations in Materials Behavior for Reactor Component Qualification.............. 42

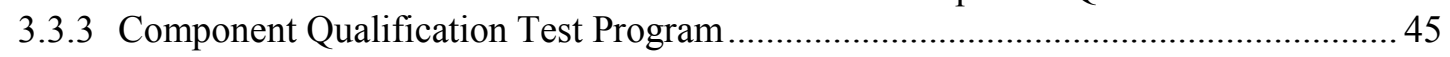

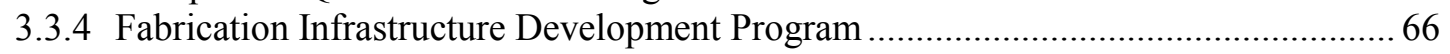

3.3.5 Codes and Standards Qualification Development .................................................... 71

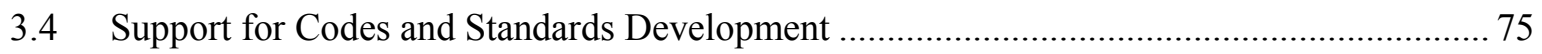



3.4.2 American Society for Testing Materials Standards Program ................................... 75

3.4.3 American Society of Mechanical Engineers Code Expansions/Additions ................... 75

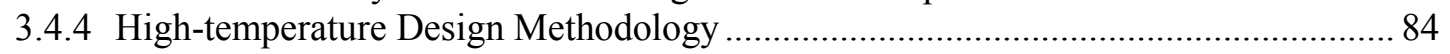

3.4.5 Component Material Life Prediction Modeling......................................................... 89

4 MATERIALS SELECTION AND QUALIFICATION DOCUMENTS .....................................90

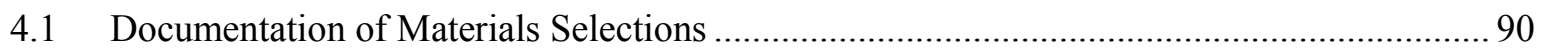

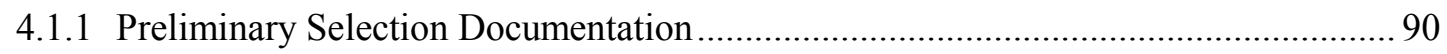

4.1.2 Component Final Material Selection Report ......................................................... 90 


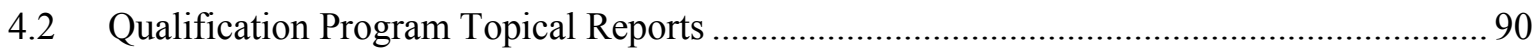

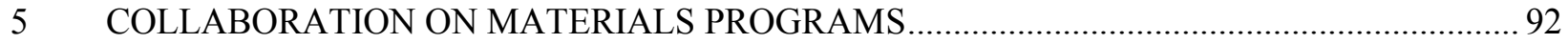

5.1 Collaboration with Other U.S. Materials Developments ................................................ 92

5.2 International Nuclear Program Collaboration ................................................................ 92

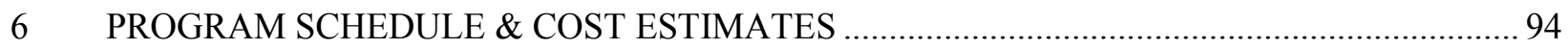





6.1.2 Schedule Basis .................................................................................. 94



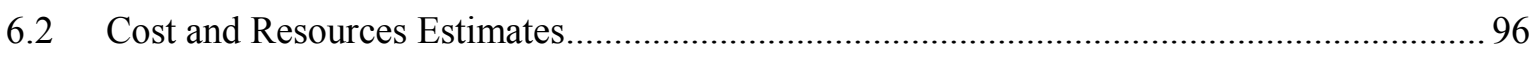

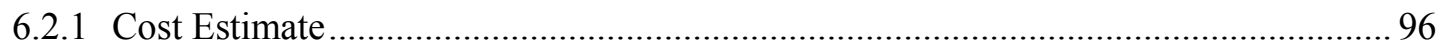

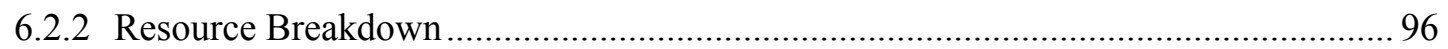

Appendix A - July 8-9, 2003, Meeting Attendees................................................................................. A-1

Appendix B - Next Generation Nuclear Plant (NGNP) Materials Review Committee Charter .............. B-1

Appendix C - Guidance on Qualification of Existing Data.................................................................

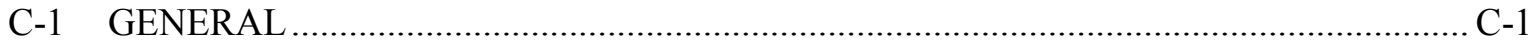

C-2 SELECTING DATA SETS FOR QUALIFICATION .................................................. C-1

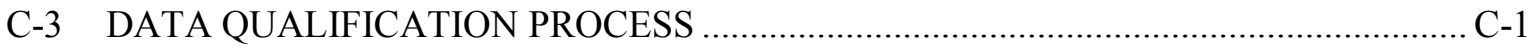

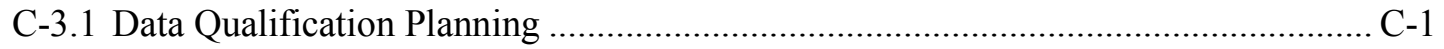



C-3.3 Data Qualification Attributes...............................................................................



C-4.1 Quality Assurance Program Equivalency Method................................................

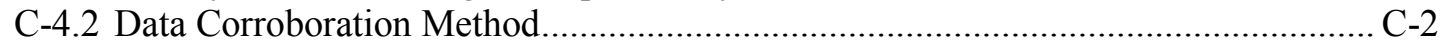

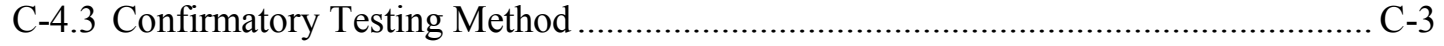

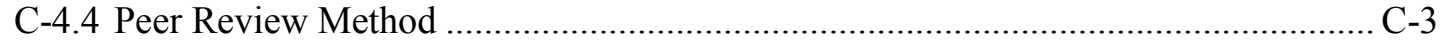

C-5 DOCUMENTATION OF RESULTS …....................................................................

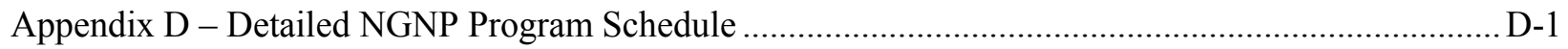






\section{FIGURES}

Figure 1-1. Materials Selection Logic Flow Diagram. ..................................................................... 5

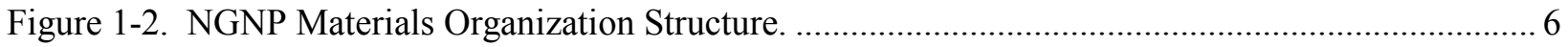

Figure 1-3. Basic Interfaces Expected Between the Materials and Design Functions.............................. 8



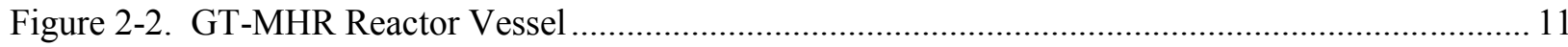

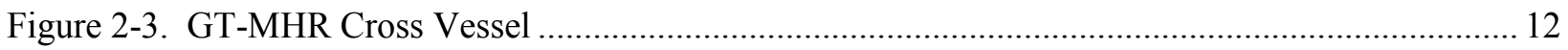

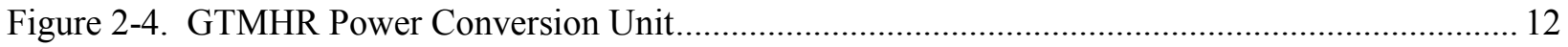

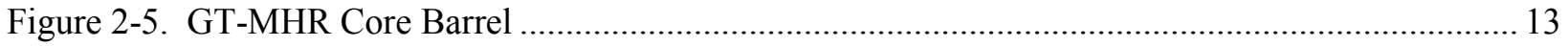

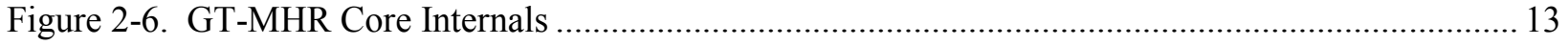

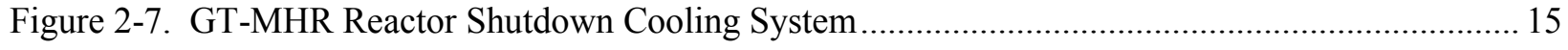

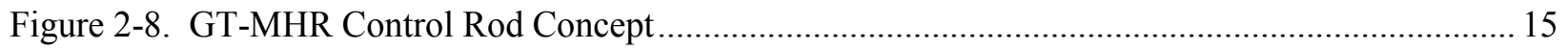



Figure 3-1. Ratio of ultimate strength of irradiation and unirradiated composites as a function

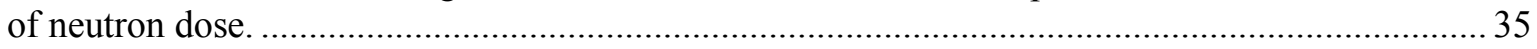

Figure 3-2. Processing steps in the production of carbon-carbon composite materials........................... 36

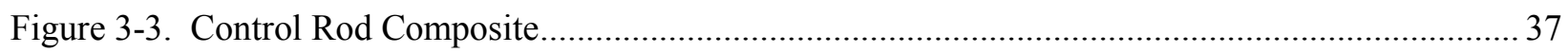



Figure 3-5. Effects of environment (argon and air) and temperature on the emissivity of type 304 SS.... 50

Figure 3-6. The process step in the manufacturing of nuclear graphite ............................................... 51

Figure 3-7. A graphite fuel element from the Fort St. Vrain reactor. ................................................... 52

Figure 3-8. The radiation damage mechanism of graphite .............................................................. 52

Figure 3-9. Schematic representation of the irradiation induced volume change behavior of a

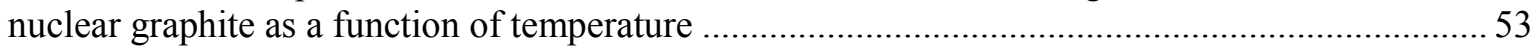

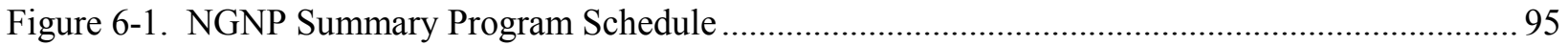

Figure B-1. NGNP Materials Review Committee, 2003 ................................................................... B-4 


\section{TABLES}

Table 3-1. Conditions Affecting Materials Selection for Intermediate and High-Temperature NGNP Components

Table 3-2. Potential Candidate Materials Selection for Intermediate and High-Temperature Metallic



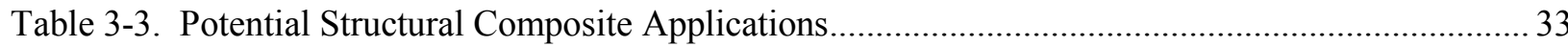

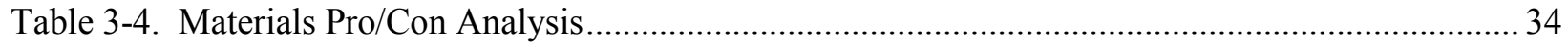

Table 3-5. Operating conditions for monolithic thermal insulators ........................................................ 39

Table 3-6. Composition helium environments (advanced HTGR) used in past tests .............................. 44

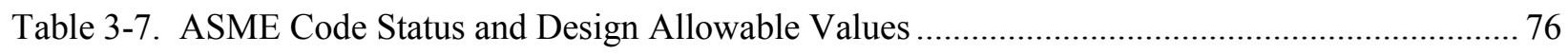

Table 3-8. Current Subsection NH materials and maximum allowable times and temperatures.............. 78

Table 6-1. NGNP Materials Program Costs (\$ in Millions) ................................................................... 97 
This page intentionally left blank. 


\section{ACRONYMS}

\begin{tabular}{|c|c|}
\hline ADTB & Alumina-Enhanced Thermal Barrier \\
\hline AGCRNR & Advanced Gas-Cooled Nuclear Reactor \\
\hline ANS & American Nuclear Society \\
\hline API & American Petroleum Institute \\
\hline ASME & American Society of Mechanical Engineers \\
\hline ASTM & American Society for Testing and Materials \\
\hline AVR & Albeitsgemeinschaft Versuchsreaktor [Germany] \\
\hline AWS & American Welding Society \\
\hline $\mathrm{B} \& \mathrm{PV}$ & Boiler and Pressure Vessel \\
\hline $\mathrm{C}_{\mathrm{f}} / \mathrm{C}$ & Carbon fiber in a carbon matrix \\
\hline CFCC & Continuous Fiber-reinforced Ceramic Composite \\
\hline CFR & Code of Federal Regulations \\
\hline $\mathrm{CMC}$ & Ceramic Matrix Composite \\
\hline CRBRD & Clinch River Breeder Reactor Project \\
\hline CTE & Coefficient of Thermal Expansion \\
\hline $\mathrm{CV}$ & Cross Vessel \\
\hline CVI & Chemical Vapor Infiltrated \\
\hline $\begin{array}{l}\text { DOE } \\
\text { dpa }\end{array}$ & $\begin{array}{l}\text { U.S. Department of Energy } \\
\text { displacements per atom }\end{array}$ \\
\hline FES & Fusion Energy Sciences \\
\hline HAZ & Heat-Affected Zone \\
\hline HHT & High-Temperature Helium Turbine System \\
\hline HTDM & High-Temperature Design Methodology \\
\hline HTGR & High-Temperature Gas Reactor \\
\hline HTR & High-Temperature Reactor [China] \\
\hline HTTR & High-temperature Engineering Test Reactor [Japan] \\
\hline IHX & Intermediate Heat Exchanger \\
\hline INEEL & Idaho National Engineering and Environmental Laboratory \\
\hline JSW & Japan Steel Works \\
\hline $\mathrm{kPa}$ & kiloPascal \\
\hline LWR & Light Water Reactor \\
\hline MCNP & Monte Carlo physics code evaluation \\
\hline $\mathrm{MPa}$ & Megapascal \\
\hline MRC & Materials Review Committee \\
\hline $\mathrm{MWt}$ & Megawatt thermal \\
\hline NDE & Non-Destructive Examination \\
\hline NGNP & Next Generation Nuclear Plant \\
\hline NPH & Nuclear Process Heat \\
\hline
\end{tabular}




$\begin{array}{ll}\text { NRC } & \text { Nuclear Regulatory Commission } \\ \text { NTD } & \text { National Technical Director } \\ \text { ORNL } & \text { Oak Ridge National Laboratory } \\ \text { PBMR } & \text { Pebble Bed Modular Reactor [South Africa] } \\ \text { PCS } & \text { Power Conversion System } \\ \text { PCV } & \text { Power Conversion Vessel } \\ \text { PNNL } & \text { Pacific Northwest National Laboratory } \\ \text { PNP } & \text { Prototype Nuclear Process Heat } \\ \text { PWHT } & \text { Post-Weld Heat Treatment } \\ \text { QA } & \text { Quality Assurance } \\ \text { R\&D } & \text { Research and Development } \\ \text { RPV } & \text { Reactor Pressure Vessel } \\ \text { RT } & \text { Reference Nil-ductility Temperature } \\ \text { SCS } & \text { Shutdown Cooling System } \\ \text { SG-ETD } & \text { Code Subgroup on Elevated Temperatures Design } \\ \text { SiC } / \text { SiC } & \text { Silicon-carbide fiber in a silicon-carbide matrix } \\ \text { TBC } & \text { Thermal Barrier Coating } \\ \text { THTR } & \text { Thorium Hochtemperatur Reaktor [Germany } \\ \text { TRISO } & \text { tri-isotopic } \\ \text { U.S. } & \text { United States } \\ \text { VHTR } & \text { Very High Temperature Reactor } \\ \text { XRD } & \text { X-ray Diffraction } \\ & \end{array}$




\section{Next Generation Nuclear Plant Materials Selection and Qualification Program Plan}

\section{INTRODUCTION}

\subsection{Background}

The U.S. Department of Energy (DOE) has selected the Very High Temperature Reactor (VHTR) design for the Next Generation Nuclear Plant (NGNP) Project. The NGNP reference concept is a helium-cooled, graphite-moderated, thermal neutron spectrum reactor with an outlet temperature of $1000^{\circ} \mathrm{C}$ or higher. The reactor core is currently envisioned to be a prismatic graphite block type core. However, it is feasible to also consider a pebble bed type of gas-cooled reactor. The final selection of a reference core concept will be made during the first year of pre-conceptual design. The plant size, reactor thermal power, and core configuration will be designed to ensure passive decay heat removal without fuel damage or radioactive material releases during accidents. The initial fuel cycle will be a once-through use of very high burn-up, low-enriched uranium.

The basic technology for the NGNP has been established in former high-temperature gas-cooled reactor plants (e.g., DRAGON, Peach Bottom, Albeitsgemeinschaft Versuchsreaktor [AVR], Thorium Hochtemperatur Reaktor [THTR], Fort St. Vrain). In addition, the technologies for the NGNP are being advanced in the Gas Turbine-Modular Helium Reactor (GT-MHR) project and the Pebble Bed Reactor (PBR) and Prismatic Modular Reactor (PMR) International Near-Term Deployment projects. Furthermore, the Japanese High-Temperature Engineering Test Reactor (HTTR) and Chinese HighTemperature Reactor (HTR)-10 projects are demonstrating the feasibility of some of the planned NGNP components and materials. (The HTTR is expected to reach a maximum coolant outlet temperature of $950^{\circ} \mathrm{C}$ in 2004.) Therefore, the NGNP is focused on building a demonstration plant, rather than simply confirming the basic feasibility of the concept. The plant is envisioned to demonstrate the following:

- The capability to Nuclear Regulatory Commission (NRC)-license the very high temperature, gascooled reactor technology

- The ability to produce electricity with high efficiency using the closed Brayton cycle

- The ability to manufacture hydrogen using the NGNP as a process heat source

- Validation of the acceptability of the materials of construction as a bridge to commercialization

- The ability to perform deep burn transmutation of actinides from spent nuclear fuel.

Demonstration of hydrogen production may use both electricity and process heat from the reactor. A separate program for development of efficient hydrogen production technologies is operating in parallel with the NGNP Reactor Project. Materials support for the hydrogen production development effort may be added to this materials program at a later date.

The operating conditions for the NGNP represent a major departure from existing water-cooled reactor technologies. Although a significant assortment of materials and alloys for high-temperature applications are in use in the petrochemical, metals processing, and aerospace industries, a very limited number of these materials have been tested or qualified for use in nuclear reactor-related systems. Today's hightemperature alloys and associated American Society of Mechanical Engineers (ASME) Codes for reactor 
applications reach about $800^{\circ} \mathrm{C}$. Some primary system components for the NGNP will require use of materials at temperatures above $800^{\circ} \mathrm{C}$. Such use will require further assessment of existing, wellcharacterized materials or selection of newer materials for which less data exists. Potential accident conditions with associated higher temperatures will dictate the use of carbon-based or ceramic materials within the reactor pressure vessel. The use of structural ceramics or composites in safety-related reactor components represents a completely new challenge to the nuclear industry.

A materials survey [1] ${ }^{\text {a }}$ was conducted in January 2003 to identify the presence of material requirements that are beyond the limits of current materials technology. That initial look indicated that the materials issues are solvable, but may be expensive to resolve.

\subsection{Assumptions}

The following assumptions are incorporated into this program plan and are used in estimating the scope, cost, and schedule for completing materials selection and qualification processes:

1. Although the reactor design has not been formally selected, for the purposes of this document it is assumed to be a helium-cooled, prismatic, graphite block core design fueled with TRISO design fuel particles in carbon-based compacts.

2. This very high temperature reactor must demonstrate the capability to NRC license the reactor technology. Therefore, the design and construction will need to meet appropriate Quality Assurance (QA) methods and criteria.

3. The demonstration is expected to be a full size $(\sim 600 \mathrm{MWt})$ reactor plant with a smaller size hydrogen demonstration unit.

4. The reactor coolant exit temperature from the core is expected to be $1000^{\circ} \mathrm{C}$ or greater unless such an outlet temperature is determined unfeasible.

5. The demonstration plant will be designed to operate for a nominal 60 years.

\subsection{Objectives}

The goal of the Generation IV NGNP Reactor Project is deployment of a full-scale, NRC-licensed demonstration reactor, capable of producing electricity and low-cost hydrogen in the 2015 to 2017 timeframe. The first three years of the project will complete the pre-conceptual and conceptual design of the NGNP, with final design beginning at the end of FY-09. The preliminary design is expected to provide the final materials requirements for the NGNP. The reactor program will need qualified materials early in the final design process. Construction of long-lead items (e.g., pressure vessel) may need to begin by FY-10.

The objective of the NGNP Reactor Materials Program is to provide the essential materials selection and qualification activities needed to support the design of the reactor and balance of plant. The materials program is being initiated prior to the design effort to ensure that materials test irradiations, long-term testing (e.g., creep), and materials codification activities are initiated early enough to support the design process. A direct relationship exists between component materials feasibility and reactor system design

a Complete bibliographic references appear in numerical order in Appendix E. Throughout this document reference notations appear in the [ref\#] format. 
requirements. An additional early objective of the materials program is to provide the preliminary materials information required to support initial reactor design/materials selection trade-off studies that will be used to set reactor system requirements. As such, the materials program must maintain a direct relationship with the design organization because timely and appropriate materials design input data is essential and integrally tied to successful completion of the design activity.

\subsection{Scope}

The NGNP materials program will perform all material identification, selection, testing, and qualification activities required to support the NGNP Reactor Project. These include:

- Development of a specific program plan for managing the selection and qualification of all component materials required for the NGNP

- Identification of specific materials for each system component

- Evaluation of the needed testing, ASME Boiler and Pressure Vessel (B\&PV) code modifications, and analysis required to qualify each identified material

- Preliminary down-selection of component materials based on known requirements, manufacturability, and feasibility of achieving needed code licenseability

- Specification and purchase of representative materials for testing

- Design and construction of capsules and vehicles for irradiation of materials where irradiation test data is required

- Irradiation of needed sample materials

- Physical, mechanical, and chemical testing of un-irradiated, aged, and irradiated materials, as required, to provide the data to qualify the material for the specific components

- Documentation of materials test data for use by reactor designers and to support required codification for ultimate reactor licensing

- Documentation of final materials selections in support of the design function.

The materials program will address the NGNP reactor, power conversion system, intermediate heat exchange (IHX) system, and associated balance of plant. Inclusion of materials for hydrogen production will be determined later. As an integral part of the reactor project, the NGNP materials program must interface directly with the reactor design and component specification efforts in an iterative process of component requirements refinement and materials applicability considerations leading to final selection of needed materials.

Because of the early start of the materials program and its synergy with the design process, the Materials Selection and Qualification Program Plan will be updated annually to reflect adjustments in the design requirements basis and their effect on the scope of the materials selection and qualification activities. 


\subsection{Materials Selection Logic}

Materials selection and qualification requires the application of a logical process of determining the most appropriate material for a given component application and obtaining the data necessary to demonstrate that the material can be used successfully. Materials Selection also requires a choice for the material to be used in a component application for the NGNP reactor or balance of plant. This methodology must adequately incorporate the following components and be accepted by the reactor designer:

- Technical acceptability

- Manufacturability

- Cost

- Schedule

- Codification/certification.

If an existing material cannot be identified for essential reactor components, the decision must be made to either develop such a material or adjust reactor requirements/design to eliminate the issue. Materials research and development $(\mathrm{R} \& \mathrm{D}) /$ alloy design activities will support the material selection process where existing materials are determined to be incapable of meeting absolute reactor system requirements, or where significant improvement in material performance is thought possible with a reasonable expenditure of resources (time and money).

The selection process will involve the following sequential steps:

1. Establishment of the Technical Requirements - The service requirements for component materials must be established as the first step in the selection process. The NGNP Reactor Project and its design contractor are ultimately responsible for defining material requirements. Where detailed design information is not available, the selection process may proceed only to the extent that the NGNP Reactor Project can bracket the range of material requirements expected for any given component.

2. Identification of the Potential Candidate Materials - This process itemizes the potential candidate materials for component construction based on known use requirements and boundary conditions. This listing of candidates could include any number of alloys, ceramics, or other materials as appropriate. An NGNP materials planning working meeting was held July 8-9, 2003 to initially review candidate materials and begin the qualification requirements identification process. The results of that and subsequent efforts resulting in the selection of potential candidate materials are reflected in Section 3.2.

NOTE: This program plan is based on the collective expert judgment of the U.S. DOE laboratory and industry materials professionals involved in that meeting (see Appendix A for a list of attendees) and subsequent planning efforts using the requirements baseline documented in Section 2. This basis and, therefore, the scope of the program plan may shift in future years as the requirements baseline is adjusted by the design process.

3. Preliminary Selection - This process focuses on a given component or group of related components for the reactor or balance of plant system with the purpose of beginning the process of material selection and itemizing the logic involved in getting to a final selection. This process will result in a document that provides the technical basis for preliminary materials selection and justifies the materials testing program by component. This process will be initiated before the start of testing and will be updated as necessary as the design and materials test information dictate. If preliminary selection identifies three or four materials for qualification testing, an 
initial scoping phase of qualification testing will then be used to narrow the list down to the two prime candidates. Scoping tests will also be performed as needed to provide early feasibility input required to assist in the selection of component design alternatives.

4. Materials Qualification Testing - This process includes generation of the specific test data, codes and standards certifications, manufacturability tests and validations needed to demonstrate that a material can be used without restriction in a specific application within an NGNP reactor that will be licensed by the NRC. As part of materials qualification and testing, a qualified database with associated empirical correlations will be maintained by the NGNP materials program.

5. Final Selection - This process results in the identification of a single material that has been identified and qualified for constructing a reactor or balance of plant component.

A final materials selection report, which documents the final selection of a material for a given application in the NGNP reactor or balance of plant, will be prepared following the completion of the qualification process. The report will contain a record of the acceptance of any existing data usable for design input and used in qualification, all qualification data generated in support of the selection and usable for design input, manufacturability validation and approved vendors, code status and acceptance, material cost information, and expected lead time required for component construction. Interim topical reports on individual qualification program elements will be generated during the qualification process to provide initial data to the design process and mark completion of interim milestones within the overall program. This selection process is shown graphically in Figure 1-1.

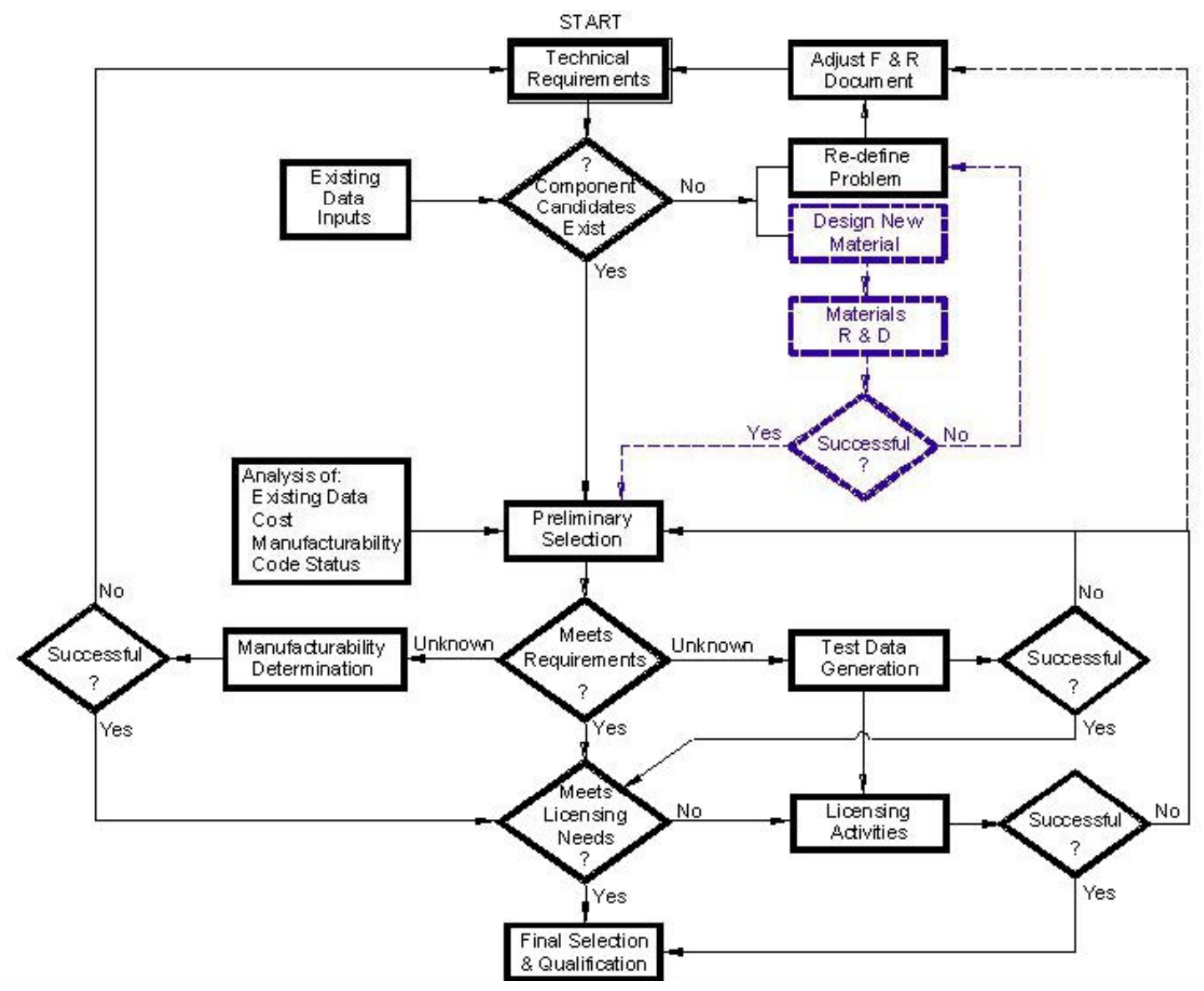

Figure 1-1. Materials Selection Logic Flow Diagram. 


\subsection{NGNP Reactor Materials Organization}

\subsubsection{Overall Organizational Structure}

A suitable organizational structure will be used for the management of the NGNP Materials Program. An initial structure, designed along material types (see Figure 1-2), is planned for the preliminary selection phase of the program. A more complex structure may evolve as the qualification program branches into the eleven or more component categories envisioned for qualification efforts and documentation.

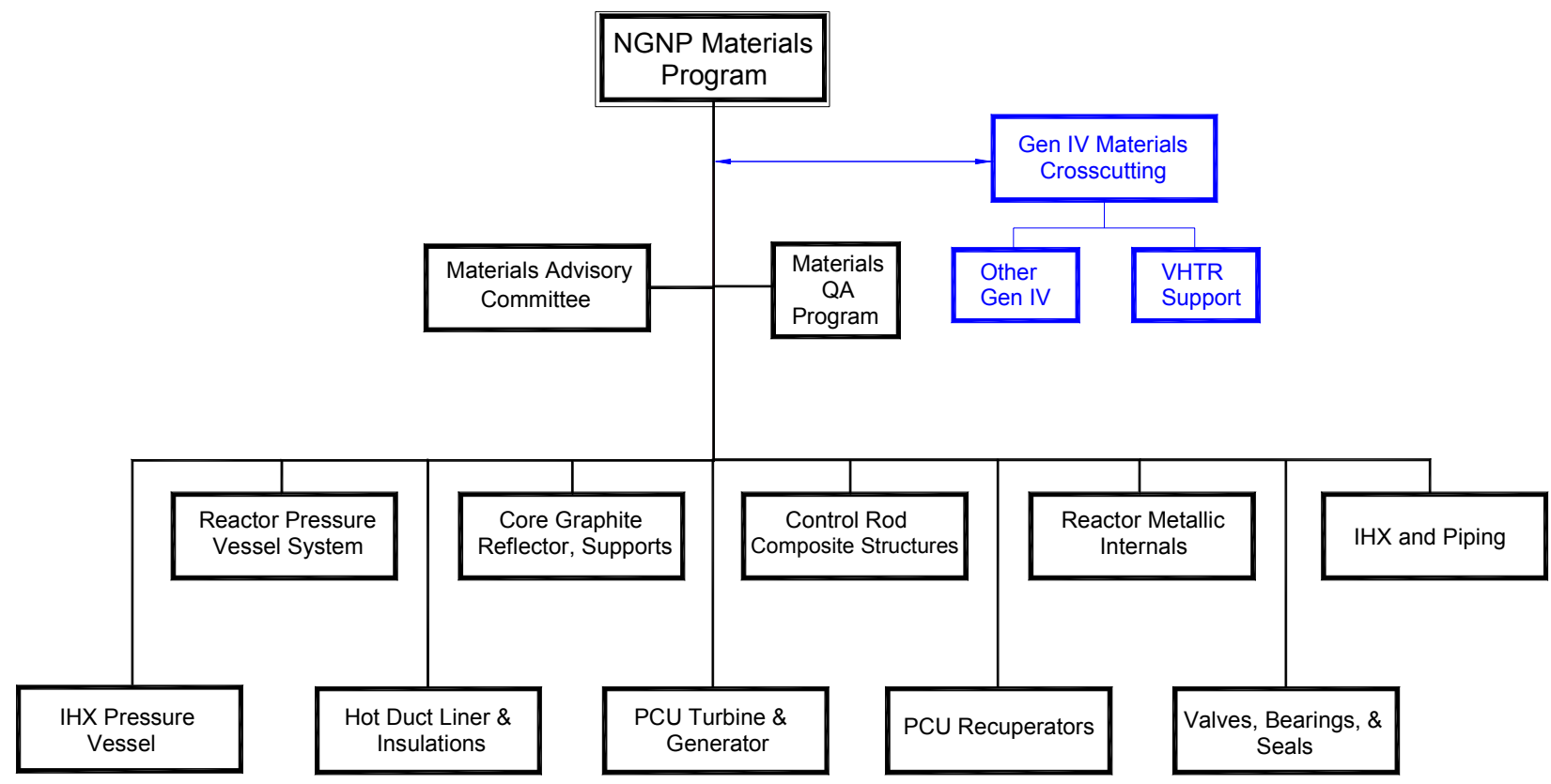

Figure 1-2. NGNP Materials Organization Structure.

\subsubsection{NGNP Reactor Materials Review Committee}

Because of the expected size and complexity of the materials effort for the NGNP reactor, an NGNP Materials Review Committee is being formed as a senior independent review body for the materials program. The Review Committee will provide objective technical review of key selected materials documentation, including, materials selection decisions, test program content, test results, etc.

\subsubsection{Generation IV Materials Crosscut Interface}

The Generation IV Reactors Materials Crosscutting Program and the NGNP Materials Program are both part of the integrated Generation IV Materials Technology Program. The National Technical Director of the Generation IV Materials Program will ensure that crosscutting materials R\&D activities include:

- Supporting the NGNP Materials Program activities with a minimum of duplication and overlap

- Supporting the NGNP product team efforts to ensure integration of product requirements into the R\&D activities. 
The Generation IV Materials Crosscutting Program supports the NGNP Materials Program in the following areas:

- Identification and development of organizations and facilities for performing materials R\&D

- Consolidation and evaluation of existing materials data from U.S. and international sources

- Development of materials modeling approaches to support code qualification of materials

- Compilation of a materials database/handbook to support all Generation IV programs

- Integration between reactor and other existing materials programs to minimize duplication of effort

- Identification of major deficiencies in existing materials technology, testing methods, and design approaches that will be needed to qualify materials for Generation IV systems.

\subsection{Program Interface with Other Design Organizations}

The NGNP Material Selection and Qualification Program is designed to provide materials selection and qualification design inputs to the NGNP Reactor and balance of plant design. A close working relationship must exist between the design and materials efforts to ensure that timely materials inputs are available when needed by the designer, and adjustments in requirements are adequately evaluated and supported by the materials qualification function.

Because of the close coupling of reactor design input, designer quality requirements, and design project performance against cost and schedule commitments, the materials program relationship with the design organization is expected to be a formal, controlled, contractual interface. Materials selection and qualification efforts will need to be rigorously scheduled and controlled along with the design effort to ensure that the needs of the designer are satisfied and additional project costs are not incurred unnecessarily.

As shown in Figure 1-3, technical requirements from the design effort provide the basis for material selection efforts. Tradeoff studies, involving both design and materials personnel will be needed to further develop reactor design requirements and materials boundary conditions for some essential components. In cases where essential selection data needed to proceed with qualification is missing, scoping tests may be required. Existing technical data (qualified to NQA-1 standards) and scoping tests will be used as design inputs for conceptual design. Qualification test data generated by the materials program will then provide more complete materials design data inputs for the preliminary and final design efforts. 


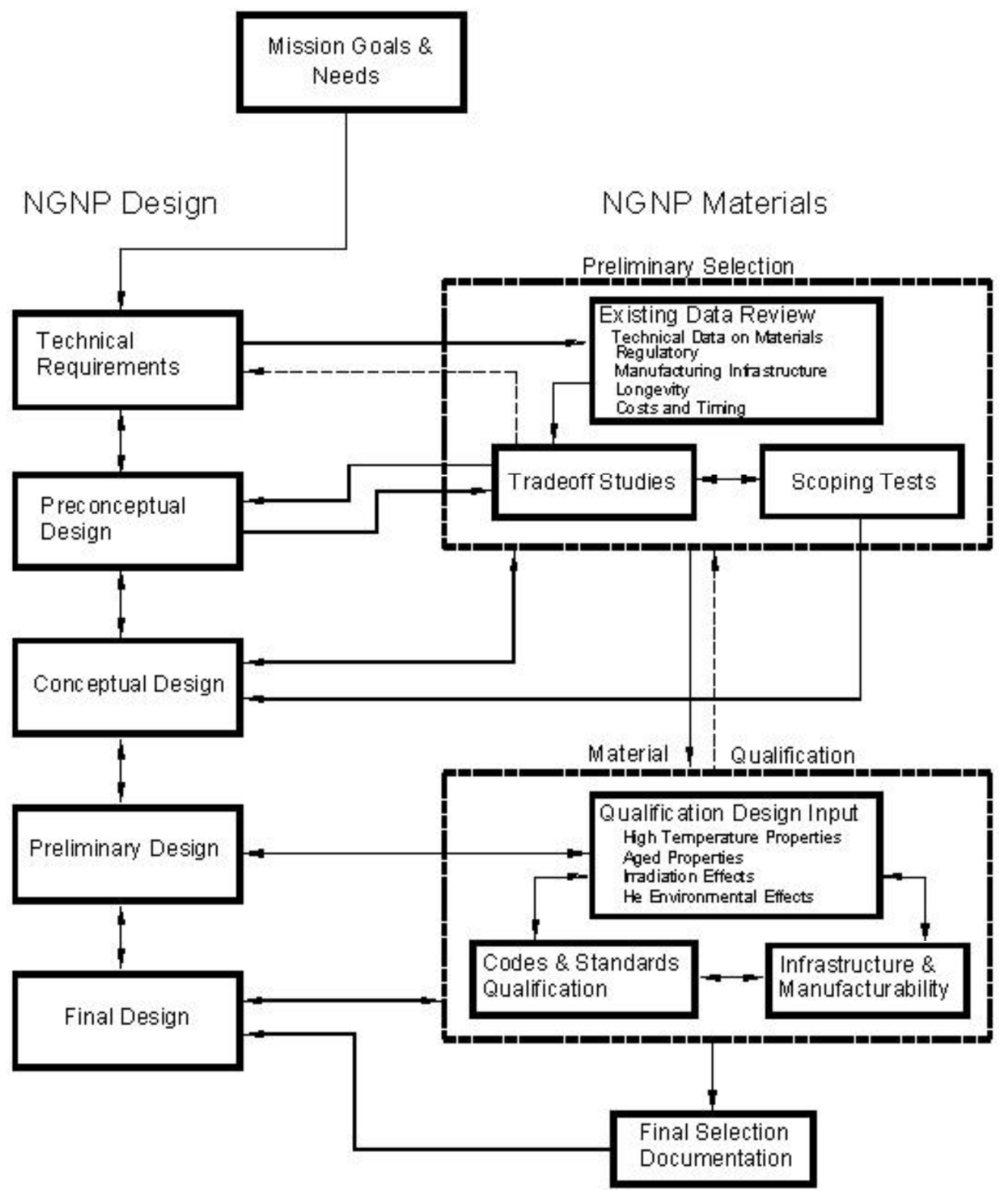

Figure 1-3. Basic Interfaces Expected Between the Materials and Design Functions. 


\section{REQUIREMENTS}

\subsection{Reactor Design Interface}

Component materials functional requirements are set by the designer, but the feasibility of selecting and qualifying materials that meet the designers requirements may be unrealistic. Where materials feasibility cannot be established, the Materials Program may dictate adjustments to the reactor design. Such design/materials trade offs will need to be fully documented and formally implemented in the design process.

\subsubsection{Requirements for High-temperature Materials Structural Design Methodology}

The use of inelastic, high-temperature materials structural design analyses is required for materials to be used in applications within their creep range to accurately predict stress-strain-time response at critical component locations. ASME Section NH requires this design approach.

Components operating at high temperature respond to thermal and mechanical loadings inelastically. At the lower end of a material's useful elevated-temperature operating range, the inelastic response can usually be separated into time-independent plasticity and time-dependent creep. Each can exhibit complex, history-dependent hardening or softening, and the two types of response can interact with one another (i.e., prior plastic strains affect subsequent creep responses, and vice versa.). At higher temperatures, the distinction between rate-dependent plasticity and time-dependent creep blurs for many materials (e.g., modified 9Cr - 1Mo steel, and Inconel 617), and the separation between behaviors is no longer valid. The response becomes rate dependent and both strain and cyclic softening occur.

This high-temperature inelastic response has significant implications for structural design involving plasticity, creep, viscoplastic behavior, and inelastic ratcheting. The high-temperature design methodology (HTDM) effort will provide test and analysis data on high temperature issues and provide direct support to the reactor designer on the design implications of these time and temperature dependent materials behaviors.

\subsubsection{Formal Materials Design Data Inputs}

Materials design data to be used by the reactor designer is one of the primary outputs of the NGNP reactor materials program. Design inputs must be controlled to ensure that the information being used by the designer is accurate and traceable to the source test/qualification database used to originate the input.

Within the reactor project, a formal document configuration control system will be developed for the management and control of design input information. This system will meet the QA requirements discussed in Section 2.3, and its use will be formally specified within the contractual arrangements between the reactor project and the designer. All existing and newly generated materials data and empirical relations to be used as design inputs from the Material Selection and Qualification Program must conform to the QA and document configuration control requirements developed by the reactor project for design input.

\subsection{Technical Requirements}

This section briefly describes the operational requirements for the components, discusses the QA requirements needed to obtain NRC licensing, explains possible approaches to NRC licensing for the materials and components, and outlines the paths to obtain ASME codification and qualification of 
component materials. Because no preconceptual design currently exists for NGNP reactor components, the Gas Turbine-Modular Helium Reactor (GT-MHR) design is used to provide the starting point for the NGNP design. The GT-MHR operational requirements are used to estimate operational requirements for the NGNP by adding estimated deltas to the GT-MHR operational requirements.

For this document, the requirements and boundary conditions are divided into three groups.

1. Pressure Vessels - Reactor pressure vessel (RPV), cross vessel (CV), and the power conversion vessel (PCV)

2. Core Internals - Internal metallic and graphite core components

3. Intermediate Heat Exchanger - For both direct cycle and indirect cycle.

\subsubsection{Pressure Vessels}

The three main vessels in the GT-MHR design are the RPV, CV, and PCV (see Figure 2-1). These vessels represent the pressure boundary of the primary coolant. The GT-MHR uses a closed Brayton cycle to generate electricity where helium coolant flows out of the reactor and directly through the main turbine. The helium exiting the main turbine is re-pressurized to the inlet operational conditions and pumped through the reactor. The NGNP reactor is envisioned to have the same three vessels. The NGNP operational inlet helium pressure and temperature for the reactor is $600^{\circ} \mathrm{C}$ at a pressure of 7.4 to $8.0 \mathrm{MPa}$. The inlet helium flows between the core barrel and the RPV maintaining the RPV at a cooler temperature than the core. Nominal operating temperature of the RPV wall is $650^{\circ} \mathrm{C}$. The helium exits the reactor core at $1000^{\circ} \mathrm{C}$ at pressures of 7.33 to $7.93 \mathrm{MPa}$. The pressure drop across the core is $\sim 70 \mathrm{kPa}$. A $400^{\circ} \mathrm{C}$ temperature increase across the core is the limiting temperature increase across the core [2] and thus fixes the inlet temperature at $600^{\circ} \mathrm{C}$, based on the stated goal of the NGNP to have a $1000^{\circ} \mathrm{C}$ outlet temperature.

Figure 2-2 identifies the components of the RPV. To determine the fluences $(\mathrm{E}>0.1 \mathrm{MeV})$ and displacements per atom (dpa) for each of the components, a Monte Carlo physics code evaluation (MCNP) [3] was performed on a prismatic core model. The model was limited to radial responses only at the mid-line of the core. The fluence for the core barrel was composed of dpa doses from iron, nickel, and chromium. The RPV wall fluence is assumed to be the same as the core barrel fluences. The MCNP model did not include the outer control rods or the borated steel pins in the permanent reflector; thus, the fluence and dpa for the RPV wall is an upper bound. The fluence for the RPV is $3.0 \mathrm{E} 19 \mathrm{n} / \mathrm{cm}^{2}$ and the dpa is 0.0075 for 60 years. 


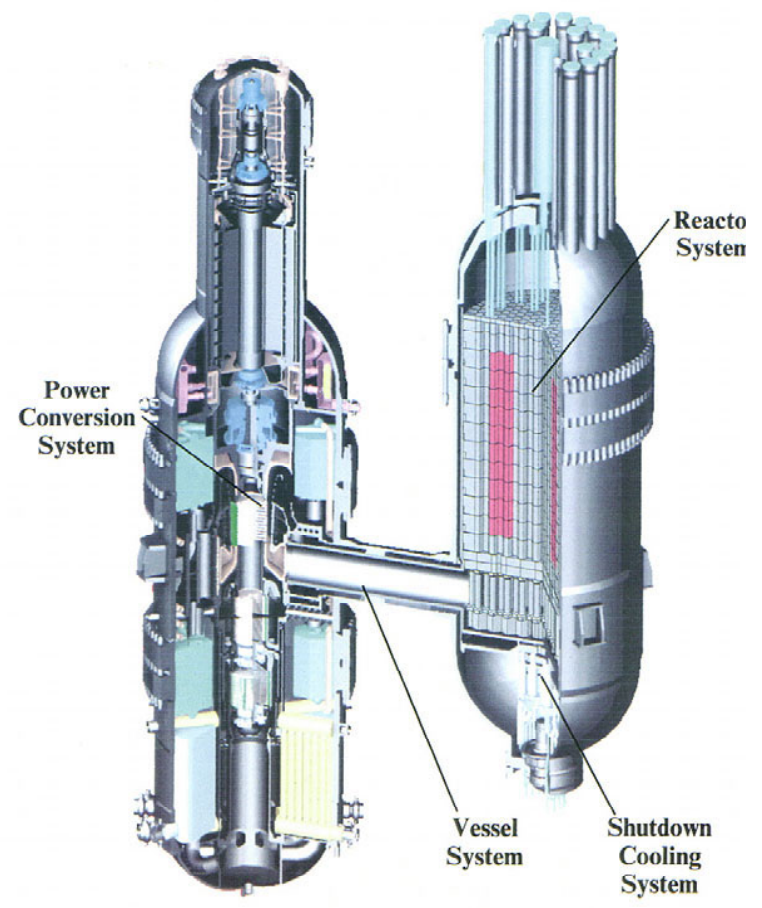

Figure 2-1. GT-MHR Full Section

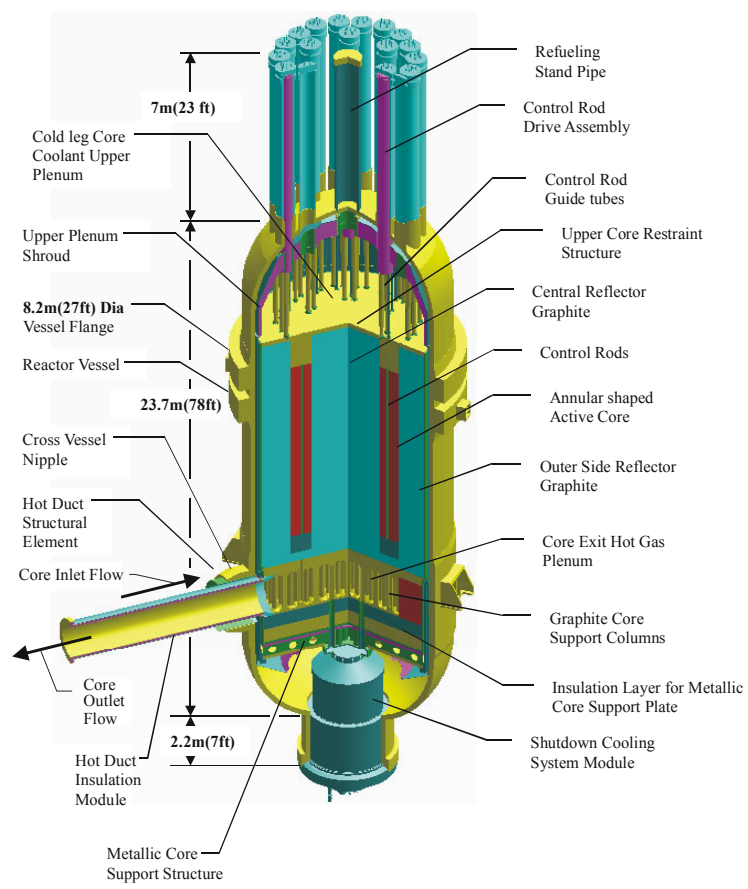

Figure 2-2. GT-MHR Reactor Vessel

The physical dimension of the RPV is a diameter of less than nine meters having wall thicknesses between $100 \mathrm{~mm}$ and $300 \mathrm{~mm}$. The vessel itself can be made of welded sections of different thicknesses. The height of the vessel is less than 24 meters.

During off-normal conditions (e.g., pressurized conduction cool down), the temperature of the helium coolant will increase resulting in the RPV mid-wall temperature reaching an upper limit that may be as high as $770^{\circ} \mathrm{C}$. This was obtained by adding $150^{\circ} \mathrm{C}$ (the difference from the $850^{\circ} \mathrm{C}$ GT-MHR outlet to the NGNP $1000^{\circ} \mathrm{C}$ outlet temperature) plus $55^{\circ} \mathrm{C}$ for conservatism to the $565^{\circ} \mathrm{C}$ upper RPV vessel midwall limit cited in the GT-MHR design document [4]. This approach is not based on engineering analysis, but is the means to obtain bounding temperatures without assistance of any thermal modeling of a non-existing design. The off-normal helium coolant temperatures are estimated to reach as high as $1200^{\circ} \mathrm{C}$ due to the flow reversal in the core. If these temperatures exceed current available materials qualifications, then this limitation will be taken into consideration during the preconceptual design phase.

The CV is the pressure boundary for the exchange of helium between the RPV and PCV (see Figure 2-3). The outside diameter of the vessel is on the order of 2.5 meters with a thickness of less than $100 \mathrm{~mm}$. The $\mathrm{CV}$ is welded to the RPV and PCV. To accommodate thermal expansion during operation, the PCV is allowed to slide laterally away from the RPV. The $1000^{\circ} \mathrm{C}$ helium flows out of the reactor in a structural duct inside the CV and returns from the PCV on the outside of the structural duct. This duct is known as the hot duct. The hot duct is insulated from the higher temperature helium by ceramic insulation on the inside surface of the duct. The ceramic insulation is removable allowing inspection of the hot duct. The return helium maintains the $\mathrm{CV}$ wall temperature at $600^{\circ} \mathrm{C}$. The hot duct only sees the pressure differential of the core across its thickness. The hot duct is welded to the core barrel at the lower core plenum outlet and is connected to the PCV by means of a metallic bellows. The hot duct is seal-welded to the metallic bellows. The bellows is mechanically connected to the turbine inlet shroud. As the CV 
expands pushing the PCV away from the RPV, the mechanical bellows expands, thus maintaining the pressure boundary between exit and return helium.

The fluence and dpa seen by the CV and hot duct is the same as the RPV and core barrel where the attachment welds are made. The fluence and dpa in the remaining portion of the vessel will see a gradient over the length of the vessel decreasing to negligible values at the PCV.

The PCV (see Figure 2-4) houses the main turbine, generator, and associated turbo machinery and heat exchangers necessary to pump and reheat the helium to $600^{\circ} \mathrm{C}$ at inlet pressures between 7.4 and 8.0 $\mathrm{MPa}$. The vessel is on the order of 35 meters tall with outer diameters between 7 and 9 meters. The wall thickness is between 100 and $200 \mathrm{~mm}$. The normal operating temperature for the vessel wall is $200^{\circ} \mathrm{C}$ with an off-normal temperature of $300^{\circ} \mathrm{C}$. The design pressure of the vessel is between 5 and $6 \mathrm{MPa}$. The temperatures and pressure of the NGNP PCV should not change much from the GT-MHR design. The fluence and dpa seen by the PCV is negligible. The two components that will see the $1000^{\circ} \mathrm{C}$ helium are the metallic bellows and a small portion of the turbine inlet shroud. The turbine inlet shroud is insulated to reduce the temperature seen by the structure except for a small portion that is un-insulated at the connection of the turbine opening. The remaining piping, turbo-machinery, and heat exchangers experience temperatures and pressures that do not challenge current ASME qualified materials. The main turbine, specifically the turbine blades, will be addressed later when more information is available.

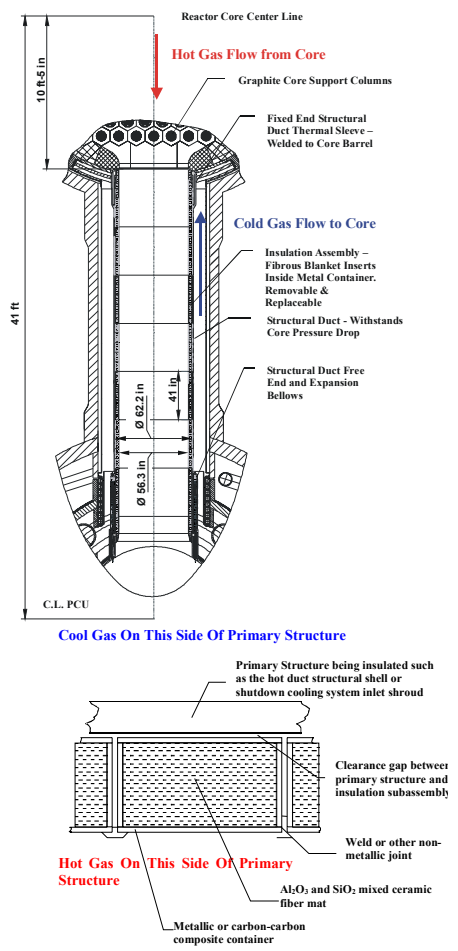

Figure 2-3. GT-MHR Cross Vessel

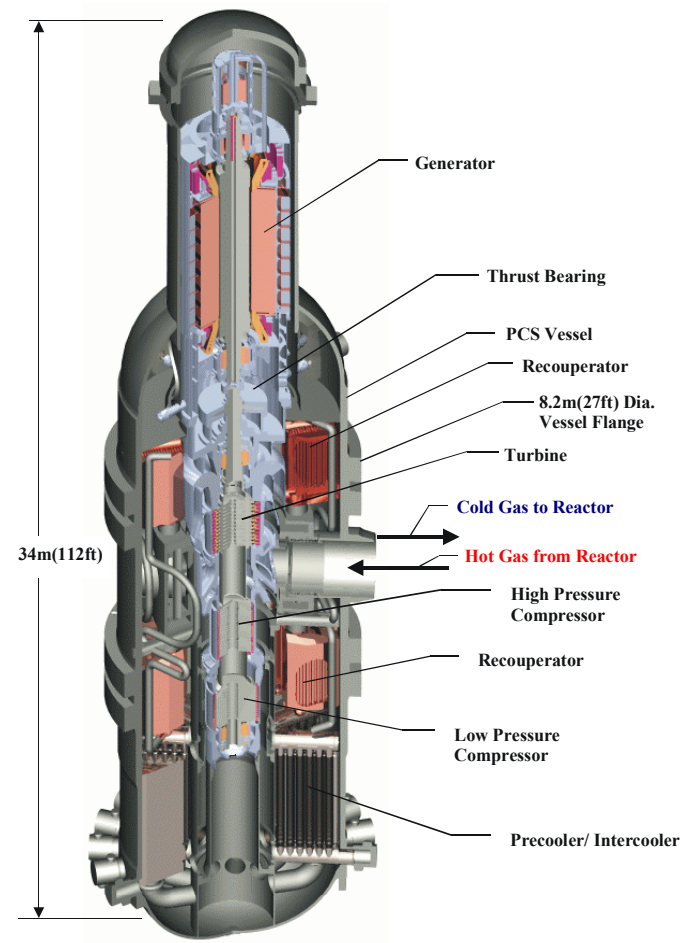

Figure 2-4. GTMHR Power Conversion Unit

\subsubsection{Core Internals}

This section deals with the metallic and graphite core internals inside the RPV. Figure 2-5 identifies the metallic core internals and Figure 2-6 identifies the graphite core components. 


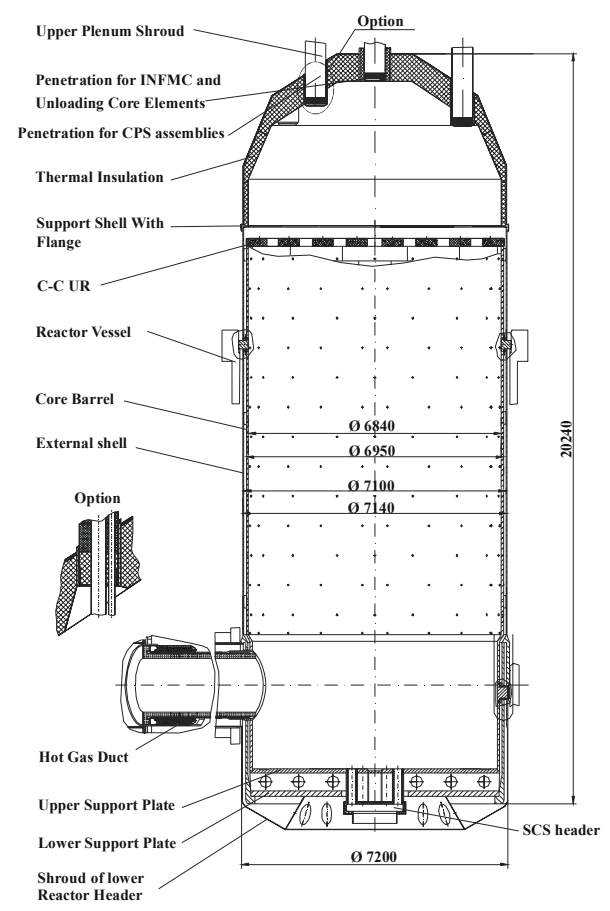

Figure 2-5. GT-MHR Core Barrel

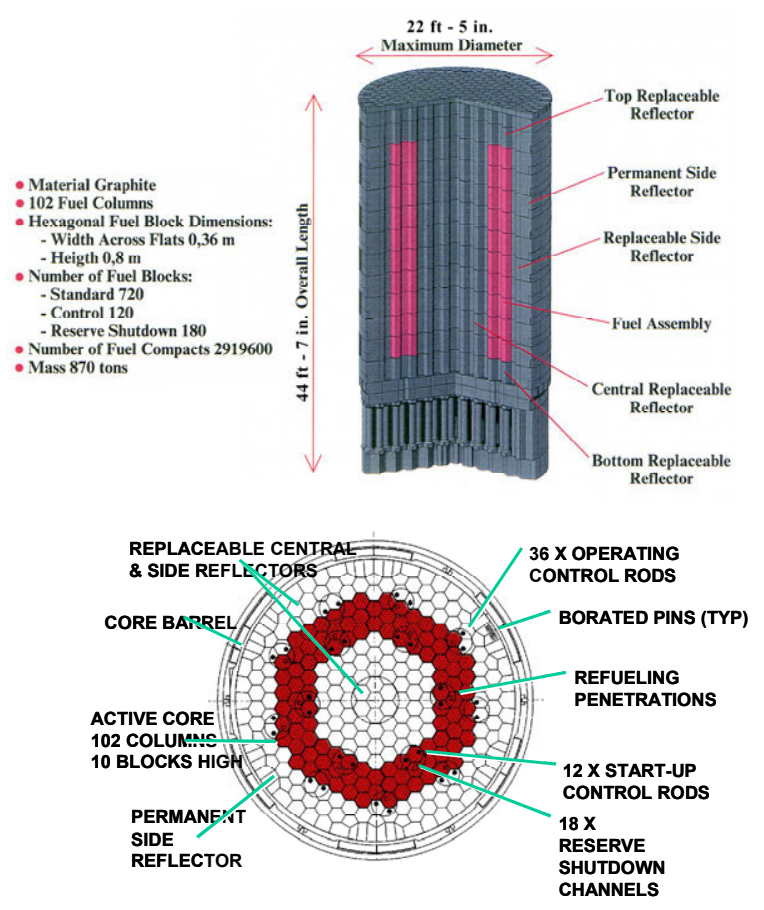

Figure 2-6. GT-MHR Core Internals

The estimated lifetime of the metallic core internals is 40 years. The fluence and dpa for these components, except for the control rods and guide tubes, are the same as described in the previous section for the core barrel. The fluence and dpa for the graphite components will be discussed individually, because of their proximity to the core.

One common concern to the metallic core reactor internals, especially with superalloys, is the exposure to microbar partial pressures of free oxygen in the helium coolant resulting in carburization/decarburization at high temperatures of 600 to $950^{\circ} \mathrm{C}$. Above $950^{\circ} \mathrm{C}$ the carburization/decarburization reaction accelerates. Controlling the contaminant level in the helium by adding or subtracting carbon monoxide in the helium coolant can minimize this condition.

The core support floor is a structure of concentric rings welded together with radial beams originating from the center ring. The entire structure rests on supports forged into the lower head of the RPV. The floor supports the mass of the graphite core, core barrel, shroud, and upper core restraints. The structure is maintained at inlet helium temperatures by circulating helium from the inlet underneath the structure and insulating the structure from the core with ceramic or graphite blocks. The mass of the core is approximately 790 metric tons. The bounding dynamic load is the $0.3 \mathrm{~g}$ Safe Shutdown Earthquake.

The core barrel is a metallic cylinder with a diameter of 6.8 to 7 meters, a height of $\sim 14$ meters and a thickness of 25 to $50 \mathrm{~mm}$. The cylinder is welded to the core support floor. The core barrel physically restrains the graphite core during earthquakes and from radial thermal expansion during normal operations. The core barrel is centered and restrained in the RPV by keys that fit into corresponding keyways in the RPV. During operation, there is no space between the permanent reflector and the core barrel; the permanent reflector blocks remain in contact with the core barrel. The normal operating temperature of the core barrel is $\sim 600^{\circ} \mathrm{C}$. Temperature during off-normal conditions could reach as high as $1070^{\circ} \mathrm{C}$ for a short period. The temperature was obtained by adding the $470^{\circ} \mathrm{C}$ delta between the normal operating and off-normal conditions found in American Nuclear Society (ANS) 2003 Gas Reactor 
Technology Course [5] for the GT-MHR core barrel temperatures to the normal operating temperature of the NGNP core barrel.

The next metallic component is the upper plenum shroud. This structure sits on top of the core barrel and supports insulation on the inside surface. Inlet helium flows up the gap between the RPV and core barrel and through the slots in the shroud just above the joint with the core barrel and into the upper plenum cavity. The shroud forms an upper plenum cavity on top of the core and serves as a heat shield to the control rod and instrumentation drives during normal and off-normal operations. During normal conditions, the shroud is maintained at $600^{\circ} \mathrm{C}$ by the circulating inlet helium. Off-Normal conditions could result in temperatures of $\sim 1200^{\circ} \mathrm{C}$ in the upper shroud due to the flow reversal. The normal operating pressure in the upper plenum is between 7.4 to $8.0 \mathrm{MPa}$.

The upper core restraint is a structure made up of individual hexagonal metallic boxes that have dowels on the bottom, which fit into the top of the upper plenum blocks. Each box is key to six of its neighbors, enforcing the lateral gap between graphite columns and allowing each graphite column to thermally expand in the axial direction independent of the adjacent column (see Figure 2-5). Normal operating temperature for these structures is $600^{\circ} \mathrm{C}$, while off-normal temperatures could approach $1300^{\circ} \mathrm{C}$.

The shutdown cooling heat exchanger (Figure 2-7) is located in the bottom of the core and is used primarily to remove heat during refueling. The system can be used for normal and off-normal heat removal during shutdown. The upper portion is a helical tube heat exchanger in an environment of inlet helium at $600^{\circ} \mathrm{C}$ mixed with $1000^{\circ} \mathrm{C}$ flow from the lower core plenum. The tubes are between 12 and 19 mm thick. Water flows through the tubes at rates necessary to keep the water sub-cooled. During startup of the shutdown cooling system (SCS), the helium temperature would increase to $1000^{\circ} \mathrm{C}$ for a period of time and even to $1200^{\circ} \mathrm{C}$ during startup of the cooling system in off-normal conditions. The operating pressure on the helium side is 7.4 to $8.0 \mathrm{MPa}$. The pressure on the waterside will vary but will be lower than the normal operating pressure of the reactor.

The last metallic internal components are the control rods and their guide tubes. In past prismatic gas reactor core designs, the control rods were metal tubes filled with $\mathrm{B} 4 \mathrm{C}$ graphite donuts as shown in Figure 2-8. The rods transverse the upper plenum inside guide tubes from the upper inner head to just inside the core. The tubes are vented to the reactor pressure. The most important mechanical aspect of the control rods is that they cannot bow or deform during normal or off-normal conditions. The rods must remain straight to enable quick insertion at any time. The control rods that see the highest fluence and temperatures reside on the inside periphery of the core between the inner core and reflector. Normal operating temperatures reach $1050^{\circ} \mathrm{C}$ with off-normal temperatures reaching as high as $1500{ }^{\circ} \mathrm{C}$. These control rods see fluences of $6.7 \mathrm{E} 20 \mathrm{n} / \mathrm{cm} 2$ per year with dpa values of about 0.56 per year. These high fluences limit the lifetime of the control rods to less than 40 years; therefore, the fluence and dpa are given on a per year basis. Since control rods may be changed out, the reactor lifetime ( $\sim 60$ years) is not limited by the life of the control rods. 


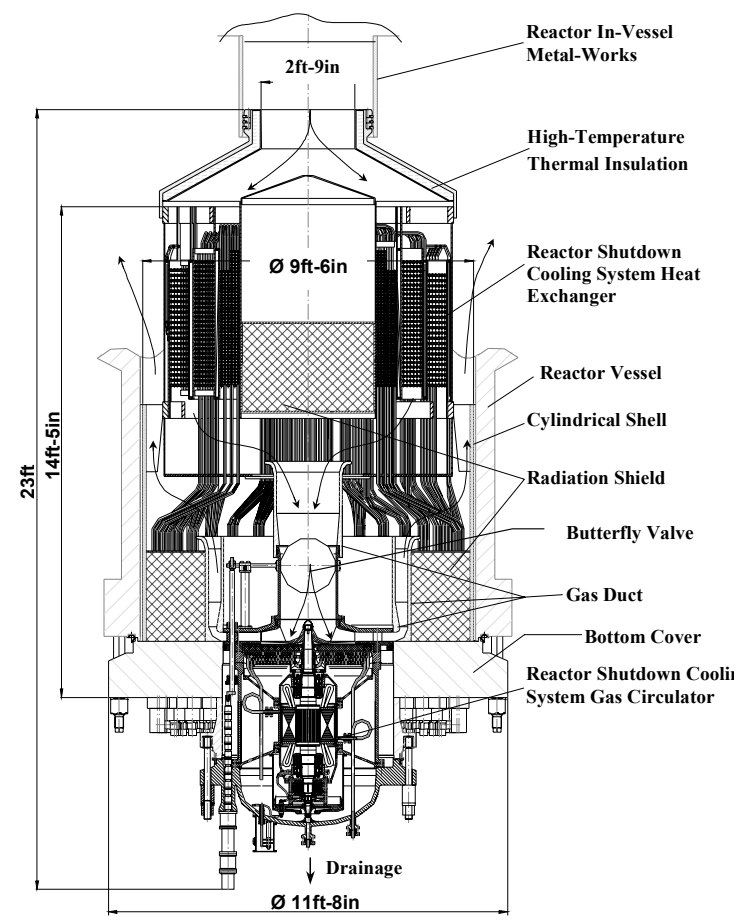

Figure 2-7. GT-MHR Reactor Shutdown Cooling System
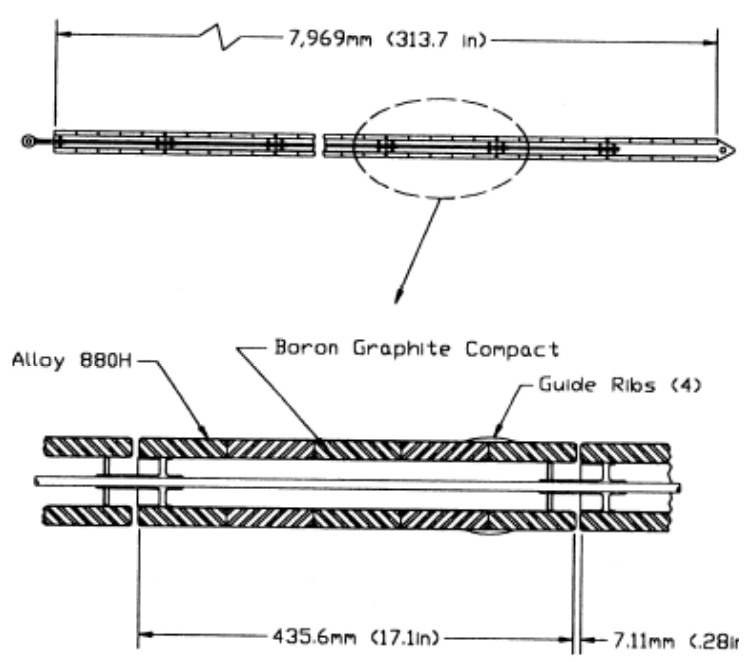

Figure 2-8. GT-MHR Control Rod Concept

The graphite core is a right circular cylinder composed of 102 columns each containing 10 blocks. A standard block (see Figure 2-9) is hexagonal in shape with a dimension of $0.36 \mathrm{~m}$ across the flat and height of $0.8 \mathrm{~m}$. The cylinder is arranged in 11 circular rings. The inner reflector uses the first five rings; the active core uses rings 6, 7, and 8; the outer reflector is composed of rings 9 and 10; and ring 11 is the permanent outer reflector. On top of the core column is a reflector block and a half height upper plenum block that caps the column. Below the core column is a bottom reflector block and two half-height insulation graphite blocks. Under each column is a graphite pedestal. The pedestals rest on two additional insulation blocks (graphite or ceramic), which in turn sit on the core support floor.
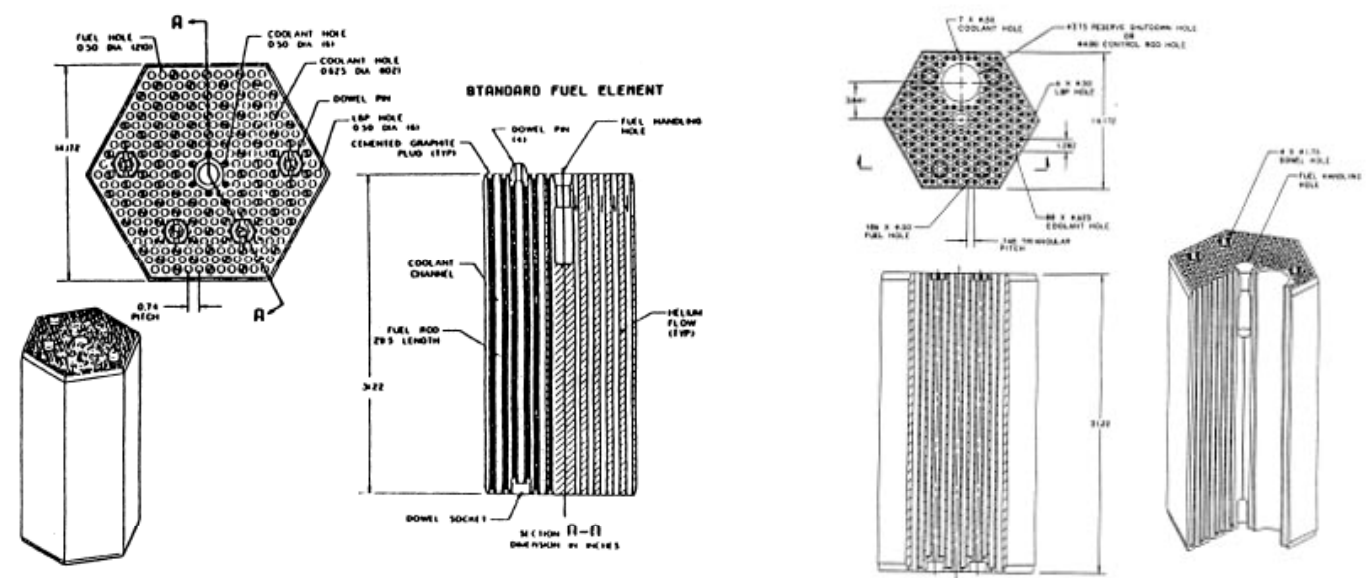

Figure 2-9. GT-MHR Fuel Blocks 
Each block has four dowel pins protruding from the top; subsequently, each block has four dowel pinholes in the bottom. These dowel pins lock the column together. The thermal expansion and flow induced motion in each block creates shear stresses on the pins and reactive stresses in the dowel pinholes. The blocks' motion creates friction generating fine carbon particulate.

The top and bottom insulator graphite blocks make up the lower plenum and insulate the top and bottom of the core. These blocks see fluences on the order of $9.1 \mathrm{E} 15 \mathrm{n} / \mathrm{cm} 2$ per year $(\mathrm{E}>0.1 \mathrm{MeV})$ and negligible dpa. Normal operating temperatures are $700^{\circ} \mathrm{C}$ for the top blocks and $1050^{\circ} \mathrm{C}$ for the bottom blocks. The off-normal temperatures are $1100^{\circ} \mathrm{C}$ for the top blocks and $600^{\circ} \mathrm{C}$ for the bottom blocks. This is due to a flow reversal in the core during off-normal conditions.

The core pedestal supports are graphite columns that support each hexagonal column in the core except for the permanent reflectors. Spaces between the pedestals create the lower plenum of the reactor where all the coolant channels flow. The fluence levels are higher in the plenum than in the insulator blocks, $3.7 \mathrm{E} 17 \mathrm{n} / \mathrm{cm} 2$ per year with negligible dpa. Temperatures in the lower plenum reach $1000^{\circ} \mathrm{C}$ during normal operation with off-normal temperatures reaching $600^{\circ} \mathrm{C}$.

Upper plenum graphite blocks are half the length of regular blocks and cap off the graphite columns. The fluence, dpa, and temperatures are the same for the top insulator blocks.

Replaceable outer and inner reflector graphite blocks are placed on the inside and outside of the core ring. The inner reflector sees the highest temperatures and fluences. At the inside interface of core ring, the fluence is $6.7 \mathrm{E} 20 \mathrm{n} / \mathrm{cm} 2$ per year $(\mathrm{E}>0.1 \mathrm{MeV})$ with a dpa of 0.56 per year. The peak fluence in the reflector block is $1.8 \mathrm{E} 20 \mathrm{n} / \mathrm{cm} 2$ per year with a dpa of 0.16 per year. Temperatures in the outer reflector blocks are $750^{\circ} \mathrm{C}$ for normal conditions and $1100^{\circ} \mathrm{C}$ for off-normal conditions. Peak temperatures in the inner blocks are $850^{\circ} \mathrm{C}$ during normal operation conditions and $1200^{\circ} \mathrm{C}$ during off-normal conditions.

The last graphite internal components are the fuel blocks. The active core is composed of three rings of fuel blocks, which see the highest temperatures and fluences of all the graphite components. The fluence is $9.9 \mathrm{E} 20 \mathrm{n} / \mathrm{cm}^{2}$ per year with a dpa of 0.82 per year. Normal operating peak temperatures for the fuel blocks are approximately $1250^{\circ} \mathrm{C}$. Off-Normal peak temperatures for the blocks are approximately $1500^{\circ} \mathrm{C}$.

\subsubsection{Intermediate Heat Exchanger}

A current NGNP requirement states that only $10 \%$ of the heat from the primary loop can be diverted to the production of hydrogen. The remaining $90 \%$ will be used to produce electricity. To accommodate this requirement, the IHX is employed to divert heat from the primary side of the reactor to the hydrogen production plant at prescribed conditions and isolate hydrogen production plant equipment from the radioactive contaminants in the helium coolant. To prevent primary radioactive contamination from entering the secondary side through leaks in the primary boundary, the secondary pressure will have to be higher than the primary pressure. The IHX can be employed in either a direct or indirect cycle application.

The direct cycle application would require a compact heat exchanger sized for the $10 \%$ heat load be placed in the PCV. The turbine inlet shroud would have a small leg diverting primary coolant to the heat exchanger. The secondary side of the heat exchanger will contain coolant coming from another IHX inside the hydrogen production plant. The outlet of the primary side would re-enter the primary loop after the turbine or in one of the turbine stages. 
The primary side of the IHX has $1000^{\circ} \mathrm{C}$ helium flowing through it with an exit temperature of $900^{\circ} \mathrm{C}$ or greater. The outlet of the secondary side of the IHX is $975^{\circ} \mathrm{C}$ with a secondary inlet side temperature of $500^{\circ} \mathrm{C}$. This temperature difference yields a thermal effectiveness of $95 \%$. This IHX will be placed in the PCV requiring the surface area density to be extremely large, greater than $1000 \mathrm{~m}^{2} / \mathrm{m}^{3}$. The pressure drop in each IHX leg must not exceed $2 \%$ of total pressure in each leg. The operating pressure in both legs is between 7.4 and $8.0 \mathrm{MPa}$ with the secondary pressure exceeding the primary pressure by $0.1 \mathrm{MPa}$ to prevent radioactive leakage from the primary side. Depressurization of the secondary side while the primary remains hot and at pressure will create significant thermal stress within the secondary side of the IHX. Membrane stresses in the IHX may also be affected, but only as a function of the IHX design and the overall pressure differential. These stresses will potentially challenge the material properties at these temperatures. Three types of heat exchangers have been suggested for this IHX, the printed circuit heat exchanger, the brazed plate and fin type heat exchanger, and the refractory metal or ceramic open-cell heat foam heat exchanger. The printed circuit IHX relies on thermal diffusion welds between plates, while the brazed plate IHX uses high-temperature brazes to join the different plates together. A rule of thumb for the discrimination of the materials is that the elastic yield at $1000^{\circ} \mathrm{C}$ exceeds the actual stress state by a factor of two. The fluence and dpa of the IHX is negligible inside the PCV. Off-normal conditions would push the primary inlet temperature up to $1200^{\circ} \mathrm{C}$ for a short period. The full consequence of this temperature spike will have to be evaluated during design.

The indirect cycle application would require the IHX to be sized to handle the entire heat load of the reactor. The IHX is placed between the RPV and PCV with structural ducts between the RPV and IHX and between the IHX and PCV. The primary side of the IHX sees flow from the reactor and exits to its own turbo-machinery pumps, intercoolers, pre-coolers and recuperator for conditioning to reactor inlet conditions. The IHX secondary side outlet helium would run the main turbine/generator. The secondary balance of plant would return the helium coolant to the secondary IHX inlet conditions using the normal turbo machinery. The heat for the hydrogen plant would be drawn from the secondary outlet before the turbine. This configuration would isolate both the hydrogen plant and the main turbine and generator from the radioactive contamination in the primary leg. The primary $\mathrm{IHX}$ inlet temperature is $1000^{\circ} \mathrm{C}$ and the secondary outlet temperature is $950^{\circ} \mathrm{C}$. The outlet of the primary and inlet of the secondary will have to be determined during design. The conditions for $95 \%$ efficiency, operating pressures, and pressure drops are the same as in the direct cycle. The fluence and dpa will be between that of the PCV and RPV depending on the distance the IHX is placed from the RPV. If the secondary side experiences a loss of flow without scram, the entire primary side heat load will be placed on the primary turbo-machinery and heat exchangers to reduce the temperature and bring the pressure back up to inlet conditions to maintain the downward flow through the core. Besides the heat exchangers discussed previously, more traditional, helically coiled tubes in a tube sheet design could be used as well [6]. This IHX would also see the $1200^{\circ} \mathrm{C}$ spike in an off-normal condition.

Design or engineering improvements to these two concepts could reduce their material challenges. One common material challenge that faces both concepts is the potential for carburization/decarburization with temperatures above $950^{\circ} \mathrm{C}$.

Even though there is currently no preconceptual design, this section has described some of the bounding conditions expected in the NGNP components to identify long-lead or long-term qualification or material acquisition issues. This will be an iterative process as the design matures. 


\subsection{QA Requirements}

All work performed to support the Technical Program for the NGNP Reactor Materials Selection and Qualification Program will be in accordance with the DOE QA requirements specified in DOE Order 414.1A, "Quality Assurance," and 10 CFR 830, "Nuclear Safety Management," including Subpart A, "Quality Assurance".

The NGNP Reactor Materials Selection and Qualification Program will utilize the national consensus standard ASME NQA 1997, "Quality Assurance Program Requirements for Nuclear Facilities Applications," and Subpart 4.2 of ASME NQA 2000, "Guidance on Graded Application of Quality Assurance (QA) for Nuclear-Related Research and Development," for project-specific materials development $R \& D$ activities.

The term $R \& D$ is defined as those scoping activities that are scientific in nature that result in the advancement of knowledge or development of technology and their supporting activities. R\&D activities will be performed under Subpart 4.2 of ASME NQA 2000. Specific material selection and qualification testing activities within the materials program are considered reactor design inputs rather than R\&D; therefore, selection and qualification testing activities will be performed to the requirements of ASME NQA 1997.

The QA requirements for specific projects under the NGNP Reactor Materials Selection and Qualification Program will be specified in project-specific Quality Assurance Plans (QAPs) and project-specific technical specifications. The project specific QAPs will include the necessary management controls commensurate with the project work scope and importance to the NGNP Reactor Materials Selection and Qualification Program goals and objectives.

\subsection{NRC Licensing Considerations}

After the successful completion of viability and performance $R \& D$, a demonstration phase is anticipated. This will involve the NRC licensing process of construction application and operation permits for this prototype or demonstration system. The NRC licensing basis is 10 CFR Part 50 modified by use of 10 CFR Part 52 or other appropriate basis.

Many of the NGNP systems involve substantial changes in safety system design and implementation that require licensing implementation significantly different from current experience. Because NGNP systems will require deployment of materials and components operating under new conditions, codes and standards must be established for their use. Materials composition and property data that are collected during the development of these new technologies will be obtained in accordance with QA standards so that they may provide the necessary basis for codes, standards, and licensing. Candidate materials that meet the requirements of NGNP systems will be identified, and databases sufficient to support design and licensing will be established. The Materials Selection and Qualification Program will establish a working relationship with the NRC to ensure that the testing program will meet the requirements for NRC licensing.

\subsection{Approaches to ASME Codification}

Once appropriate materials have been designated for the NGNP use, additional efforts will be necessary to gain ASME B\&PV Code acceptance of those materials at the desired operating conditions. Since the ASME B\&PV Code establishes the rules for the construction of pressure vessels and many nuclear power plant components, ASME acceptance of the designated materials at the temperatures and environments 
expected during NGNP use is a significant programmatic step forward. The ASME B\&PV Code is not the only national consensus standard that will have to be satisfied. However, the ASME B\&PV Code is believed to be the most significant from the perspective of actually designing and constructing an NGNP demonstration plant.

\subsubsection{Background}

The charter for the ASME B\&PV Code committee is:

To establish the rules of safety governing the design, fabrication, and inspection during construction of boilers and pressure vessels, and to interpret these rules when questions arise regarding their intent.

Many engineers consider the goal of the ASME B\&PV Code is "to maintain the pressure boundary". The current ASME B\&PV Code has been in use for many decades and Section III (the nuclear power portion of the Code) has matured greatly over the last 30 years. But it was written mainly for pressurized and boiling water reactors that typically have temperature limits below $427^{\circ} \mathrm{C}\left(800^{\circ} \mathrm{F}\right)$. Under Section III, Subsection $\mathrm{NH}$ addresses temperature limits up to $816^{\circ} \mathrm{C}\left(1500^{\circ} \mathrm{F}\right)$, but only for a limited number of materials.

The NGNP is a helium-cooled reactor operating in excess of these temperature limits; consequently, numerous areas of the ASME B\&PV Code will need to be modified or expanded, including (but not limited to) new materials approved for use, new temperature limits for existing approved materials, new design considerations, new weld procedures, new equipment considerations, and more. Other sections of the ASME Code have temperature limits for certain materials in the 816 to $900^{\circ} \mathrm{C}\left(1500\right.$ to $\left.1650^{\circ} \mathrm{F}\right)$ range but these temperature limits are still below what is desired for NGNP balance-of-plant and hydrogen generation uses.

The ASME Main Committee has a large number of reporting subcommittees. It is important to note that once a material has been approved for use under Section II, it is still necessary to interact with the other affected subcommittees, especially the Section III and Section VIII Subcommittees, to gain full ASME B\&PV Code acceptance.

\subsubsection{Current ASME B\&PV Code Material Acceptance Criteria}

Section II of the ASME B\&PV Code addresses materials approved for Code use. Besides various specifications for ferrous, nonferrous, and welding materials, Section II also contains material properties such as Young's modulus, thermal conductivity, allowable stresses and stress intensities, etc. To achieve ASME B\&PV Code acceptance, specific material information must be provided to the appropriate subcommittees. Appendix 5 (contained in Part D of Section II) lists the guidelines established for approval of new materials. The items listed below summarize those guidelines.

\section{Code Policy}

- Only specifications approved by American Society for Testing and Materials (ASTM), American Welding Society (AWS), or other recognized national/international organizations

- Grant ASME permission to reprint the specification

- Consider requests from boiler, pressure vessel, and nuclear power plant component manufacturers or end users 
- Application

- Identify which Section(s) and Division(s) the new material is to be incorporated

- Identify temperature range of application

- Identify if cyclic service is to be considered

- Identify all product forms, size ranges, and specifications

- In English language in U.S. or SI/metric units

Mechanical Properties

- Stress-rupture and creep rate data starting at $25^{\circ} \mathrm{C}$ below where time-dependent properties may govern and extending to $50^{\circ} \mathrm{C}$ above the maximum intended use temperature

- Sufficient time-dependent data for welded applications

- Notch toughness data

- Stress-strain curves for external pressure uses

- Fatigue data over desired temperature range

- Data for all mechanical properties provided from at least three heats of material

- Ultimate tensile strength, yield strength, reduction of area, and elongation $\left(50^{\circ} \mathrm{C}\right.$ intervals from room temperature to $50^{\circ} \mathrm{C}$ above maximum intended use temperature)

- Information describing service experience in temperature range contemplated is useful

\section{Other Properties}

- Over the range of temperatures for which the material is to be used, adequate data necessary to establish:

- Coefficient of thermal expansion (CTE)

- Thermal conductivity and diffusivity

- Young's modulus

- Shear modulus

- Poisson's ratio

\section{Weldability}

- Data on weldability, including procedure qualification tests per Section IX

- Welding tests made over full range of material thicknesses 
- Pertinent information s provided regarding:

- Post-weld heat treatment (PWHT)

- Susceptibility to air hardening

- Effect of welding procedure, heat-affected zone (HAZ) and weld metal notch toughness

- Any welding experience

\section{$\underline{\text { Request for Additional Data }}$}

- Committee may request additional data on properties or material behavior not explicitly treated in the construction Code in which adoption is desired

New Materials Checklist

- Useful materials checklist provided to assist inquirers $\underline{\text { Code Case }}$

- Committee will consider a Code Case (3-year effective period) permitting use of new material provided:

- Evidence provided that request for material specification coverage has been made

- Material commercially available and can be purchased per proposed specification

- Inquirer shows reasonable demand

- Specification form clearly described

- Requirements of Appendix 5 satisfied.

The items above summarize Section II guidelines and may require a significant effort to satisfy. The higher temperatures and operating environment for the NGNP may require even further efforts. Section III, Subsection NH guidelines are discussed in detail in Section 3.4.4.2 of this document.

\subsubsection{ASME B\&PV Code Process}

The preferred approach to gaining ASME B\&PV Code acceptance of NGNP materials and construction details is to incorporate the materials into Section II and write applicable rules for NGNP construction, where necessary. However, Code Cases are an alternative option for gaining ASME B\&PV Code acceptance. Code Cases are used when it is necessary to clarify the intent of existing Code requirements or, when the need is urgent, to provide rules for material or construction issues not covered by existing Code rules. Code Cases are also useful since one can quickly determine the Main Committee's acceptance of an idea and the limited scope of a Code Case may gain easier NRC acceptance. However, a potential downside of a Code Case is its limited (3-year) effective period, unless it is renewed.

\subsubsection{Beyond ASME B\&PV Code Material Acceptance}

The determination of NGNP materials followed by gaining ASME B\&PV Code approval is certainly a very important first step toward building an NGNP demonstration plant. However, additional ASME B\&PV construction rules for an NGNP demonstration plant will probably be needed. The Subgroups, Working Groups, and Special Working Group report to the Subcommittee where the details of the rules governing construction are proposed, debated, and approved. Participation on behalf of the NGNP Project at these levels is essential. 
Other ASME committee groups may be identified once further details of the plant design become finalized. Due to the lack of current high-temperature, gas-cooled reactors, new groups (e.g., under Section XI) may need to be added to the organizational structure.

\subsection{Procurement Requirements}

A variety of procurement activities are anticipated to occur during the NGNP Materials Program. These procurements include:

- Materials for R\&D and other Test Activities

- Consultants and Review Committee Membership

- Materials R\&D and other Testing Services

- Proprietary Vendor Data.

Such procurements will be managed according to the current DOE regulations involved with procurement operations. Testing services will be procured by normal services subcontracts for private industrial entities, using competition to the extent possible. Where testing or R\&D services are required from DOE laboratories, the work authorizations, requirements, and funding will be provided directly by DOE in accordance with agreed-upon NGNP program plans. Consultants will be obtained using the services subcontracting route with specific justification provided in cases where a specific person or organization is required.

Procurement of test materials for qualification activities presents some special issues. Test materials will need to come from both primary metal or ceramics producers and product fabricators. Most primary materials producers and fabricators will not be working to an existing NQA-1 type QA program. This is especially true for the NGNP where many of the materials are not those that are historically used in the nuclear industry. In some cases the specific processes used by the fabricators may be proprietary but essential to achieving the desired products needed for the NGNP.

The following general plan will be used to procure appropriate test materials and develop qualified vendors for NGNP components:

- Compete procurements whenever reasonable or practical.

- Select vendors that have a significant share of the world market or a unique capability for manufacturing of the specific material or product involved. Testing of product from two or more vendors may be required.

- Design procurements to obtain a vendor commitment to develop materials and/or processes that are acceptable, per established quality and certification standards, for use in the NGNP.

- Use flexible QA approaches for procurements that allow a prospective vendor to provide initial test articles with minimal QA documentation and assist the vendor with development of QA plans and certification methodology for later test articles and qualification to produce NGNP components.

- Avoid the purchase of proprietary process or materials test data where possible. Any purchases of such data need to be on condition that the data can be verified as usable through the methods of data qualification discussed in this plan. This may not be feasible in cases where the specific product, process, or material is unique but required for an NGNP component. 


\section{TECHNICAL PROGRAM}

\subsection{Preliminary Selection Approach}

\subsubsection{Preliminary Material Selection}

The preliminary selection of candidate materials for qualification testing is the initial step in the selection process. It will focus on a given component or group of related components for the reactor or balance of plant. A preliminary selection document(s) will be generated to detail the status of the current material options and the process for achieving material qualification, itemizing the logic and steps involved to get to a final selection. The selection activity will document the potential for successful selection of specific materials based on at least the following criteria:

- Technical acceptability - will meet technical requirements for usage

- Regulatory acceptability - material is licensable for its intended purpose

- Manufacturability - the material can be fabricated into the desired component

- Cost - the cost of the material is not prohibitive

- Longevity - the material will meet design life requirements

- Qualification timing - the material can achieve qualification on a schedule that will support the reactor program.

The following preliminary selection documents have been identified as necessary to guide the qualification testing program. Other such documents could be added if determined necessary at a later date:

1. RPV System

2. Reactor Core Graphite, Reflector, and Supports

3. Control Rod and Composite Structures

4. Reactor Metallic Internals

5. IHX and Piping

6. IHX Pressure Vessel

7. Hot Duct Liner and Insulations

8. Power Conversion Turbine and Generator

9. Power Conversion Recuperators

10. Valves, Bearings, and Seals.

The selection document provides the detailed technical status of the alloys/materials being considered. It will itemize and justify the materials testing program selected for qualification. The document would normally be generated before the start of testing and would be updated as necessary to incorporate additional reactor requirements, design, and materials test information. The preliminary selection document will cover the following issues:

- Review of the existing materials database supporting each material option identified in the Program Plan and any additional options that may have been missed.

- Determination of the quality of the existing database per NQA-1 standards and evaluation of what existing data would be required as part of the qualification data set. (See Section 3.1.2)

- Review the materials options against the design requirements and boundary conditions. An evaluation will be made on what flexibility exists for the reactor designer to adjust the materials requirements set and what requirements are absolute. (If this determination cannot be made, the 
selection document would recommend specific design tradeoff studies to further evaluate the alternatives.)

- Evaluation of the codes and standards status for pressure boundary and safety system materials. Based on the work required, the materials would be graded on their potential to successfully complete the standardization and codification processes. The work required for codification would be itemized.

- A determination would be made on what primary material manufacturers and component fabricators currently exist for supplying the materials as finished components. This determination must show whether or not existing manufacturers and fabricators could provide the components to the size, technical requirements, and certifications necessary for reactor use. If current capability does not exist, an evaluation must be provided on what is missing and the potential for its availability by the time procurements are needed. (Such feedback would be provided back to the manufacturers and fabricators for their consideration).

- Recommend the top candidate materials for inclusion in a materials testing and qualification program to the extent possible with existing information. A goal would be a minimum of two materials for any given component. If the top candidate materials cannot be selected because of the need for additional scoping data, identification of the needed scoping tests will be provided.

\subsubsection{Data Sources and Data Qualification}

Existing data will need to be used for the determinations documented in the preliminary selection documents. This existing data may include any documented evidence (journal articles, lessons learned, internal test reports, vendor data, etc.) of materials behavior from the collective international body of materials information. Data on similar or related alloys is also permissible for use in confirming the database properties on the specific material in question.

The content of the qualification test program will be developed based on the existing data set. A qualification of the existing data may be necessary for various reasons.

The qualification process of existing data, including data of indeterminate quality, would include data qualification planning, a controlled process for evaluating and establishing data quality, and documentation of the results of this process. Existing data is defined as data developed prior to the implementation or outside of Part I of NQA-1-1997; or data published in scientific publications. Existing data does not include information, which is accepted by the scientific and engineering community as established fact (e.g., engineering handbooks, density tables, gravitational laws, etc.). One or more of the following methods should be used to qualify data:

- Quality Assurance Program Equivalency - The Quality Assurance Program Equivalency method may be used to determine if the acquisition, development, or processing of data have been performed in accordance with sound technical, administrative practices or procedures that can be demonstrated to generally meet the applicable requirements and guidance of NQA-1.

- Data Corroboration - The Data Corroboration method may be used in order to determine if subject matter data comparisons can be shown to substantiate or confirm parameter values.

- Confirmatory Testing - The Confirmatory Testing method may be used when tests can be designed and performed to establish the quality of existing or indeterminate data. Confirmatory 
Testing also may be used when previous test results are not verifiable because of questionable testing methodology or a lack of applicable documentation.

- Peer Review - The Peer Review Method is used to independently evaluate data to determine if the employed methodology is acceptable; confidence is warranted in the data acquisition or developmental results; or the data have been used in a similar range of applications.

Results of the data qualification task shall be documented in a report that includes:(a) the scope of the task; (b) the data set(s) for qualification; (c) the expertise of the individuals performing the data qualification effort; (d) the method(s) of qualification and rationale for the selected option(s); (e) the rationale for abandoning any of the qualification methods, if appropriate; (f) evaluation criteria; (g) qualification criteria; (h) data generated by the evaluation (if applicable); (i) the results of the evaluation; and (j) a recommendation for/against changing the qualification status of the data.

Management should evaluate the recommendation and disposition the data appropriately (i.e., if the data set(s) is determined to be "qualified", update the data qualification status from "existing" to "qualified," OR if the data set(s) is determined to be "not qualified", a decision should be made and documented regarding the need to collect more data.)

\subsubsection{Design Tradeoff Studies}

A close relationship needs to exist between reactor and balance of plant component functional requirements and the materials of construction for those components. Because of the known design requirements for some components, selection of a suitable material or group of materials may not be feasible or may result in selection of exotic materials that are very costly and probably impractical. In such situations, it may be best to put a hold on the preliminary selection process while a design tradeoff study is conducted.

Design tradeoff studies compare the design flexibility with the difficulty in obtaining a usable material of construction and provide an adequate justification for proceeding. The trade study results should include recommendations for adjustments in design requirements or boundary conditions for the plant or validation that the requirements are essential and accommodating materials must be qualified.

\subsection{Candidate Materials Identified for NGNP Components}

A variety of options have been identified for potential use in the NGNP reactor and balance of plant components. These options originated through an initial look at the materials issues for a very hightemperature reactor in January $2003^{1}$ and a much larger, focused NGNP materials options identification activity that included meetings at the Idaho National Engineering and Environmental Laboratory (INEEL) and the Oak Ridge National Laboratory (ORNL) in July 2003. The information shown in this section is a summary of the options identified because of these activities and any others that have been identified since the July meeting. These options provide the input basis for the preliminary selection activity discussed in Section 3.1.

\subsubsection{Reactor Pressure Vessel System}

The RPV system envisioned for the NGNP is illustrated in Chapter 2. It will comprise a large RPV containing the core and internals, a second large vessel for PCV containing the main turbine, generator, and associated turbo machinery and heat exchangers, and a pressure-containing CV joining the RPV and the PCV. Because of the wide range of material thicknesses in the RPV, it will be constructed in a segmented configuration. Although the specific design is not yet available, such a configuration will play 
a role in the materials selection as it relates to fabrication issues, effects of loading variables such as cycling, etc. The vessels will be exposed to air on the outside and helium on the inside, with emissivity of the chosen material an important factor regarding radiation of heat from the component to the surrounding air to ensure adequate cooling during accident conditions. The materials tentatively selected for gascooled RPV service are low-alloy ferritic/martensitic steels, alloyed primarily with chromium and molybdenum. The most significant difference in demands placed on the RPV system between the GTMHR and the NGNP are the temperatures at which they will be required to operate, with the currently anticipated temperatures for the NGNP being significantly higher and more challenging relative to materials selection. There are uncertainties regarding the abnormal temperatures and times, loads, loadtime history, time-temperature-load histories, and the temperature and neutron flux gradients through the RPV walls. The current estimate for temperature gradient through the RPV wall is about $50^{\circ} \mathrm{C}$. Additionally, the current estimate for fatigue cycles is for about 150 cycles plus hydrogen cycles for a total of about 600 small cycles. It is recognized that the normal operating temperatures for the RPV system are dependent on the capabilities of the materials of construction. Thus, an iterative approach will be required to eventually match the limiting material capabilities and the design operating conditions.

The potential candidate materials for the three pressure vessels and closure bolting are discussed in the next subsection, while the materials development and qualification research that will be required to resolve questions about the suitability of these materials are addressed in Section 3.3.

3.2.1.1 Pressure Vessel Alloys for Consideration. Because of the high operating temperature, low Cr-Mo steels such as $21 / 4 \mathrm{Cr}-1$ Mo do not have adequate high-temperature strength for the RPV and $\mathrm{CV}$. In fact, the current operating temperature of $593^{\circ} \mathrm{C}$ for the $\mathrm{RPV}$ and $\mathrm{CV}$ is at the limit for any ferritic or ferritic-martensitic steel currently in any part of the ASME B\&PV Code, while the abnormal (offnormal accident) temperature of $770^{\circ} \mathrm{C}$ for 50 hours is beyond that limit and provides an even greater challenge. For the ferritic steel option, there are four classes of advanced, higher alloy ferritic-martensitic steels that have been identified as potential candidate alloys, while the $21 / 4 \mathrm{Cr}-1 \mathrm{Mo}$ alloy is listed as providing a possible fall back position if the system can be designed such that the reactor inlet temperature is significantly reduced. These five alloy classes are shown below. There are specific alloys identified within each class, as well as statements regarding available data, experience, and Code status. These classes of alloys are listed in the order recommended as priority for consideration as the structural material for the RPV and CV components for the NGNP. Additionally, the class of austenitic stainless steels is listed as well, also as a fallback option, but an option that retains the potential for operation at the desired temperatures, especially considering the abnormal temperatures under accident conditions, albeit at a significantly higher capital cost.

\section{Class of $9 \mathrm{Cr}-1 \mathrm{MoVNb}$}

a. This class of materials has the most industrially mature high strength database. For example, the $9 \mathrm{Cr}-1 \mathrm{Mo}-\mathrm{V}$ (grade 91) alloy is ASME Code approved to $593^{\circ} \mathrm{C}$ for Section III, Class 1 components.

b. There are, of course, limits to Code applicability-involving time at temperature, thickness of forgings, etc.

c. Within this class of alloys, it seems prudent to consider variants, such as 9Cr-1MoWV (grade 91, grade 92), etc., because available research data show significantly improved hightemperature strength for those alloys relative to the grade 91 . 


\section{Class of 7-9Cr2WV}

a. Various alloys of this class are currently being developed under the Fusion Materials Program.

b. There is a smaller database than for the $9 \mathrm{Cr}-1 \mathrm{MoVNb}^{t}$ classes mentioned above, but some of these alloys offer the possibility of better high strength properties.

c. Examples of specific alloys within this group include F82H (7.5Cr2WV), JLF1 and EUROFER (9Cr2WV).

d. A potential advantage of these alloys is the fact that they have also been developed to reduce activation under neutron irradiation with resultant advantages for decommissioning.

\section{Class of $3 \mathrm{Cr}-3 \mathrm{WV}$}

a. This class of alloys, currently under development at ORNL, offers good high strength properties, but has a very limited database. In relatively modest section sizes evaluated to date, the yield strength of the specific $3 \mathrm{Cr} 3 \mathrm{WV}$ alloy underdevelopment at ORNL is about twice that of the SA508 grade 3 forging steel used for current light-water reactor (LWR) RPVs.

b. Because of its lower alloying content, it offers the potential for substantially lower cost than those more highly alloyed steels in the two classes discussed above. However, because of its lower alloying content, environmental effects at high temperatures may be limiting.

c. There are indications that this alloy offers the possibility of no need for a PWHT.

d. One other alloy in this class is a $2.75 \mathrm{Cr}-1 \mathrm{MoV}$ variant under development in Russia.

\section{Class of $12 \mathrm{Cr}-1 \mathrm{MoWV}$}

a. The alloy designated HT9 is an older existing alloy within this class of materials.

b. The HT9 alloy has a broad database available, but has poorer high-temperature strength and poorer radiation resistance than, for example, $9 \mathrm{Cr}-1 \mathrm{MoVNb}$.

c. There are some more recent $12 \mathrm{Cr}$ variants that offer improved properties relative to the HT9. For example, the HCM 12A alloy has a good database and is currently approved by ASME Code Case 2180 to $649^{\circ} \mathrm{C}$ for application in Sections VIII and I. Additionally, a Japanese alloy designated SAVE12 appears to have good high-temperature strength, but the available database needs to be reviewed.

5. Fallback for Lower Temperature Operation: $2.25 \mathrm{Cr}-1 \mathrm{Mo}$

a. There is an extensive database for this alloy, including data in different operating environments such as helium.

b. Another advantage is the extensive industrial experience with this alloy in many different applications around the world.

c. However, its high-temperature strength is significantly lower than the alloy classes discussed 
above and, as such, is only applicable for substantially lower vessel temperature, such as in the case of the HTTR at JAERI.

\section{Class of Austenitic Stainless Steels (Types 304, 316, etc.)}

a. There is an extensive database for many of these alloys, including some data in helium with various impurity contents.

b. There is extensive industrial experience with this class of steels in many different applications, including in irradiation environments.

c. The tensile strengths of these alloys are much inferior to the ferritic-martensitic steels, but their strength properties do not degrade as rapidly at high temperatures. However, at temperatures in the range of $650^{\circ} \mathrm{C}$, their maximum allowable stresses are not necessarily superior to some ferritic-martensitic steels. The primary reason for inclusion of the class of stainless steels here is their metallurgical stability at the higher temperatures currently anticipated for the abnormal conditions.

d. In general, stainless steels have superior oxidation and corrosion resistance in many media, but they are not immune to severe degradation in some common environments. Austenitic materials also have much lower thermal conductivity, which may cause design issues with heat transfer during accident conditions.

Potential candidate alloys for the PCV could include those for the RPV and CV, but there are lower cost options available because of the lower operating temperatures. Even under abnormal conditions, the PCV will be subjected to temperatures about the same as those currently used for commercial LWR vessels. Moreover, the size of the vessel is well within normal fabrication capability. Thus, the current LWR pressure vessel materials, SA508 grade 3 class 1 forgings or SA533 grade B class 1 plates are potential candidates, as is the $21 / 4 \mathrm{Cr}-1$ Mo alloy, dependent on material compatibility issues. It is noted that the $\mathrm{CV}$ is welded to the PCV and the welded joint with dissimilar materials must be a consideration.

Potential candidate alloys for high-temperature closure bolting are alloy 718 and types 304 and 316 stainless steels. Although alloy 718 has superior strength, it is currently approved up to $566^{\circ} \mathrm{C}$ in ASME Section III, Subsection NH. The two types of stainless steels, however, have allowable stress intensities for bolting up to $704^{\circ} \mathrm{C}$. An evaluation of the database for the alloy 718 will be conducted to assess the data needed, if any, for increasing the allowable temperature to that required for the NGNP. Also, the estimated irradiation exposure for closure bolting will be assessed to evaluate the need for inclusion of bolting in the irradiation program.

\subsubsection{Reactor Metallic Internals}

The following sections will develop additional data used to make metallic and nonmetallic materials choices for intermediate and high-temperature materials for the NGNP reactor internals and balance of plant components. Table 3-1 lists possible choices from an initial materials scoping document ${ }^{1}$ and additional information developed during reviews and discussions between materials experts at a meetings held at the INEEL and ORNL in July 2003. 
Table 3-1. Conditions Affecting Materials Selection for Intermediate and High-Temperature NGNP Components

\begin{tabular}{|c|c|c|c|c|c|c|c|c|c|}
\hline Conpts & Normal Temp & $\begin{array}{l}\text { Maximum } \\
\text { Temp }\end{array}$ & Loading & $\begin{array}{l}\text { Environment } \\
\text { Issues }\end{array}$ & $\begin{array}{l}\text { Radiation } \\
\text { Issues }\end{array}$ & Aging Issues & $\begin{array}{l}\text { Joining } \\
\text { Issues }\end{array}$ & $\begin{array}{c}\text { Manufacturing } \\
\text { Issues }\end{array}$ & $\begin{array}{c}\text { Prime } \\
\text { Materials }\end{array}$ \\
\hline SCS Tube & $600^{\circ} \mathrm{C}$ & $600^{\circ} \mathrm{C}$ & $\begin{array}{l}\text { Thermal } \\
\text { Stress, } \\
\text { LCF/HCF }\end{array}$ & $\begin{array}{l}\text { Helium, } \\
\text { Pressurized } \\
\text { water, SCC, }\end{array}$ & Not significant & Some & Some & None & $\begin{array}{l}316 \mathrm{FR} \\
\text { Alloy } 800 \mathrm{H}\end{array}$ \\
\hline Core Barrel & $600^{\circ} \mathrm{C}$ & $700^{\circ} \mathrm{C}$ & Core Weight & Helium & $\begin{array}{l}\text { Negligible } \\
<0.005 \mathrm{DPA}\end{array}$ & Some & Some & None & $\begin{array}{l}\text { Alloy } 800 \mathrm{H} \\
\text { 316FR }\end{array}$ \\
\hline $\begin{array}{l}\text { Core Support } \\
\text { Floor }\end{array}$ & $600^{\circ} \mathrm{C}$ & $700^{\circ} \mathrm{C}$ & Core Weight & Helium & $\begin{array}{l}\text { Negligible } \\
<0.005 \mathrm{DPA}\end{array}$ & Some & Some & None & $\begin{array}{l}\text { Alloy } 800 \mathrm{H} \\
\text { 316FR }\end{array}$ \\
\hline SCS Shell & $600^{\circ} \mathrm{C}$ & $1200^{\circ} \mathrm{C}$ & Own Weight & $\begin{array}{l}\text { Helium, Off } \\
\text { Normal } \\
\text { Helium }\end{array}$ & $\begin{array}{l}\text { Negligible } \\
<0.005 \mathrm{DPA}\end{array}$ & $\begin{array}{l}\text { None, if CC } \\
\text { composite }\end{array}$ & $\begin{array}{l}\mathrm{N} / \mathrm{A} \text {, if CC } \\
\text { composite }\end{array}$ & $\begin{array}{l}\text { Major, if CC } \\
\text { composite }\end{array}$ & $\begin{array}{l}\text { CC composite } \\
\text { Alloy } 617 \\
\text { Alloy } 230 \\
\text { Alloy HR-120 } \\
\text { Alloy X, XR }\end{array}$ \\
\hline $\begin{array}{l}\text { Upper Core } \\
\text { Restraint }\end{array}$ & $600^{\circ} \mathrm{C}$ & $1200^{\circ} \mathrm{C}$ & Own Weight & $\begin{array}{l}\text { Helium, Off } \\
\text { Normal } \\
\text { Helium }\end{array}$ & $\begin{array}{l}\text { Negligible, } \\
\text { Evaluate } \\
\text { effect of Co }\end{array}$ & $\begin{array}{l}\text { None, if CC } \\
\text { composite }\end{array}$ & $\begin{array}{l}\mathrm{N} / \mathrm{A} \text {, if CC } \\
\text { composite }\end{array}$ & $\begin{array}{l}\text { Major, if CC } \\
\text { composite }\end{array}$ & $\begin{array}{l}\text { CC composite } \\
\text { Alloy } 617 \\
\text { Alloy } 230 \\
\text { Alloy HR-120 } \\
\text { Alloy X, XR }\end{array}$ \\
\hline $\mathrm{IHX}$ Indirect & $1000^{\circ} \mathrm{C}$ & $1000^{\circ} \mathrm{C}$ & $\begin{array}{l}\text { Thermal } \\
\text { Transients }\end{array}$ & Helium & None & Some & Some & Major & $\begin{array}{l}\text { Alloy } 617 \\
\text { Alloy } 230 \\
\text { Alloy HR-120 } \\
\text { Alloy X, XR }\end{array}$ \\
\hline Hydrogen $\mathrm{HX}$ & $950^{\circ} \mathrm{C}$ & $950^{\circ} \mathrm{C}$ & $7 \mathrm{MPa}$, Cycles & $\begin{array}{l}\text { Helium, Heat } \\
\text { transfer fluid }\end{array}$ & None & Some & Some & Some & $\begin{array}{l}\text { Alloy } 617 \\
\text { Alloy } 230 \\
\text { Alloy HR-120 } \\
\text { Alloy X, XR }\end{array}$ \\
\hline Bellows & $600^{\circ} \mathrm{C}$ & $700^{\circ}$ & Fatigue & Helium & None & Some & Some & Major & $\begin{array}{l}\text { Alloy } 800 \mathrm{H} \\
\text { 316FR }\end{array}$ \\
\hline He Circulator & $600^{\circ} \mathrm{C}$ & $600^{\circ} \mathrm{C}$ & $\begin{array}{l}\text { Fatigue, } \\
\text { Creep Fat. }\end{array}$ & Helium & None & Some & Some & Some & $\begin{array}{l}316 \mathrm{FR} \\
\text { Alloy } 800 \mathrm{H}\end{array}$ \\
\hline $\begin{array}{l}\text { Primary to } \\
\text { Secondary } \\
\text { Piping }\end{array}$ & $950^{\circ} \mathrm{C}$ & $950^{\circ} \mathrm{C}$ & $7 \mathrm{MPa}$ & $\begin{array}{l}\text { Helium, Heat } \\
\text { transfer fluid }\end{array}$ & None & Some & Some & Major & $\begin{array}{l}\text { Alloy } 617 \\
\text { Alloy } 230 \\
\text { Alloy HR-120 } \\
\text { Alloy X, XR }\end{array}$ \\
\hline Recuperator & $600^{\circ} \mathrm{C}$ & $600^{\circ} \mathrm{C}$ & & & None & Some & Some & Some & $\begin{array}{l}347 \mathrm{SS} \\
316 \mathrm{FR}\end{array}$ \\
\hline
\end{tabular}

3.2.2.1 Status and List of Alloys for Consideration. The components addressed in this subsection may be classified as core supports and core internals. They include:

- Core barrel

- Inside shroud

- Core support floor

- Upper core restraint

- SCS shell

- SCS tubes. 
Depending on the specific component, the normal operating temperatures will range from 600 to $1000^{\circ} \mathrm{C}$. However, the maximum temperature estimated for accident conditions ranges from 600 to $1200^{\circ} \mathrm{C}$ from one component to another. The maximum temperature $\left(1200^{\circ} \mathrm{C}\right)$ is by no means a certainty, and possibility exists that an innovative design could significantly reduce this temperature for some components. In regard to loading, these components are not pressure boundary components, except for the SCS tubes. In some cases, however, the weight loads can be quite significant. This is the case for the core barrel. The fatigue, thermal-fatigue, seismic, and other loadings that could produce damage are largely unidentified at this time. Compatibility with the coolant gas is a requirement for core metallic internals. In addition, radiation and thermal aging effects on properties are important considerations in material selection. Fabrication and joining must be considered. Finally, the materials must be ASME Code approved for the design conditions. Metallic core support structures must conform to ASME Sect. III, Div. 1, Subsection NG. Other core internals may conform to different rules. It is not clear whether the SCS tubes will be considered to be Class 1 or Class 2 components. At this point in time, it is best to assume that the materials of construction, regardless of the applicable subsection, will be limited to those listed in ASME Section II, Part D, Tables 2A, 2B, and 4. These tables cover temperatures to $370^{\circ} \mathrm{C}$ for ferritic alloys and $425^{\circ} \mathrm{C}$ for austenitic alloys. Subsection $\mathrm{NH}$ of Section III permits construction to higher temperatures for a limited number of materials. These are $21 / 4 \mathrm{Cr}-1 \mathrm{Mo}$ steel (Class 1 ), $304 \mathrm{H}$ stainless steel, $316 \mathrm{H}$ stainless steel, and alloy $800 \mathrm{H}$. Potential candidate materials for the internals, as well as the other high-temperature components likely to be constructed from metallic alloys, are listed in Table 3-2. These materials include alloys for which significant databases exist and new state-of-the-art alloys which are being developed for other high-temperature applications. ASME Code status and design allowable values for the subset of candidate materials being considered for the reactor vessel and intermediate and high-temperature components are listed in Table 3-7 (see Section 3.4.3.1).

For very-high-temperature components $\left(>760^{\circ} \mathrm{C}\right)$, the most likely material candidates are:

1. Variants or restricted chemistry versions of Inconel 617

2. Variants of Alloy $800 \mathrm{H}$

3. Hastelloy X and XR. 
Table 3-2. Potential Candidate Materials Selection for Intermediate and High-Temperature Metallic NGNP Components

\begin{tabular}{|c|c|c|c|c|}
\hline Nominal Composition & UNS No. & Common Name & $\begin{array}{c}\text { Existing Data } \\
\text { Max Temp }\left({ }^{\circ} \mathrm{C}\right)\end{array}$ & $\begin{array}{c}\text { Helium } \\
\text { Experience }\end{array}$ \\
\hline Ni-16Cr-3Fe-4.5Al-Y & & Haynes 214 & 1040 & \\
\hline $63 \mathrm{Ni}-25 \mathrm{Cr}-9.5 \mathrm{Fe}-2.1 \mathrm{Al}$ & N06025 & VDM 602CA & 1200 & \\
\hline $\mathrm{Ni}-25 \mathrm{Cr}-20 \mathrm{Co}-\mathrm{Cb}-\mathrm{Ti}-\mathrm{Al}$ & & Inconel 740 & 815 & \\
\hline $60 \mathrm{Ni}-22 \mathrm{Cr}-9 \mathrm{Mo}-3.5 \mathrm{Cb}$ & N06625 & Inconel 625 & & \\
\hline 53Ni-22Cr-14W-Co-Fe-Mo & N06230 & Haynes 230 & 1100 & \\
\hline $\mathrm{Ni}-22 \mathrm{Cr}-9 \mathrm{Mo}-18 \mathrm{Fe}$ & N06002 & Hastelloy X & 1000 & Yes \\
\hline $\mathrm{Ni}-22 \mathrm{Cr}-9 \mathrm{Mo}-18 \mathrm{Fe}$ & & Hastelloy XR & 1000 & Yes \\
\hline $46 \mathrm{Ni}-27 \mathrm{Cr}-23 \mathrm{Fe}-2.75 \mathrm{Si}$ & N06095 & Nicrofer 45 & & \\
\hline $45 \mathrm{Ni}-22 \mathrm{Cr}-12 \mathrm{Co}-9 \mathrm{Mo}$ & N06617 & Inconel 617 & 1100 & Yes \\
\hline $\mathrm{Ni}-23 \mathrm{Cr}-6 \mathrm{~W}$ & & Inconel $618 \mathrm{E}$ & 1000 & \\
\hline $\mathrm{Ni}-33 \mathrm{Fe}-25 \mathrm{Cr}$ & N08120 & HR-120 & 930 & \\
\hline $35 \mathrm{Ni}-19 \mathrm{Cr}-11 / 4 \mathrm{Si}$ & N08330 & RA330 & & \\
\hline $33 \mathrm{Ni}-42 \mathrm{Fe}-21 \mathrm{Cr}$ & N08810 & Incoloy 800 & 1100 & Yes \\
\hline $33 \mathrm{Ni}-42 \mathrm{Fe}-21 \mathrm{Cr}$ & N08811 & $800 \mathrm{HT}$ & 1100 & \\
\hline $21 \mathrm{Ni}-30 \mathrm{Fe}-22 \mathrm{Cr}-18 \mathrm{Co}-3 \mathrm{Mo}-3 \mathrm{~W}$ & R30566 & Haynes 556 & 1040 & \\
\hline $18 \mathrm{Cr}-8 \mathrm{Ni}$ & S30409 & $304 \mathrm{H} \mathrm{SS}$ & 870 & Yes \\
\hline $16 \mathrm{Cr}-12 \mathrm{Ni}-2 \mathrm{Mo}$ & S31609 & $316 \mathrm{H} \mathrm{SS}$ & 870 & Yes \\
\hline $16 \mathrm{Cr}-12 \mathrm{Ni}-2 \mathrm{Mo}$ & & $316 \mathrm{FR}$ & 700 & \\
\hline $18 \mathrm{Cr}-10 \mathrm{Ni}-\mathrm{Cb}$ & S34709 & $347 \mathrm{H} \mathrm{SS}$ & 870 & \\
\hline $18 \mathrm{Cr}-10 \mathrm{Ni}-\mathrm{Cb}$ & & 347HFG & 760 & \\
\hline $18 \mathrm{Cr}-9 \mathrm{Ni}-3 \mathrm{Cu}-\mathrm{Cb}-\mathrm{N}$ & & Super 304 & 1000 & \\
\hline $15 \mathrm{Cr}-15 \mathrm{Ni}-6 \mathrm{MnCb}-\mathrm{Mo}-\mathrm{V}$ & S21500 & Esshete 1250 & 900 & \\
\hline $20 \mathrm{Cr}-25 \mathrm{Ni}-\mathrm{Cb}$ & & NF 709 & 1000 & \\
\hline $23 \mathrm{Cr}-11.5 \mathrm{Ni}-\mathrm{N}-\mathrm{B}-\mathrm{Ce}$ & & NAR-AH-4 & 1000 & \\
\hline $\mathrm{Ni}-20 \mathrm{Cr}-\mathrm{Al}-\mathrm{Ti}-\mathrm{Y}_{2} \mathrm{O}_{3}$ & NO7754 & Inconel MA 754 & 1093 & \\
\hline Ni-30Cr-Al-Ti- $\mathrm{Y}_{2} \mathrm{O}_{3}$ & & Inconel MA 754 & 1093 & \\
\hline $\mathrm{Fe}-20 \mathrm{Cr}-4.5 \mathrm{Al}-\mathrm{Y}_{2} \mathrm{O}_{3}$ & S67956 & Incoloy MA956 & 1100 & \\
\hline
\end{tabular}

Inconel 617 has the significant advantage in the United States of having gone through ASME Code deliberations that culminated in the draft Code case, and the body of experts that developed the case simultaneously identified what must be done before the Code case could be applied. Alloy $800 \mathrm{H}$ is in Subsection NH, and would be the leading candidate for the intermediate temperature range of $600-760^{\circ} \mathrm{C}$. Hastelloy XR has a significant database and body of experience in Japan.

However, the upper limit of these materials is judged to be $1000^{\circ} \mathrm{C}$. Any component that could experience excursions above $1000^{\circ} \mathrm{C}$ would have to have a very high temperature capability in regard to strength and corrosion resistance. Carbon-carbon composites would then be the leading materials choices. 


\subsubsection{Reactor Core Graphite, Reflector, and Supports}

The use of graphite is envisioned primarily as a structural material and neutron moderator for the NGNP core, permanent side reflectors, and core supports. The challenges related to graphite for the NGNP relate to the fact that the previous U.S. standard grade qualified for nuclear service, H-451 is no longer commercially available. The precursors from which those grades of graphite were made no longer exist. Hence, it will be necessary to qualify new grades of graphite for use in the NGNP. Fortunately, likely potential candidates currently exist, including fine grained isotropic, molded or isostatically pressed, highstrength graphite suitable for core support structures, fuel elements and replaceable reactor components, as well as near isotropic, extruded, nuclear graphite suitable for the above-mentioned structures and for the large permanent reflector components.

The fine-grained isotropic, molded or isostatically pressed, high-strength graphite suitable for core support structure includes Carbone USA grade 2020 and Toyo Tanso grade IG-110. Toyo Tanso grade IG-110 was used in the Japanese HTTR for fuel blocks and in the Chinese HTR-10 pebble bed reactor. These fine-grained materials are suitable for the fuel elements and replaceable reactor components.

New near isotropic, extruded, nuclear graphite have been developed in the United States and Europe for the South African Pebble Bed Modular Reactor (PBMR). The new, currently available graphites are GrafTek (UCAR) grade PCEA — a petroleum coke graphite, and SGL Grade NBG-10 — a pitch coke graphite based on United Kingdom Advanced Gas-Cooled Reactor (AGR) fuel sleeve graphite. This graphite may be a candidate for the fuel elements and replaceable reactor components.

Graphite's suitable for the large permanent reflector components are currently in production (e.g., SGL grade HLM or GrafTek [UCAR] grade PGX). Some data are available for these graphite grades. Grade PGX was used for the permanent reflector of the Japanese HTTR, also PGX and HLM were used in Fort St. Vrain for the core support and permanent reflectors respectively. Fine-grain, high strength, graphite's are available from POCO Graphite, Inc. However, the available billet sizes are small and very expensive, thus not suited for NGNP core applications.

Near-isotropic, extruded, nuclear graphite's (e.g., grade H-451 manufactured by SGL Carbon) were developed in the 1970's for large helium cooled reactors such as the Fort St. Vrain reactor. However, grade $\mathrm{H}-451$ graphite has not been manufactured in the United States for more than 25 years.

There is a substantial database for Grade H-451, including data for the effects of neutron irradiation on the properties, statistical variation of properties, oxidation behavior, etc. This body of data was considered sufficient to license the Fort St. Vrain reactor. Moreover, graphite behavior models were developed for Grade H-451 graphite. Fine grained isotropic, molded or isostatically pressed, high strength graphites suitable for core support structure (e.g., Carbone USA grade 2020 or Toyo Tanso grade IG-110) are available today. These fine-grained materials are suitable for the fuel elements and replaceable reactor components, but they cost about three or four times more than fin-grain, isotropic, extruded graphite.

\subsubsection{Control Rod and Composite Structures}

A number of structural composites were identified for use in control rods and other composite structural applications in the reactor. The components and potential materials are shown in Table 3-3. 
Table 3-3. Potential Structural Composite Applications

\begin{tabular}{|c|c|c|c|c|c|}
\hline & Graphite & C-C & SiC-SiC & $\begin{array}{c}\text { Insulating } \\
\text { Material }\end{array}$ & $\begin{array}{c}\text { Insulating } \\
\text { Material }\end{array}$ \\
\hline Hot Duct & & $\mathrm{X}$ & $\mathrm{X}$ & $\begin{array}{l}\mathrm{X} \text { (castable } \\
\text { oxide) }\end{array}$ & X (mat) \\
\hline Core Support Pedestal & $\mathrm{X}$ & & & & \\
\hline Fuel Blocks & $\mathrm{X}$ & & & & \\
\hline $\begin{array}{l}\text { Replaceable } \\
\text { Outer/Inner Reflector } \\
\text { Blocks }\end{array}$ & $\mathrm{X}$ & & & & \\
\hline $\begin{array}{l}\text { Top/Bottom Insulation } \\
\text { Blocks }\end{array}$ & $\mathrm{X}$ & & & & \\
\hline Upper Plenum Block & $\mathrm{X}$ & & & & \\
\hline Floor Block & $\mathrm{X}$ & $\mathrm{X}$ & $\mathrm{X}$ & $\begin{array}{l}\mathrm{X} \text { (monolithic } \\
\text { oxide) }\end{array}$ & \\
\hline $\begin{array}{l}\text { Upper Core Restraint } \\
\text { \& Upper Plenum } \\
\text { Shroud (Structural } \\
\text { Liner \& Insulation) }\end{array}$ & & $\mathrm{X}$ & $\mathrm{X}$ & $\mathrm{X}$ & $\mathrm{X}$ \\
\hline $\begin{array}{l}\text { Control Rods and } \\
\text { Guides }\end{array}$ & & $\mathrm{X}$ & $\mathrm{X}$ & & \\
\hline
\end{tabular}

Composites of either carbon/carbon $\left(\mathrm{C}_{\mathrm{f}} / \mathrm{C}\right)$ or silicon-carbide/silicon-carbide $\left(\mathrm{SiC}_{\mathrm{f}} / \mathrm{SiC}\right)$ could be potentially used to fabricate several different components. Future qualification tests will be required to delineate which of the Composites are the best choice for a given component based upon the response of the composite to exposure conditions expected within the reactor. For simplicity, $\mathrm{C}_{\mathrm{f}} / \mathrm{SiC}$ composites were not included in the table, but were considered to be an intermediate between $\mathrm{C}_{\mathrm{f}} / \mathrm{C}$ and $\mathrm{SiC}_{\mathrm{f}} / \mathrm{SiC}$ composites. The $\mathrm{C}_{\mathrm{f}} / \mathrm{SiC}$ composites will be lower in cost than $\mathrm{SiC}_{\mathrm{f}} / \mathrm{SiC}$ composites, but might exhibit cracking problems due to the use of dissimilar materials. The $\mathrm{C}_{\mathrm{f}} / \mathrm{SiC}$ composites were classified as a subcategory of $\mathrm{SiC}_{\mathrm{f}} / \mathrm{SiC}$ and would require the same qualification tests as $\mathrm{SiC}_{\mathrm{f}} / \mathrm{SiC}$.

A preliminary list of selection factors for the previously identified types of ceramic composites is shown in Table 3-4. 
Table 3-4. Materials Pro/Con Analysis

\begin{tabular}{|c|c|}
\hline Pros & Cons \\
\hline \multicolumn{2}{|l|}{$\mathrm{SiC}_{\mathrm{f}} / \mathrm{SiC}$ Composites } \\
\hline Good oxidation resistance & Higher cost than C-C \\
\hline Stronger than $\mathrm{C}-\mathrm{C}$ & Many have Boron coated interfaces \\
\hline Greater radiation damage resistance than C-C & Free silicon (not desired) \\
\hline \multirow[t]{2}{*}{ Less change-out, lasts longer } & Lack of manufacturing/infrastructure \\
\hline & $\begin{array}{l}\text { Qualification - different weaves require a new } \\
\text { qualification. ASME specification issue. }\end{array}$ \\
\hline \multicolumn{2}{|c|}{$\begin{array}{l}\mathbf{C}_{\mathrm{f}} / \mathbf{C} \text { Composites (Note: Replacement for super alloys. Could be used for guide tubes [ } \sim 10 \text { feet long, telescope } \\
\text { feature] and the Upper Core Restraint structure.) }\end{array}$} \\
\hline Good material for accident situation. & More Radiation damage/shrinkage than SiC-SiC. \\
\hline Flaking is less likely than SiC-SiC. & $\begin{array}{l}\text { Qualification-different weaves require a new } \\
\text { qualification. ASME specification issue. }\end{array}$ \\
\hline Eliminates metal from the core. & Lack of design criteria. \\
\hline \multicolumn{2}{|c|}{$\begin{array}{l}\text { Good Residual properties (e.g., strength). Strength and } \\
\text { fracture resistance is greater than graphite. }\end{array}$} \\
\hline \multicolumn{2}{|l|}{$\mathrm{C}_{\mathrm{f}} / \mathrm{SiC}$ Composites } \\
\hline Higher thermal conductivity than $\mathrm{SiC}_{\mathrm{f}} / \mathrm{SiC}$ & Possible Radiation damage \\
\hline Higher strength & $\begin{array}{l}\text { Qualification - different weaves require a new } \\
\text { qualification. ASME specification issue. }\end{array}$ \\
\hline Higher moderating power & \\
\hline
\end{tabular}

The use of $\mathrm{C}_{\mathrm{f}} / \mathrm{C}$ composites appears to be desirable for many applications within the reactor because of their strength retention at high temperatures. For example, $\mathrm{C}_{\mathrm{f}} / \mathrm{C}$ is a top candidate for the control rod sheath or guide tubes for a prismatic NGNP because metallic materials cannot withstand the level of neutron irradiation and high temperature of $1050^{\circ} \mathrm{C}$ or higher found in the core. In addition, there is some evidence that $\mathrm{SiC}_{\mathrm{f}} / \mathrm{SiC}$ composites have the potential to be lifetime components (no change-out required) within the high radiation environment within the core. Unfortunately, these $\mathrm{SiC}_{\mathrm{f}} / \mathrm{SiC}$ composites have not been as well characterized as $\mathrm{C}_{\mathrm{f}} / \mathrm{C}$ composites, so there is more uncertainty in the applicability. Therefore, it will be necessary to carefully evaluate both $\mathrm{C}_{\mathrm{f}} / \mathrm{C}$ and $\mathrm{SiC}_{\mathrm{f}} / \mathrm{SiC}$ for the control rod material.

3.2.4.1 SiC/SiC Composite's Status. Ceramic composites made from silicon carbide fibers and silicon carbide matrices $\left(\mathrm{SiC}_{\mathrm{f}} / \mathrm{SiC}\right)$ are promising for nuclear applications because of the excellent radiation resistance of the $\beta$ phase of $\mathrm{SiC}$ and their excellent high-temperature fracture, creep, corrosion and thermal shock resistance. The $\beta$ phase of $\mathrm{SiC}$ has been shown by numerous studies to have a saturation swelling value of about 0.1 to $0.2 \%$ at 800 to $1000^{\circ} \mathrm{C}$. This suggests that composites of $\mathrm{SiC}_{\mathrm{f}} / \mathrm{SiC}$ have the potential for excellent radiation stability. The continuous fiber architecture, coupled with engineered interfaces between the fiber and matrix, provide excellent fracture properties and fracture toughness values on the order of $25 \mathrm{MPa} \mathrm{m}{ }^{1 / 2}$. The strength and fracture toughness are independent of temperature up to the limit of the fiber stability. Also, these fiber/matrix microstructures impart excellent thermal shock and thermal fatigue resistance to these materials so start-up and shutdown cycles and coolant loss scenarios should not induce significant structural damage. 
Composites produced with the advanced fibers, Hi-Nicalon Type S and Tyranno-SA have been irradiated and the test results are presented and compared to other data in Figure 3-1 [7,8,9,10,11,12,13,14].

Comparison is made to both monolithic $\mathrm{SiC}$ and composites made with Ceramic Grade-Nicalon and HiNicalon fibers. The results cover a range of temperatures but the trend of the irradiated to unirradiated ultimate strength, $S_{u}$ irrad $/ S_{u}$ unirr , clearly shows that composites with the advanced fibers Hi-Nicalon Type $S$ and Tyranno SA showed no loss in strength up to a dose of $10 \mathrm{dpa}$. The results of Price $[12,13]$ and Jones, et al. [9] give some support to the possibility that the strength of irradiated advanced fiber material could remain unchanged up to at least $10 \mathrm{dpa}$ and perhaps higher.



Figure 3-1. Ratio of ultimate strength of irradiation and unirradiated composites as a function of neutron dose.

A major issue to be considered when using $\mathrm{SiC}_{\mathrm{f}} / \mathrm{SiC}$ in a high-temperature neutron radiation environment, or in other non-radiation environments where components or structures are subjected to a high heat flux is the expected in-service behavior of its effective transverse thermal conductivity, $\mathrm{K}_{\text {eff }}$. Modeling studies, completed at Pacific Northwest National Laboratory (PNNL), have shown how $\mathrm{K}_{\text {eff }}$ depends on fiber/matrix interface design as well as constituent fiber and matrix thermal conductivity values, their volume fractions and distributions $[15,16,17]$. However, many experimental measurements have indicated that interfaces between fibers and matrices in a composite introduce a thermal barrier that may affect $\mathrm{K}_{\text {eff }}[18,19,20,21]$. Furthermore, $\mathrm{K}_{\text {eff }}$ may depend on physical changes of the interface and even the surrounding atmosphere. As with mechanical behavior, to attain desired thermal behavior of $\mathrm{SiC}_{\mathrm{f}} / \mathrm{SiC}$ proper attention needs to be given to the design of the interphase and the control of interfacial thermal effects. Classical composite models recently have been updated to include the effect of interfacial thermal barriers [22]. Interfacial thermal barriers are quantitatively characterized by a value called the interfacial conductance, which includes the effect of imperfect matching of surfaces at an interface as well as the effect of interfacial gaps brought about by debonding of the fiber from the matrix or microcracking within the fiber coating [22]. The effects of temperature and irradiation on $\mathrm{K}_{\text {eff }}$ were predicted for a hypothetical 2D-SiC $/ \mathrm{SiC}_{\mathrm{f}}$ composite made with high conductivity Tyranno $\mathrm{SA}^{\mathrm{TM}}$ fiber, a thin $(0.2-\mu \mathrm{m})$ PyC fiber coating and a CVI-SiC matrix. For example, it was predicted for this composite that $\mathrm{K}_{\text {eff }}$ would decrease from $34 \mathrm{~W} / \mathrm{mK}$ before irradiation to $<6 \mathrm{~W} / \mathrm{m}-\mathrm{K}$ (at $200^{\circ} \mathrm{C}$ ) after irradiation at $200^{\circ} \mathrm{C}$. Similarly, 
$\mathrm{K}_{\text {eff }}$ would decrease from $26 \mathrm{~W} / \mathrm{m}-\mathrm{K}$ at $1000 \mathrm{C}$ before irradiation to $<10 \mathrm{~W} / \mathrm{m}-\mathrm{K}$ (at $1000^{\circ} \mathrm{C}$ ) after irradiation at $1000^{\circ} \mathrm{C}$.

Transient thermal conditions will occur in a fission reactor from both the system duty cycle and a loss of coolant accident. Shutdown of the system will cause some stress build-up in the material with the magnitude being dependent on the cooling rate and thermal gradients. Start-up will also induce stress of the opposite sign to that produced by shutdown and may relax the cool-down stresses. Coolant loss will induce a rapid heating and subsequent rapid stress change. The limited, existing data suggests continuous fiber ceramic matrix composites, such as $\mathrm{SiC}_{\mathrm{f}} / \mathrm{SiC}$, exhibit very good thermal shock characteristics but most data was obtained for $-\Delta \mathrm{T}$ conditions as a result of quenching from an elevated temperature. Thermal shock in a fission reactor will result from loss of coolant and will result in a $+\Delta \mathrm{T}$. One study was reported for $\mathrm{SiC}_{\mathrm{f}} / \mathrm{SiC}$ composites given a $+\Delta \mathrm{T}$ with no loss in strength following 25 cycles at a heating rate of $1700^{\circ} \mathrm{C}_{\mathrm{f}} / \mathrm{C}$. Monolithic $\mathrm{SiC}$ failed in 1.5 cycles at a heating rate of $1400^{\circ} \mathrm{C} / \mathrm{s}$. Thermal fatigue test results also suggest that $\mathrm{SiC}_{\mathrm{f}} / \mathrm{SiC}$ composites will exhibit little or no degradation for 100's of cycles.

3.2.4.2 $C_{f} / C$ Composite's Status. A carbon-carbon-composite material comprises a carbon or graphite matrix that has been reinforced with carbon or graphite fibers. Multi-directional reinforced carbon-carbon-composite materials are substantially stronger, stiffer, and tougher than conventionally manufactured graphite's, and are thus preferred over graphite's for certain applications where high tensile strength is needed. Carbon-carbon-composite manufacture involves two major processing stages, namely, preform weaving (i.e., fiber architecture) and billet densification. The preform is woven from carbon fibers derived from a variety of precursors and arranged in multi filament bundles or tows. The woven fiber preform is converted to a densified composite material by repetitive impregnation, using resins or pitch, followed by carbonization and graphitization. Alternatively, densification can be achieved by using carbon vapor infiltration or a combination of pitch or resin impregnation and carbon vapor infiltration. Typically, the desired final density is achieved by several re-impregnations, carbonizations, and graphitization. Final densities of $1.9-2.0 \mathrm{~g} / \mathrm{cm}^{3}$ can be attained. A flow diagram for a typical carboncarbon-composite material manufacturing process is shown in Figure 3-2.

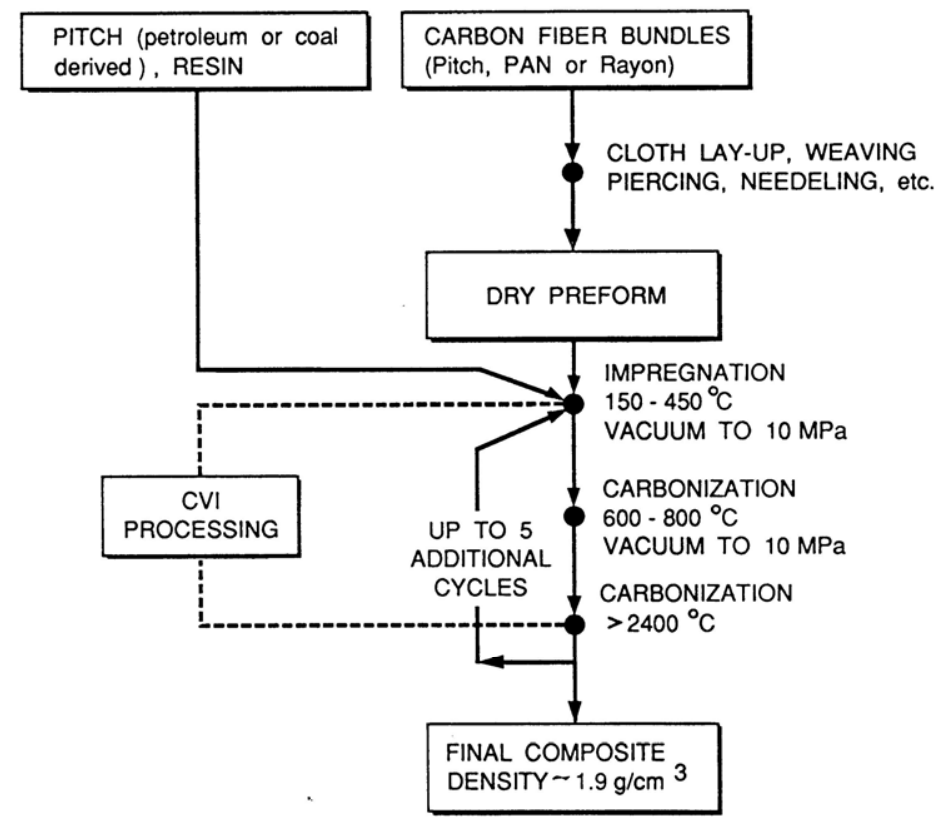

Figure 3-2. Processing steps in the production of carbon-carbon composite materials. 
Figure 3-3 shows a prototype carbon-carbon-composite control rod that was developed for the NPGTMHR and reveals the structure of a three-directionally reinforced carbon-carbon-composite material such as that used for the connecting components of the control rods.
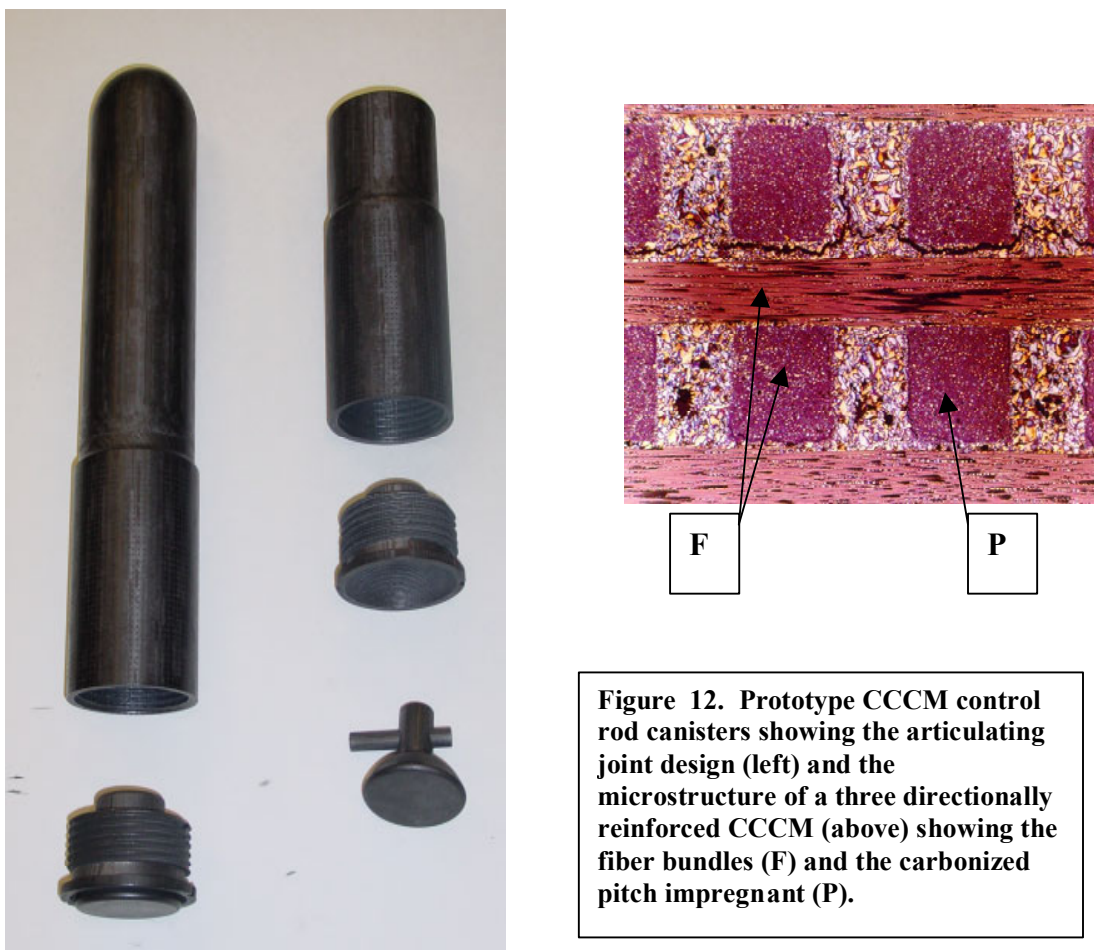

Figure 12. Prototype CCCM control rod canisters showing the articulating joint design (left) and the microstructure of a three directionally reinforced CCCM (above) showing the fiber bundles $(F)$ and the carbonized pitch impregnant (P).

Figure 3-3. Control Rod Composite

Carbon-carbon-composite materials are typically developed for specific applications and are not available off the shelf. The composite architecture (i.e., fiber type, fraction, orientation, lay-up) and processing conditions are selected to tailor the carbon-carbon-composite material for a specific application. Thus, prototype components must be produced from which material test specimens are cut and subjected to the appropriate thermal and irradiation conditions in the materials test program.

\subsubsection{Intermediate Heat Exchanger and Piping}

For the Indirect Power Generation Cycle, the normal operating temperature is $1000^{\circ} \mathrm{C}\left(1832^{\circ} \mathrm{F}\right)$ and the maximum temperature in the event of an accident is thought to be similar to the normal operating temperature. Materials for the IHX will need to come from the list in Table 3-2. Pressure is $7 \mathrm{MPa}$, but the difference from primary to secondary circuit is small $(0.1 \mathrm{MPa})$ and the IHX will be contained within a pressure vessel. The leading IHX design for this cycle is a compact counter-flow configuration that involves channels passing through diffusion-bonded metallic plates. Another option that could be considered is the refractory metal or ceramic open-cell heat foam heat exchanger. Transient thermal loadings could be a problem but the details needed to identify the materials performance requirements will depend on the design that will be selected. Environmentally induced degradation of the metals from impurities in the helium or flow induced erosion is a concern. Aging effects are a concern for very longtime thermal exposure since embrittlement could affect the performance of the IHX during thermal transients. Welding/brazing and fabrication issues exist that will depend on the IHX design details. Again, the leading potential candidates for service at $1000^{\circ} \mathrm{C}$ are Inconel 617 , alloy X, and alloy XR. Other nickel base alloys such as CCA617, Inconel 740, and alloy 230 could be considered. There is a possibility that the compact IHX could be fabricated from a C-C composite. 
The primary-to-secondary piping operates at $950^{\circ} \mathrm{C}$ and will experience an operating pressure as high as 7 $\mathrm{MPa}$. Creep-type conditions will prevail. Further, thermal stresses and expansion loads are always a concern in such piping systems. Again, the materials in all components are subject to environmental and aging-induced degradation.

The leading potential candidate alloys for all components discussed above are identical to those selected for the metallic core components. Inconel 617 is the lead for service above $760^{\circ} \mathrm{C}$. Alloy $800 \mathrm{H}$ is the lead for 600 to $760^{\circ} \mathrm{C}$. A number of choices exist for alloys that are intended for service to $600^{\circ} \mathrm{C}$.

Alternate IHX designs such as tube-and-shell introduce concerns that can only be addressed when more is known about the performance requirements. The operating temperature and environment for the indirect power generation cycle are not likely to change. Rather, the loading conditions will require a database that is extended to a broader range of design criteria than the reference compact IHX configuration. Except for the fact that the tube and shell IHX would be helium to helium, the design and associated materials issues might be similar to the heat exchangers already evaluated in the German and Japanese gas-cooled programs.

The hydrogen plant $\mathrm{HX}$ will operate at 950 to $1000^{\circ} \mathrm{C}$ and will experience an operating pressure as high as $7 \mathrm{MPa}$. Details of the HX are unknown. The operating pressure and corrosion potential of heat transfer fluid to the hydrogen plant are unknown and these will have influence on the choice of materials for the HX. The HX designs will likely result in only about $10 \%$ of the power being diverted to the hydrogen plant and the remaining $90 \%$ to the turbine. It seems likely that thermal stresses and expansion loads will be a concern in the HX if it is a tube and shell design. A compact unit similar to the IHX will also present problems with respect to fabrication and inspection. A design methodology is needed for this relatively complex structure and characterization of materials will be an essential element of this technology. Again, the materials of construction are subject to environmental and aging-induced degradation. In addition to corrosion effects of the impurities in the helium, there may are concerns about corrosion effects or even mass transfer in HX should molten salts be used for heat transfer in the hydrogen plant. These issues cannot be adequately assessed until a more mature design of the IHX evolves.

\subsubsection{Intermediate Heat Exchanger Pressure Vessel}

The IHX pressure vessel is one of the least well-defined components in the NGNP system. To minimize the technical issues surrounding the IHX itself, the inclusion of an external pressure vessel is expected to be necessary. This vessel would operate at a lower temperature than the IHX internals and maintain a positive pressure close to the reactor primary system ensure that the IHX does not experience a large pressure differential that would dramatically reduce its lifetime. Pressure vessel materials choices would be limited to the materials in Table 3-2 above, but even preliminary selection will not be feasible until further pre-conceptual design information is developed to provide requirements for such a vessel.

\subsubsection{Hot Duct Liner and Insulations}

Next Generation Nuclear Plant insulation will include both structural ceramics of low thermal conductivity (typically designed to be stressed in compression, since ceramics exhibit high compressive yield strengths) and low-density ceramics (e.g., foams or fibers) that will provide excellent thermal insulation. There are many design concepts available to achieve insulation. For example, a meter of graphite $\left(\mathrm{K}_{\mathrm{th}}>10 \mathrm{~W} / \mathrm{m}-\mathrm{K}\right)$ thickness plus 0.2 meter of carbon-carbon composite blocks is sufficient to insulate the lower metallic core support structure from the core outlet gas. However, where room is limited to a few inches of insulation thickness to do the same job, a more efficient form of insulation is required. A suitable insulation system, where significant structural support is not required, is to sandwich 
$\mathrm{Al}_{2} \mathrm{O}_{3}-\mathrm{SiO}_{2}$ mixed ceramic fiber mats $\left(\mathrm{K}_{\mathrm{th}}<0.1 \mathrm{~W} / \mathrm{m}-\mathrm{K}\right)$ between metallic cover plates that are attached to the primary structure. Figure 3-4 illustrates the basic principle of this type of insulation as applied to the hot gas duct.

\section{Cool Gas On This Side Of Primary Structure}

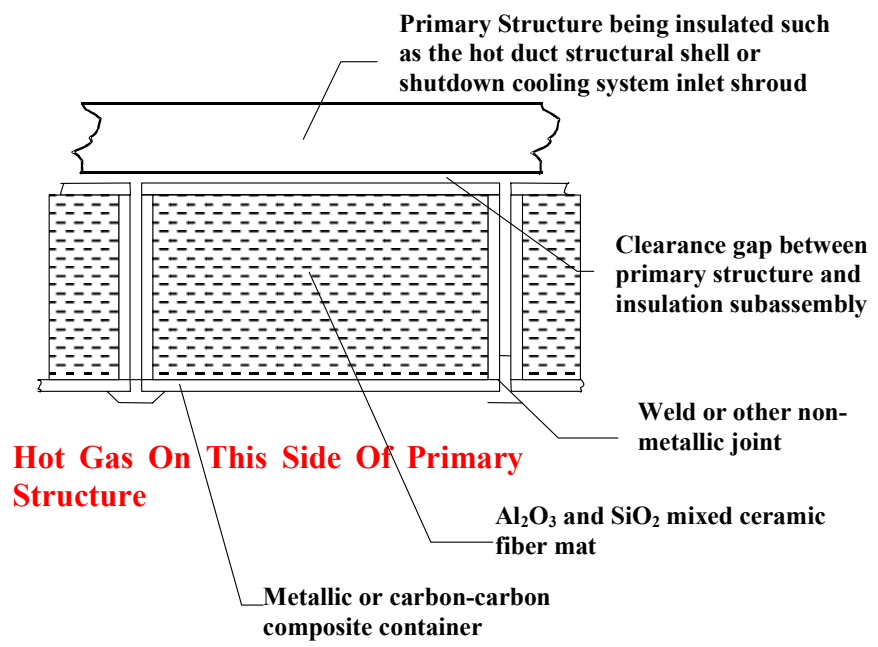

Figure 3-4. Thermal insulation system for the GT-MHR.

Structural ceramics (excluding ceramic matrix composites) probably will be monolithic (fabricated as single large pieces), being of high density and creep resistance [23] (with low levels of chemical impurities, moderate grain sizes and low applied stresses). These large pieces might be engineered as interlocking blocks to provide lateral structural stability. Examples of candidate ceramics compositions for the blocks are high-purity alumina [24] and stoichiometric mullite [25]. In one reactor design (prismatic), an example is the "Floor Blocks", where the blocks support the considerable weight of reactor core materials above them. Typical operating parameters for components suitable for monolithic ceramics are given in Table 3-5.

Table 3-5. Operating conditions for monolithic thermal insulators

\begin{tabular}{lccc}
\hline & $\begin{array}{c}\text { Operating } \\
\text { Temp. }\left({ }^{\circ} \mathbf{C}\right)\end{array}$ & $\begin{array}{c}\text { Maximum } \\
\text { Temp. }\left({ }^{\circ} \mathbf{C}\right)\end{array}$ & $\begin{array}{c}\text { Lifetime Neutron } \\
\text { Dose (dpa/30yr) }\end{array}$ \\
\hline Ceramic Floor Block & 600 & 600 & 0.001 \\
Top Insulator Block & 700 & 1100 & 0.0003 \\
Bottom Insulator Block & 1050 & 600 & 0.0003 \\
\hline
\end{tabular}

Ceramic insulating materials could be in the form of bricks, easily poured powders or "castable cements" containing voids or hollow spheres, sheets (e.g., Grafoil [26]), or fibers (loose fibers, woven fibers, or fiber "blankets"). Fiber blankets would provide ease of installation, durability, and low thermal conductivity. Grafoil ${ }^{\mathrm{TM}}$ is a sheet form of graphite that has low thermal conductivity in the direction perpendicular to the sheet and can be used as high-temperature gaskets. Examples of fibers include Kaowool [27] (representative of a family of mullite compositions in many different purities and physical forms), alumina, zirconia, and carbon (loose fibers or fiber blankets). Significant thermal data is available for alumina-enhanced thermal barrier (AETB) $\mathrm{Al}_{2} \mathrm{O}_{3}-\mathrm{SiO}_{2}$ rigid fiber tiles produced for space shuttle applications. An example of a low-density carbon fiber blanket is one manufactured by Calcarb [28]. 
Because of their low thermal conductivity, high-temperature fibrous insulations are prime candidates to be used throughout the reactor system and the power conversion unit. Typical applications would be within the Hot Duct (tubular-shaped structural line plus insulation), upper plenum shroud, SCS helium inlet plenum, and turbo-compressor. The Hot Duct canisters would be in direct contact with the hottest gas conditions in the reactor. Thus, the materials chosen for these canisters will need to withstand temperatures in the $1000^{\circ} \mathrm{C}$ to $1200^{\circ} \mathrm{C}$ range. This is a very high service temperature for super-alloy metals; therefore, non-metallic materials such as carbon-carbon composites may be required for the canisters. The sandwich design would apply to the Hot Duct canister with the outer shells being constructed of metal or a ceramic matrix composite (see Figure 2-3). The insulation within the canisters is required to retain its physical characteristics during normal operating and conduction-cool-downaccident conditions up to $1200^{\circ} \mathrm{C}$.

An alternative to the sandwich design is one where ceramic fiber "blankets" of various configurations can be attached to cooler outside structures using refractory pins and washers. This design could possibly eliminate containment canisters, but would leave the outside of the fiber blankets directly exposed to the full velocity of the cooling gas. Refractory ceramic coatings (e.g., SiC) would probably have to be used on the exposed surfaces of the fibrous structures in order to minimize erosion or "powdering" that would produce entrained (probably erosive) particles within the cooling gas.

Operating conditions for fibrous insulation include low neutron fluence $(<0.01 \mathrm{dpa})$ and gamma flux, and high temperatures. Mechanical loads on the thermal insulation result from differential thermal expansion, acoustic vibration, seismic vibration, fluid flow friction, and system pressure changes. As an example, a pressure drop difference of between $70-100 \mathrm{kPa}(10.2-14.5 \mathrm{psi})$ is anticipated between the hot and cold side of the Hot Duct. Mechanical loading on the thermal insulation could result from differential thermal expansion, acoustic vibration, seismic vibration, fluid flow friction, and system pressure changes of up to $100 \mathrm{kPa}$ (14.5 psi). The insulation (or insulation/canister package) must withstand these forces over an extended period of time.

The maximum temperature rating is typically $1260^{\circ} \mathrm{C}$ for the highest rated $\mathrm{Al}_{2} \mathrm{O}_{3}-\mathrm{SiO}_{2}$ mixed-ceramic fiber mat insulation. By reducing the fraction of silica in the fibers, or through the addition of $\mathrm{ZrO}_{2}$, insulating mats can achieve continuous and maximum operating temperatures of 1300 and $1400^{\circ} \mathrm{C}$, respectively. High purity alumina fiber mat can be used at operating temperatures above $1500^{\circ} \mathrm{C}$. The carbon fiber insulation materials can operate at temperatures considerably higher than $1500^{\circ} \mathrm{C}$ in inert atmospheres and should have minimal chemical compatibility problems in the NGNP internal environment of helium and graphite (if fibers were encapsulated in $\mathrm{C}_{\mathrm{f}} / \mathrm{C}$ canister or shell). Therefore, carbon fiber insulation should be considered as a serious candidate.

\subsubsection{Power Conversion Turbine and Generator}

The NGNP power conversion unit involves the turbine, turbine inlet shroud, the generator and recuperators. The recuperators are covered in a separate section. Although considerable materials work is involved in both the turbine and the generator components, it is expected that existing component manufacturers are the best source of the needed materials information. As such, both the turbine and generator materials efforts will primarily be performed via subcontracts to existing manufacturers. The high-temperature bellows and turbine inlet shroud will be the primary focus of the NGNP materials efforts. These components operate continuously at close to $1000^{\circ} \mathrm{C}$. Off-normal (accident) temperatures for these components are about the same as their maximum operating temperatures. The potential materials to be selected for these components will need to come from the listing of high-temperature materials listed in Table 3-2. 
The turbine inlet shroud accepts the coolant exiting the hot duct and directs it to the turbine inlet. It is insulated to minimize thermal gradients and heat loss across the shroud wall. There is, however, a stiffening element or collar between the shroud and the turbine that is not insulated and experiences the maximum system operating temperature, $1000^{\circ} \mathrm{C}$. This non-insulated collar can be exchanged at each period of planned turbine maintenance (nominally every 7 years). The boundary/container material for the shroud insulation must also withstand the $1000^{\circ} \mathrm{C}$ helium temperature. Prime potential candidates for the non-insulated turbine inlet shroud collar are Inconel 617 and the cast Ni-base alloys.

\subsubsection{Power Conversion Recuperators}

The recuperator is a modular counter-flow helium-to-helium heat exchanger; its most likely design has corrugated-plate heat exchange surfaces. Helium inlet temperature will be $\sim 600^{\circ} \mathrm{C}$ and desired design life is 60 years. Prime candidate materials for this application are the 300 Series stainless steels listed in Table 3-2.

The power conversion recuperator operating temperatures are relatively low, with a $600^{\circ} \mathrm{C}$ inlet gas temperature from the turbine exhaust and a less than $200^{\circ} \mathrm{C}$ outlet temperature. Recuperator technology for the temperatures and pressures of operation is relatively mature. For gas turbine applications, tubeon-plate and primary surface units are often fabricated from fine-grained 300 series stainless steels. Type 347 stainless steel is typical. Recuperators in which the corrugated plate surfaces are sealed by brazing have suffered from thermal fatigue when pushed to higher temperatures, but the NGNP operating conditions will not subject the recuperator to the severe cycling. A pressure differential across the membrane wall is expected, so some consideration of creep will be needed to prevent closure of the lowpressure gas passages in the corrugations. Since relatively thin sections will be present, there is concern that environmental effects could be significant. Also, long-time exposure of 300 series stainless steels at these high temperatures often leads to sigma phase embrittlement and carburization.

\subsubsection{Valves, Bearings, and Seals}

A few valves may be required in the primary or secondary piping systems for this plant, and a flapper valve is used in the SCS. Bearing surfaces exist between the RPV and the core barrel. Seals may be required in a variety of locations. However, insufficient information relating to the specific requirements and issues relating to valves, bearings, and seals is available at this time to initiate a selection activity. It is expected that a materials program covering these areas will be added in later revisions to the plan.

\subsection{Materials Qualification Testing Program}

\subsubsection{Qualification Testing Facility for Helium Environmental Effects}

The environment expected for the Next Generation Nuclear Plant reactor will be very challenging for the structural materials. The sustained operating temperature may reach $1000^{\circ} \mathrm{C}$ in a helium atmosphere with a pressure of $7.5 \mathrm{MPa}$ and flow velocities on the order of $40 \mathrm{~m} / \mathrm{s}$. A pure helium atmosphere would not cause environmental degradation of high-temperature materials but the helium could be contaminated with gaseous impurities such as $\mathrm{CO}, \mathrm{CO}_{2}, \mathrm{CH}_{4}, \mathrm{H}_{2}, \mathrm{H}_{2} \mathrm{O}$, and $\mathrm{O}_{2}$ ). A reducing atmosphere, for instance, may be quite aggressive for conventional high-temperature alloys since they are typically designed to form a thin protective $\mathrm{Cr}$ or $\mathrm{Al}$ oxide to protect them from attack. High-velocity flowing gases may also contain particulates from abrasion of the graphite or other materials in the system. A particulate laden high velocity gas also raises the potential issue of particle erosion in some components.

In order to select materials for the NGNP reactor and predict their performance for a time period up to 60 years it is necessary to identify the degradation mechanism(s) for different gas compositions and 
determine the kinetics of deterioration. An environmental testing program will determine the corrosion and oxidation performance of candidate alloys and the effect of environmental degradation on mechanical properties. While it might be feasible to predict reactions resulting in alteration of surface chemistry for the gas compositions of interest, the influence of high gas velocity and particle erosion are nearly impossible to predict without appropriate high velocity testing.

To meet the need for high velocity and long-term testing of materials in potentially contaminated helium environments, the materials program will investigate the possible existence of high-temperature, high velocity helium loops in the United States. If none are available, a new test loop will be designed and constructed for performing the required testing.

It is envisioned that the test capability would be helium with controlled impurity levels at temperatures up to $1100^{\circ} \mathrm{C}, 7.5 \mathrm{MPa}$ pressure and a flow rate up to $50 \mathrm{~m} / \mathrm{s}$. Despite the additional complexity and cost, it is apparent that a closed loop with gas clean-up capability and compressor will be the only feasible design.

The system would be set up in two stages. The first stage would evaluate helium with chemical modifications only. The second stage of testing would modify the test loop so that particle erosion on test coupons would be added to the flow of controlled chemistry hot helium. Capability for generation of particulate and characterization of the density and velocity of particles would be added. An important system capability for the erosion test loop will be the capability to control the angle of impingement of the particles on the surface.

\subsubsection{Considerations in Materials Behavior for Reactor Component Qualification}

The three primary factors that will most affect the properties of the structural materials from which the NGNP components will be fabricated are effects of irradiation, high-temperature exposure, and interactions with the gaseous environment to which they are exposed. An extensive testing and evaluation program will be required to assess the effects of these factors on the properties of the potential materials to qualify them for the service conditions required. Other factors, such as interactions with other components, stress loading, relative motion, friction vibrations, thermal cycling, etc., are equally important and rely on direct interaction with the design organization. These issues will be addressed once the design organization is identified and working relationships between it and the materials program have been established. Mockups will be considered based on materials issues and needs as the program continues with the activities noted in the program plan.

3.3.2.1 Irradiation. When a material is irradiated, virtually every property will change. This includes physical dimensions, as well as mechanical, electrical, magnetic, thermo-physical and other properties. The reason for this is that the existing crystal and defect structure is deconstructed and reconstructed on an atom-by-atom basis during irradiation. In a high-dose irradiation, each atom may be displaced from its lattice site numerous times. The standard measure of radiation dose in metallic materials is the displacement per atom (dpa). Conditions during irradiation, such as temperatures, dose, dose rate, and local materials composition, determine the property changes that will ultimately result. Three of the irradiation-induced changes of greatest concern are swelling, irradiation creep, and embrittlement.

Swelling is the isotropic volume expansion of an irradiated material. It occurs by the net absorption of interstitials at dislocations, with a corresponding net number of vacancies accumulating at cavities. It may reach tens of percent or more at high doses (e.g., tens to hundreds of dpa). In graphite, which has a very anisotropic crystal structure, swelling can itself be anisotropic and is highly dependent upon texture of the graphitic microstructure and the macroscopic direction of a component with respect to the crystal texture. 
Irradiation creep is a shape change in compliance with an applied stress, in excess of ordinary thermal creep. It occurs even at quite low temperatures, where thermal creep is entirely negligible. Dislocationclimb creep occurs by the asymmetrical partitioning of self-interstitials and vacancies to dislocations differently oriented to the stress axis. Climb-enabled glide creep occurs when a dislocation climbs and overcomes an obstacle, permitting it to glide. Creep may therefore result directly from net climb of particularly oriented dislocations, or indirectly from any climb that triggers glide in response to the applied stress.

Embrittlement occurs, broadly speaking, by two processes. In the first type of process, hardening of the material progresses by creation of many types of obstacles by radiation. This hardening reduces ductility. Most irradiation-induced hardening centers are so small they are beyond the ability to detect with transmission electron microscopy. However, atom probe field-ion microscopy has contributed significantly to the knowledge of the structure and properties of these ultra-fine hardening features. The second type of process is grain boundary weakening, caused by preferential diffusion of transmutation products, such as helium, or tramp elements, such as phosphorus, to the grain boundary.

Swelling, irradiation creep, and embrittlement have received a great deal of experimental and theoretical attention. As a result, a certain measure of understanding of these phenomena has been achieved, but investigation of these processes in the particular alloys, graphite's, and structural composites being considered for NGNP applications will still be required under the particular conditions of interest. The activities needed to assess these changes are incorporated into appropriate sections of the qualification test plans.

3.3.2.2 High-Temperature Exposure. At high temperatures, thermally activated processes such as microstructural changes, plastic flow, and some types of fractures produce a number of time-related degradation mechanisms that must be recognized in the design and operation of high-temperature components.

In regard to microstructural changes, there are several concerns to the NGNP. First, the RPV will most likely be fabricated from a ferritic/martensitic that derives its strength from a fine precipitate of carbides formed on highly dislocated martensite lath boundaries. With time, these precipitates will coarsen and the lath structure will reform into a fine-grain structure with much lower tensile and creep strength than the starting steel. The rate at which this aging process occurs is highly dependent on the elemental constituents that makes up the carbide microstructure. A second time-related degradation mechanism that occurs on the structural steels is that of intermetallic phase precipitation. In this process, coarse intermetallic phases precipitate that rob the matrix of solid-solution strengtheners and impart brittleness to the grain boundaries. In stainless steels and nickel-base alloys that will likely be used for the core internal components, piping, and other high-temperature components, some strengthening is often derived from stable carbides and fine dispersions of intermetallics that develop in-service. With time, these beneficial precipitates may coarsen or dissolve in preference to less desirable precipitate phases. Again, loss of strength and embrittlement are concerns. Work is needed in the NGNP materials program to define the kinetics of the precipitation processes and can predict the development of metastable, and eventually, the stable microstructures.

High-temperature yield strength and resistance to plastic flow are properties that are important in structural components. Good resistance to thermal transients, mechanical fatigue, ratcheting, and buckling depends on materials with good short-time strength properties. At the extreme temperatures expected in the NGNP components, the yield and flow properties of the structural materials are expected to be very rate sensitive and will be more sensitive to loading rates in the components. To address these issues, the materials testing program needs to produce information that can lead to improved analysis methods that accommodate greater rate dependency of short-time deformation and fracture. For very 
long service times there are additional concerns. The database on which allowable stresses are based is quite limited for several of the candidate materials, particularly at the upper temperature range that service in the NGNP will require. New deformation and fracture mechanisms may prevail at the long time and low stresses thought to represent steady-state operation of the NGNP. It is critical that predictive continuum damage mechanics models be developed on a sound metallurgical basis. The activities needed to assess both the microstructural stability and effects of temperature on both short- and long-term mechanical properties are incorporated into the following sections of experimental plans.

3.3.2.3 Helium Gas-Cooled Reactor Environment. From a corrosion viewpoint, the internals of reactor will operate in a helium environment, and the externals of the reactor, including the pressure vessel, will operate in air.

The interactions between structural materials in the helium atmospheres associated with gas-cooled reactors have been the subject of numerous investigations (see Kimball [29]). The results of these studies conducted by various organizations in the United States, Germany, England, Norway, Japan, and other places have demonstrated the importance of small changes in impurity levels, high temperatures and high gas flow rates. Metallic materials can be carburized or decarburized, and oxidized internally or at the surface. These corrosion reactions, depending on their rate, can substantially affect long-term mechanical properties such as fracture toughness, fatigue, crack-growth rate, etc.

Typical simulated advanced High-Temperature Gas Reactor (HTGR) helium chemistries used in various previous test programs are shown in Table 3-6. Because of the low partial pressures of the impurities, the oxidation/carburization potentials at the metallic surface of a gas mixture are established by the kinetics of the individual impurity catalyzed reactions at the surface. As shown, the main impurities are $\mathrm{H}_{2}, \mathrm{H}_{2} \mathrm{O}$, $\mathrm{CO}$ and $\mathrm{CH}_{4}$. The hot graphite core is considered as reacting with all free $\mathrm{O}_{2}$ and much of the $\mathrm{CO}_{2}$ to form $\mathrm{CO}$, and with $\mathrm{H}_{2} \mathrm{O}$ to form $\mathrm{CO}$ and $\mathrm{H}_{2}$. In addition, in cooler regions of the core, $\mathrm{H}_{2}$ reacts with the graphite via radiolysis to produce $\mathrm{CH}_{4}$. Because of the change in surface temperatures around the reactor, and associated changes in reaction mechanisms and rates of reaction on bare metal versus on scaled surfaces, reaction rates and order of reactions are important.

Table 3-6. Composition helium environments (advanced HTGR) used in past tests ${ }^{\mathrm{b}}$

\begin{tabular}{llllllll}
\hline \multicolumn{1}{c}{ Program } & $\begin{array}{c}\mathbf{H}_{2} \\
(\boldsymbol{\mu a t m})\end{array}$ & $\begin{array}{c}\mathbf{H}_{2} \mathbf{O} \\
(\boldsymbol{\mu} \mathbf{a t m})\end{array}$ & $\begin{array}{c}\mathbf{C O} \\
(\boldsymbol{\mu} \mathbf{a t m})\end{array}$ & $\begin{array}{c}\mathbf{C O}_{2} \\
(\boldsymbol{\mu a t m})\end{array}$ & $\begin{array}{c}\mathbf{C H}_{4} \\
(\boldsymbol{\mu a t m})\end{array}$ & $\begin{array}{c}\mathbf{N}_{2} \\
(\boldsymbol{\mu a t m})\end{array}$ & $\begin{array}{c}\mathbf{H e}(\mathbf{a t m} \\
\text { absolute) }\end{array}$ \\
\hline NPH/HHT & 500 & 1.5 & 40 & & 50 & $5-10$ & 2 \\
PNP & 500 & 1.5 & 15 & & 20 & $<5$ & 2 \\
AGCNR & 400 & 2 & 40 & 0.2 & 20 & $<20$ & 2 \\
\hline
\end{tabular}

NPH: Nuclear process heat

HHT: High-temperature helium turbine systems

PNP: Prototype Nuclear Process Heat

AGCRNR: Advanced Gas Cooled Nuclear Reactor

The overall stability of the proposed helium environment that will be representative of the NGNP must be evaluated in order to ensure that testing proposed in the various experimental sections that follow is performed in environments that have consistent chemical potentials. In addition, the corrosion of metals and nonmetals must be evaluated to establish baseline data where it does not exist. Therefore, testing of both the helium environment to be used for mechanical properties and general corrosion evaluations of

b Information based largely on data from Table 3-2 of Natesan, K., A. Purohit, and S. W. Tam (July 2003). Materials Behavior in HTGR Environments. NURET/CR-6824 and ANL-02/37. Argonne, IL: Argonne National Laboratory. 
the candidate materials to establish their overall compatibility with that environment will be performed at temperatures up to at least $50^{\circ} \mathrm{C}$ above the proposed operating temperature for the various metallic components.

The bulk of the experimental plans needed to assess the effects of the helium environment on mechanical properties of the metallic internal materials, as well as those needed to evaluate the long-term emissivity on the outside of the RPV in air are included in the portions of Section 3.3.2 that deal with individual components. However, in addition to those studies, it will be necessary to assess the stability of the helium environment itself as well as the general effects of corrosion on the various structural materials being considered for use within the primary circuit. The schedule for these studies that are generally applicable to all metallic components is shown in Appendix D.

\subsubsection{Component Qualification Test Program}

\subsubsection{Reactor Pressure Vessel Qualification.}

\subsection{Baseline Materials Test Program (e.g., mechanical, fracture, thermo-} physical, corrosion, and microstructural characterization) - The materials qualification program will begin with procurement of plate and forging test material of the required thickness to model the RPV wall for properties' testing. Microstructural characterization of sample sections will be performed to assess any non-metallic secondary phase segregation, non-uniform microstructure or porosity from the ingot stage. The test samples will be prepared to measure the properties in the longitudinal, transverse and through thickness directions. The thickness of the various portions of the RPV is directly related to the maximum allowable stress at a particular temperature. For a given operating pressure, as the allowable stress decreases the thickness necessary to resist deformation increases. However, it is recognized that the various parameters will evolve with maturity of the design and associated analyses and close contact between the designers and materials researchers will be a continuing aspect as the program progresses. Research will be directed toward a better understanding of the high-temperature strength, stability, and long-time performance of the materials. Because the design service life is $60 \mathrm{y}$ for this reactor, long-time performance is an issue of particular importance since that amount of time exceeds the experience database for most of the potential candidate materials. For current LWRs, the temperature allows the RPV to operate well below the creep regime. However, because of the high temperatures of the NGNP, the RPV and CV materials will operate well within the creep regime. Thus, damage assessment and life prediction are of high importance in this case, as it is for the in-core metallic internals and the materials data produced in this area will need to be closely coordinated with the hightemperature design methodology needs and schedules.

For structural components operating in the creep regime, evaluation of welding processes, welded joints, and component inspections must be emphasized. Of course, inclusion in the ASME Code for the materials of construction is required and the research, testing, and qualification needs will be directed towards development of the data and information necessary to meet those requirements as delineated in Section 2.5.2. For an alloy such as $9 \mathrm{Cr}-1 \mathrm{MoV}$ (grade 91) that has already attained Code approval for operation to $593^{\circ} \mathrm{C}$, additional testing will be required but not nearly as much as that required for an alloy that is not currently approved for Code use. However, in that regard, given the currently estimated abnormal condition temperature of $770^{\circ} \mathrm{C}$, data would be required up to $820^{\circ} \mathrm{C}$ for ASME Code approval. Such data are not available for most of the materials discussed earlier. 
Besides the requirements discussed in Section 2.5.2, other application specific information and data are required. For example:

1. The contamination levels of the helium coolant are needed to determine and bound the effects of the coolant environment on the material properties and the materials must be tested under those conditions. Small amounts of impurities can contaminate the coolant from a variety of sources throughout the reactor system and quite small amounts of these contaminants can degrade the materials both by corrosion processes and by effects on mechanical properties. Carburization and decarburization are issues of particular interest. In the case of this system, the effects of $\mathrm{O}_{2}$ may not be such a problem because the large amount of graphite in the core is such that $\mathrm{CO}$ will be a more likely culprit. Because the degradation levels of the coolant on the potential candidate alloys are unknown, the concept of application of a cladding on the inner surfaces of the RPV and CV will be considered. Because the cladding is not a structural member, the primary issue is corrosion; the first material to be considered and evaluated would be type 308 stainless steel because it is a common clad used for current LWR RPVs.

2. Although not expected to be a limiting issue, irradiation effects data on the RPV and $\mathrm{CV}$ material are needed for regulatory requirements and for assessment of structural integrity. For the $9 \mathrm{Cr}-1 \mathrm{MoV}$ (grade 91) alloy, there are some data available on irradiation effects, but data at the specific temperatures for the NGNP are sparse at best. There are some data for some of the other potential candidate alloys listed in Section 3.1.3.1.1 but, again, insufficient data for the NGNP conditions. Similarly, long-time thermal aging data are needed as a complement to the irradiation effects data for potential embrittlement due to either hardening or softening of the material.

3. Emissivity data on the various potential candidate materials are needed. This is necessary because cooling of the RPV is partially conducted by radiation from the outer surface to the air in the cavity between the RPV and surrounding concrete. Depending on the emissivity of the selected material, it may be necessary to incorporate a high emissivity coating on the outer surface of the RPV. Early testing to establish limitations of potential candidate materials emissivity and the performance and durability of proposed surface modifications to improve emissivity must be performed early to provide design feedback and limitations.

4. The ASME Code requires determination of the reference nil-ductility temperature $\left(\mathrm{RT}_{\mathrm{NDT}}\right)$ for Section III, Class 1 components, such as the RPV and CV. Fracture toughness data will be required, primarily for regulatory needs, but also for providing complete information to allow for a comprehensive assessment of structural integrity for the pressure boundary components.

5. As mentioned previously, damage accumulation data are needed due to long-time hightemperature exposure. Particular attention is needed in the area of welding to ensure that the issues of hot cracking and premature creep failures in the heat-affected-zones of ferritic-martensitic steels, observed in the fossil industry, are adequately addressed.

6. Besides the physical properties discussed in Section 2.5.2, the designers for the RPV and CV materials need damping coefficient data to determine whether or not there will be a vibration problem with the core. 
The first step in the research program on materials for the RPV system will be a comprehensive and detailed review of the potential candidate alloys discussed. The existing database for those alloys will be assembled, analyzed, and evaluated with respect to the design and operating requirements presented above, including effects of thermal aging and irradiation. Fabrication and transportation for the RPV ring forgings are critical issues to be included within that first step. This review will enlist the assistance of a consultant with expertise in large vessel fabrication, particularly with medium level chromium ferritic steels. In addition, three different screening projects will conduct testing of a number of potential candidate RPV/CV materials. The first of these tests involves so-called "limiting high-temperature tests for ferritic RPV steels" to evaluate the load-carrying capability of those potential candidate materials at the currently envisioned limiting temperature $\left(\right.$ e.g., $\left.770^{\circ} \mathrm{C}\right)$. This project would test only those alloys for which such information does not exist as identified by the literature review. Such testing would consist of a creep-rupture test for a short time (e.g., 100h). The second screening project is a so-called combined cycle (creep and stress rupture, creep-fatigue, in helium) test program as a means of performing initial screening experiments to identify those materials that cannot meet even the most basic requirements of high-temperature environmental performance. Again, the tested alloys will be determined following the detailed literature review. All of the high-temperature testing for the RPV/CV materials will be conducted in close cooperation with the in-reactor metallic components task and the HTDM task, including procurement of sufficient material for the conduct of such tests. The third screening project is an assessment of emissivity of the potential candidate materials. The results from this project will be critical to a decision regarding the need to pursue a surface preparation or surface coating project to attain the required emissivity value for the RPV. In anticipation of the irradiation requirements, preliminary evaluations will begin to identify potential irradiation facilities, capsule design requirements, etc. If sufficient materials are available, some amount of each available material will be prepared for thermal aging exposures.

The primary experimental program will involve the procurement of additional materials in sufficient quantities to allow for the complete Phase 1 testing program, the objective of which is to test and evaluate the preliminary candidate materials with regard to all the mechanical properties under evaluation. This includes tensile, creep and stress rupture, fatigue, creepfatigue, Charpy impact and drop-weight, fracture toughness, and fatigue crack growth, to include appropriate testing in impure helium and in air. Moreover, various physical properties (see Section 2.5.2) of the alloys will be determined. Again, the high-temperature testing will be closely coordinated with the in-reactor metallic components and HTDM tasks. Once the baseline-testing program is completed, including testing of weldments applicable to the preliminary candidate materials, the results will be evaluated with respect to all the other factors, such as the aged material test program, the irradiated materials test program, etc. From this experimental program will come the selection of at least two prime candidate materials for more comprehensive testing, especially as regards irradiation and environmental effects.

3.3.3.1.2 Aged Material Test Program - Initially, limited amounts of the potential candidate alloys will be prepared for thermal aging in air. Materials will be aged for 1000 , 3000 , and 10,000 hours at $650^{\circ} \mathrm{C}$. These experiments will serve to provide a relatively early indication of each material's response to long-time high-temperature exposure in air, a condition applicable to the uncoated outer surface of the RPV. Following aging at 10,000 h, a portion of each material will be further aged at about $770^{\circ} \mathrm{C}$ for $50-100 \mathrm{~h}$. The aged materials will then be tested for tensile, creep, and toughness behavior, and characterized microstructurally. Moreover, if deemed appropriate at the time, portions of the materials will be tested for emissivity as well. Candidate materials and weldments will also be aged in the impure helium environment for the same times, mechanically tested, and microscopically 
examined as discussed above. In addition, portions of the candidate materials and weldments will remain under thermal aging in both air and in helium until at least 25,000 h and tested to provide longer time data to allow for comparisons with predictive models. Finally, thermal aging of the prime candidate alloys at the RPV operating temperature will continue for more years to accumulate data for very long-times.

3.3.3.1.3 Irradiated Materials Test Program - Initially, a detailed literature review of irradiation effects on all the potential candidate alloys will be conducted. The design of the irradiation experiments will be started. Also, preliminary evaluations will be initiated regarding design of an irradiation facility for irradiation of candidate alloys under relatively low flux test reactor conditions, as well as identification and evaluation of potential test reactors.

The design of the irradiation experiments will be completed for materials identified in the preliminary component material selection documents. An irradiation facility to accommodate a relatively large complement of mechanical test specimens will be designed and fabricated for placement in a test reactor. The facility will, of course, include temperature control to allow for irradiation at the temperatures of interest and operate at a flux low enough to provide results that are applicable to the dose rates anticipated in service in the NGNP. Although the operating temperature of the RPV/CV may change with evolution of the design, it is currently planned to irradiate mechanical test specimens at 550 and $650^{\circ} \mathrm{C}$. The choice of these temperatures is based on the assumptions that (1) $650^{\circ} \mathrm{C}$ is the highest possible operating temperature that can be envisaged for the RPV/CV at this time, (2) $550^{\circ} \mathrm{C}$ is the lowest operating temperature that would allow for reasonable achievement of the objectives for the NGNP, and (3) those two temperatures would likely provide sufficient information for design and operation of the RPV at any intermediate temperature with respect to irradiation effects. A limited number of small test specimens (miniature tensile and Charpy impact specimens) of the potential candidate materials will be prepared for irradiation at high fluxes as an early screening experiment to identify alloys that may be particularly and unexpectedly sensitive to irradiation effects.

The small test specimens will be irradiated and tested. Additional irradiations of the preliminary candidate materials, both base metals and weldments, will begin later, with the choice of materials to be based on results of the literature review, as well as the baseline and aging tests completed at the time. For purposes of this plan, specimens to be irradiated will include those for tensile, hardness, creep and stress rupture, Charpy impact, fracture toughness, and fatigue crack growth testing. Based on the currently estimated maximum exposure of about $3 \times 1019 \mathrm{n} / \mathrm{cm} 2(>0.1 \mathrm{MeV})$ and $0.0075 \mathrm{dpa}$, the specimens will be irradiated to an exposure about $50 \%$ greater to accommodate uncertainties in the exposure estimates. A limited number of irradiated specimens will be aged in the impure helium environment for up to 10,000 $\mathrm{h}$, tested, and examined by light optical and electron microscopy.

A decision to conduct test reactor irradiations beyond that time will be based on the results, but may include additional and more comprehensive irradiations of the final selected RPV/CV materials. However, as currently required by 10 CFR 50, Appendix $\mathrm{H}$, and for reasons of prudence, the NGNP should incorporate a surveillance program. The specific design of the surveillance program, to include the specimen complement, will be based on the results obtained from the test program discussed above, but will likely include, as a minimum, tensile, Charpy impact, fracture toughness, and creep specimens. Because the NGNP is a demonstration reactor, it is recommended that the surveillance program be more extensive than might be required by the regulatory authority, such that it could serve as a test bed for irradiation experiments of more advanced materials that may be developed as the NGNP operations progresses. 
3.3.3.1.4 Joining Technology and Welding Metallurgical Effects - As with all the tasks, the literature review will include a comprehensive review of joining issues for the potential candidate alloys. As with the in-core metallic components task, it is expected that the effort on joining technology will be a major part of the RPV/CV research program. The initial purchase of welding consumables and will be based on the results of the literature review and preliminary materials selection documents. This test program will include enough materials to ensure the capability to fabricate weldments of sufficient size to enable machining of the numbers of mechanical test specimens needed for inclusion in the baseline, aging, and irradiation tasks. Additionally, development of welding techniques and processes, to include PWHT schedules, will be included in the program for those preliminary candidate materials for which a mature welding technology does not exist.

In addition to the evaluation of weld metals and HAZ for the preliminary candidate materials, this task includes an evaluation of structural weldments fabricated with the prime candidate materials and representative of the thicknesses of the RPV and CV welds. Testing of these weldments would include evaluation of the base metal, weld metal, and HAZ in the final heattreated condition and through the thickness to ensure the achievement of minimum throughthickness mechanical properties. This task is related to and will be coordinated with activities in the Fabrication Infrastructure Development task (see section 3.2.2.6), especially regarding the assessment for field fabrication. Specimens for an extended irradiation program and for the surveillance program could come from these structural weldments if the test results are deemed to be representative of the final RPV/CV construction.

3.3.3.2 Surface Engineering/Coatings Test Program. Preliminary emissivity screening testing of the potential candidate materials will be performed to determine the detailed experimental program needed for developing a stable surface with minimum emissivity required for adequate cooling of the RPV. Concurrent with that testing, a surface treatment/coatings program will be conducted to investigate the efficacy of various potential concepts for either increasing the emissivity of the RPV materials or providing a coating that would have the required emissivity. If the tests of the potential candidate materials indicate a high probability that the materials will have sufficiently high emissivity under operating conditions, a special coatings development program will not be required. As mentioned earlier, emissivity is a critical issue for the RPV. The external air environment is significant in that the pressure vessel must be able to radiate sufficient heat during any anticipated accident conditions throughout the life (60 years) of the reactor. It is, therefore, necessary to have a stable, high emissivity surface on the external surface of the pressure vessel at elevated temperatures. While the emissivities of steel can be increased by the formation of an oxide film [30], as shown in Figure 3.1 for type 304 stainless steel, the conditions under which this film can be created and the stability of this film in air (including the effect of humidity) at operating temperature needs to be established for each specific steel. An industrial partner will be used to provide for scaling of the materials and methods that have proven to be viable. The use of industrial partners through subcontracts is currently planned for the last two years of this research plan. The estimated costs for the emissivity evaluations are included in the cost table as a separate item. 


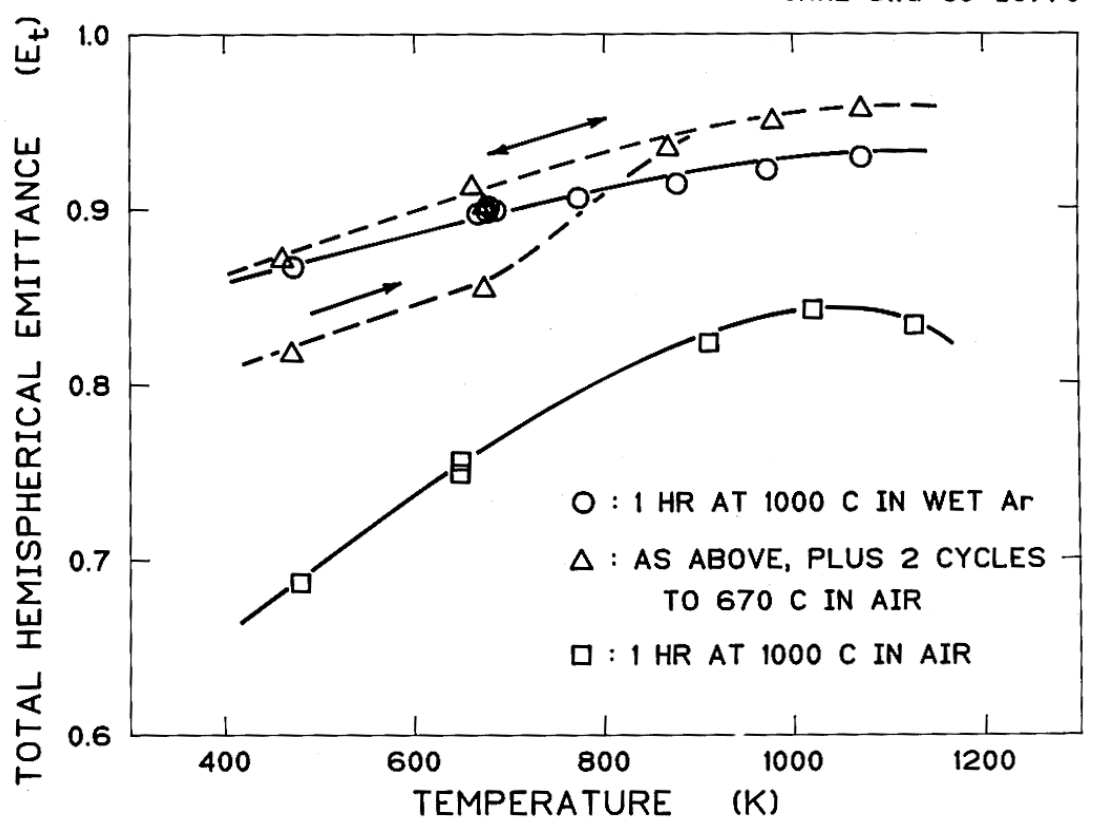

Figure 3-5. Effects of environment (argon and air) and temperature on the emissivity of type 304 SS.

3.3.3.3 Graphite, Reflectors, and Supports Qualification Test. Candidate graphite materials are known (See Section 3.2.2). However, certain tests must be conducted to verify the candidate's relevant material properties meet the claims of the manufacturer. The Preliminary Selection process will need limited irradiation response data for the different grades of graphite. These test results will be used to establish the general behavior of a particular grade of graphite and confirm that it behaves similarly to previously "qualified" (for other nuclear reactors), near-isotropic, nuclear grades of graphite.

Graphite is comprised of a composite structure manufactured from a filler coke and pitch binder. Nuclear graphites are usually manufactured from isotropic cokes (petroleum or coal-tar derived) and are formed in a manner to make them near-isotropic or isotropic materials. Figure 3-6 shows the major processing step in the manufacturing of nuclear graphite. After baking, (carbonization) the artifact is typically impregnated with a petroleum pitch and re-baked to densify the part. Impregnation and re-bake may occur several times to attain the required density. Graphitization typically occurs at temperatures $>2500^{\circ} \mathrm{C}$. Additional halogen purification may be required. Typical manufacturing times are 6-9 months. 




Figure 3-6. The process step in the manufacturing of nuclear graphite

The forming and densification processes impart property variations within the billet. The properties will be somewhat different in the forming direction compared to the perpendicular to forming direction. Moreover, a density gradient will exist from billet edge to center. These variations must be quantified for the selected grades of graphite. In addition, variations in property will arise from billet to billet within a batch, and between production lots.

Finished graphite is machined to the complex geometries required for the reactor components (fuel elements, reflector blocks, core support post, etc.). Figure 3-7 shows a graphite fuel element from the Fort St. Vrain reactor. 


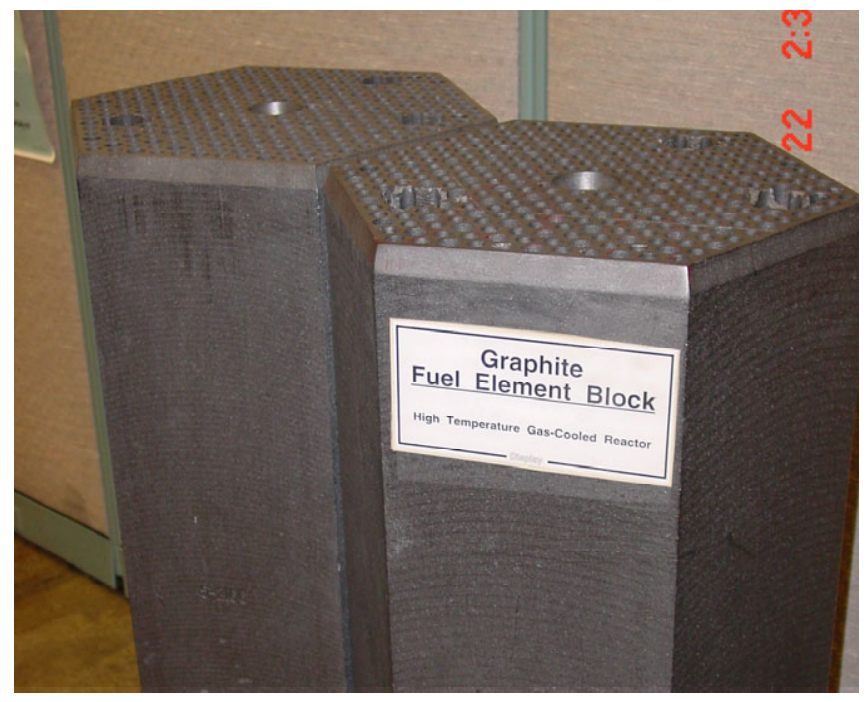

Figure 3-7. A graphite fuel element from the Fort St. Vrain reactor.

Impinging fast neutrons displace carbon atoms from the graphite crystal lattice into interstitial positions, creating an interstitial-vacancy pair. The displaced carbon atom may recoil through the lattice displacing further carbon atoms in a cascade. Depending upon the irradiation temperature the interstitial and vacancy may be free to migrate about the lattice. Interstitials are free to migrate at room temperature whereas vacancies are essentially immobile below $300^{\circ} \mathrm{C}$. Migrating interstitials may recombine with vacancies, or may form clusters, essentially new grapheme layers in the graphite structure. This causes an expansion of the graphite crystal in the $<\mathrm{c}>$-direction. Vacancies may also combine and coalesce into a collapsed vacancy loop, causing a crystallographic contraction in the $<\mathrm{a}>$-direction (see Figure 3-8).
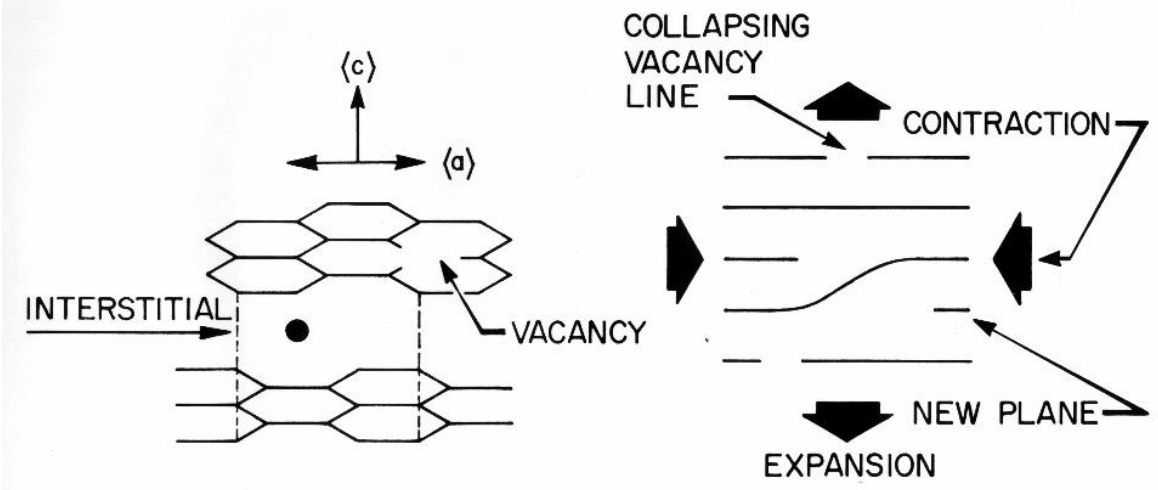

Figure 3-8. The radiation damage mechanism of graphite

During the manufacture of graphite a network of fine cracks, develop parallel to the graphite basal planes due to differential thermal strains on cooling from graphitization temperatures. It should be noted that inplane graphite bonds are strong, covalent bonds, whereas the bonds between the graphite planes are secondary (Van der Waals) bonds. Cracks and pores within the structure (between the basal planes) tend to accommodate the $<\mathrm{c}>$-axis expansion caused by irradiation damage and thus the bulk behavior of graphite under irradiation is initially dominated by the $<\mathrm{a}>$-axis contraction. Thus, the graphite initially undergoes volumetric shrinkage. With continued irradiation large crystal strains, resulting from the $<\mathrm{a}>$ axis contraction causes the formation of internal voids, pores, and cracks. The rate of formation of these defects ultimately becomes such that void formation dominated over pore filling and the graphite 
behavior reverses from shrinkage to growth. This behavior is shown schematically in Figure 3-9. The dose at which turnaround occurs is temperature dependant. At low temperature $\left(\mathrm{T}<300^{\circ} \mathrm{C}\right)$ the irradiation defects are less mobile and cannot diffuse freely in the lattice and recombine. Turnaround thus occurs at relatively low doses. At intermediate temperatures, $\left(500-700^{\circ} \mathrm{C}\right)$ there is increased mobility and the turnaround is shifted to higher doses. However at higher temperatures the thermal expansion of the graphite crystals tends to fill the "accommodating" porosity and the irradiation induced $<\mathrm{c}>$-axis swelling causes a turn-around in the volume change behavior at lower doses than for the intermediate temperatures (Figure 3-9).

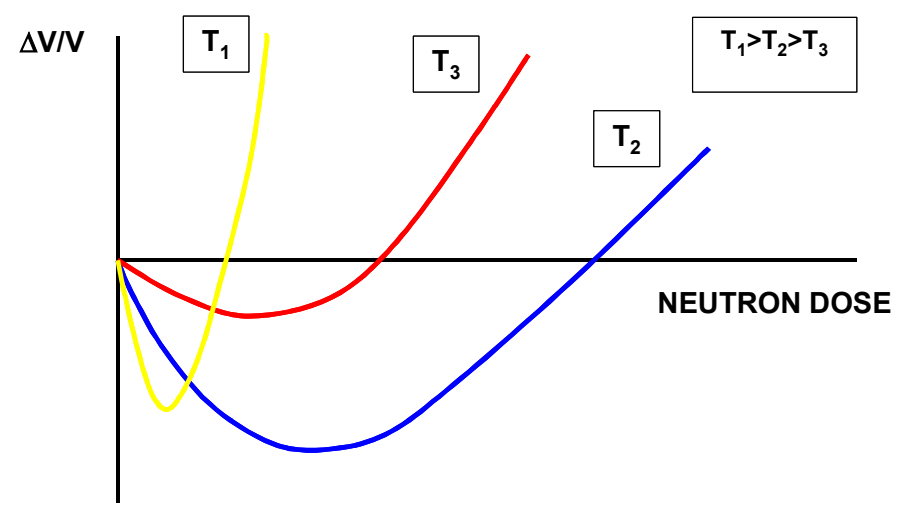

Figure 3-9. Schematic representation of the irradiation induced volume change behavior of a nuclear graphite as a function of temperature

The grade of nuclear graphite (H-451) previously used in the United States is no longer available. New graphite grades have been developed and are currently considered as candidates for the NGNP. Early in the program, it will be necessary to review and document the existing data, from all available sources, on the properties of these new grades of graphite. Irradiation data from ongoing experiments in the Petten Reactor (European program) will be of great value. A complete properties database on the new (available) candidate grades of graphite must be developed to support the design of graphite core components. Data is required for the physical, mechanical (including radiation induced creep) and oxidation properties of graphites. Moreover, the data must be statistically sound and consider in-billet, between billets, and lot-to-lot variations of properties. The data will be needed to update and benchmark existing design models for graphite performance. Since the available near-isotropic, extruded graphites are somewhat similar to the prior grade $\mathrm{H}-451$, design models for $\mathrm{H}-451$ can be incrementally adjusted for the currently available graphites as new data becomes available. This review will provide data that will be input into the preliminary selection process.

As part of the preliminary selection process, a radiation effects database must be developed for the currently available graphite materials. As mentioned above, there is the potential to leverage data from European Union activities in the area of irradiation experiments on PBMR graphites (Petten Reactor irradiation experiments are currently being initiated). However, it is anticipated that a substantial number of additional graphite irradiation tests will be needed to complete the database. Since NGNP graphite service temperatures are anticipated to be as much as $200^{\circ} \mathrm{C}$ greater than that in the GT-MHR, additional data are required for all properties at these higher temperatures, including radiation damage effects. Therefore, in order to be qualified for the NGNP, existing graphite behavior models need to be modified based on sound materials physics and then validated/verified against new data for the currently available graphite grades. Property data must support the service conditions, including effects of higher temperature, helium gas (plus air and water), and neutron irradiation effects. Irradiation creep data for the candidate graphites must also be obtained. 
3.3.3.3.1 Graphite Baseline Materials Test Program - The baseline graphite test program will "fill in the blanks" in the database that cannot be abstracted from European and Japanese programs. The baseline materials test program must be sufficient to fully characterize and quantify property variations within candidate graphite billets arising from the raw materials forming process (e.g., parallel and perpendicular to the forming axis), as well as spatial variations (i.e., billet edge and center). Microstructural characterization of candidate graphites will be conducted in order to establish filler particle and pore size distribution (required for fracture modeling). X-ray diffraction (XRD) will be applied to establish crystal parameters and appropriate crystalinity factors for neutron irradiation behavior modeling and prediction.

Prior work and data for nuclear graphite behavior will be reviewed and assessed in an effort to minimize the extent of the testing program.

Physical and Mechanical properties to be determined include:

- Mechanical Properties - Strength (tensile, compressive, flexural), Biaxial/multiaxial strength, Stain to Failure, Elastic Modulus, Poisson's Ratio, Fatigue Strength, Fracture Toughness.

- Thermal Properties - Thermal Conductivity, Thermal Diffusivity, CTE, Emissivity, Specific Heat.

- $\quad$ Tribology - Significant work has been previously performed on graphite-graphite friction couples. This work needs to be reviewed and documented in the graphite materials database. Previous work did not indicate a significant problem with regard to erosion or grinding of components other than dust generation (which needs to be quantified- including measurements made during FSV reactor operation). The graphite dust will have to be removed using the helium purification system. System requirements can be developed from the dust generation data. Previously, circulating graphite dust was not found to be an erosion or grinding problem, but graphite dust will need to be cleaned out of the helium to prevent clogging of small instrumentation passages, etc.

The chemical purity and Boron equivalent content of the candidate graphite will be determined.

3.3.3.3.2 Graphite Aged Material Test Program - For qualification, variations between billets within a single lot and between different lots must be fully characterized. Sufficient data must be taken such that the data are statistically significant. Therefore, it will be necessary to purchase full-size billets of graphite from several lots for qualification testing. Ideally, several graphite billets will be purchased from a pre-production lot (this may require the purchase of the entire lot) in order to establish and quantify the extent of in-billet and between billet property variations. And graphite purchased should meet the requirements established for the ASTM Nuclear Graphite Materials Specification. Graphite thus purchased will additionally be used for ASTM test method development.

For qualification, property data is needed as a function of temperature and environment (helium). Moreover, the long-term effects of impurities in the coolant helium (air, water oxygen) on the graphite properties must be established (Graphite oxidation). All of the properties determined under the baseline graphite materials test program will need to be reassessed for the effects of oxidation from helium coolant impurities (air, $\mathrm{CO}_{2}$, water, Graphite 
air oxidation kinetic data must be obtained for the candidate graphites for air-ingress accident simulation and modeling.

Design specification data will be required on the helium coolant purity limits, as this will control the severity of the property degradations.

3.3.3.3.3 Graphite Irradiated Materials Test Program - Significant structural changes occur upon neutron irradiation. The single crystal effects and gross structural effects combine to modify practically all of the properties. Thus, for preliminary selection of candidate graphites, those properties listed in the baseline program above must be examined for the effects of irradiation at a temperature representative of service conditions.

The effects of neutron irradiation over the temperature and dose range appropriate to the NGNP must be established as part of the qualification process. A significant body of data on the effects of irradiation exists and prior data on near-isotropic nuclear graphites will serve to guide experimentation. The selected reactor type (e.g., prismatic or pebble-bed) will significantly impact the irradiation program because the anticipated maximum neutron doses are much greater in the pebble-bed design. The irradiation experiment temperatures should bracket the design envelope for the selected reactor.

A major component of the irradiation Qualification-testing program will be determination of the irradiation creep coefficient in compression and tension. Under irradiation, graphite will creep at temperatures where thermal creep does not occur. The rate of creep is related to the applied stress, the initial modulus and neutron dose and temperature.

\subsubsection{Control Rod and Composites Qualification Test.}

\subsection{Composites Baseline Materials Test Program -}

3.3.3.4.1.1 $\quad C_{f} / C$ Materials Test Program. Currently there are several manufacturers of carbon-carbon composites of the type that are thought to be required for reactor-core components (pitch based matrix with pitch based fibers). However, these manufacturers have not qualified any of their recent highperformance materials and processing routes for nuclear applications. The manufacturers need to bring potential candidate structural composite materials to a more advanced level (prime candidate material) such that appropriate characterization can be made to qualify the materials for reactors. Then, these prime candidate materials will be used to make a final selection such that full-scale prototype components can be fabricated and tested for reactor components that meet the design requirements.

For $\mathrm{C}_{\mathrm{f}} / \mathrm{C}$ materials, there is limited tensile, compression, and bend strength data as well as modulus of elasticity, Poisson's ratio, thermal expansion rate, and thermal conductivity at elevated temperatures. In addition, the manufacturers and their prime candidate materials must be examined for repeatability, quality, and eventual size of manufacture, as many of the parts will be very large. The scale-up of parts will be aided by stress analysis codes, which are quite mature for carbon-carbon; however, the codes will need to be adapted for the specific fiber architectures selected for qualification in this program. For instance, modification of modeling codes may be required if the current codes cannot handle braided fiber architecture. 
The first experimental areas for research in this program will be developing the proper architecture to achieve the specific properties specified by the reactor designers with carbon-carbon (and also silicon-carbide) composites. It is recommended that this fabrication work be conducted by the manufacturers of $\mathrm{C}_{\mathrm{f}} / \mathrm{C}$ composites (this is the early involvement mentioned above). Once appropriate samples are available, a complete suite of material tests at elevated temperatures on mechanical properties, thermal properties, fracture behavior, etc., including elevated temperature testing, off normal condition testing, oxidation and post irradiation to obtain design guidelines will be required. In addition, each potential vendor will need to be qualified to ensure that they can repeat the process sufficiently that the material variation from batch to batch is within acceptable limits determined by this program. Some economic measures should be applied to limit the scope and cost of the testing. It is anticipated that not every material-architecture will need to be fully tested, but sufficiently tested so that data from other candidate materials can be applied. Hence, it is possible to envelope the materials testing requirements for several components with values from one that is similar in design and operating environments. For example, it is anticipated that the oxidation kinetics on the control rod material will be similar to that of the hot gas duct, just more rapid.

Friction/wear data is not available for the couples $\mathrm{Cf} / \mathrm{C}$ on metal or $\mathrm{C}_{\mathrm{f}} / \mathrm{C}$ on $\mathrm{C}_{\mathrm{f}} / \mathrm{C}$ in a dry helium environment. A dry helium environment typically enhances friction. It is predicted that $\mathrm{C}_{\mathrm{f}} / \mathrm{C}$ control rods will wear preferentially over metallic guide tubes. The situation of $\mathrm{C}_{\mathrm{f}} / \mathrm{C}$ control rods interfacing with $\mathrm{C}_{\mathrm{f}} / \mathrm{C}$ guide tubes needs to be investigated to assure that the guide tubes would last their intended service lives. Thus friction pairs of $\mathrm{C}_{\mathrm{f}} / \mathrm{C}$ on metal and $\mathrm{C}_{\mathrm{f}} / \mathrm{C}$ on $\mathrm{C}_{\mathrm{f}} / \mathrm{C}$ should be investigated in a dry helium atmosphere. Tests at high temperatures should also be conducted because higher fraction factors are expected at elevated temperatures. Tests after irradiation are not deemed necessary at this time.

3.3.3.4.1.2 SiC $\mathrm{SiC}_{f} / \mathrm{SiC}$ Materials Test Program. Large-sized $\mathrm{SiC}_{\mathrm{f}} / \mathrm{SiC}$ composites are not as available as $\mathrm{C}_{\mathrm{f}} / \mathrm{C}$ composites (see Manufacturing Needs Section 3.3.5.3, below). Therefore, much of the knowledge about the behavior of $\mathrm{SiC}_{\mathrm{f}} / \mathrm{SiC}$ composites has been generated with laboratory-sized samples using simple testing conditions. It is recognized that these composite materials have undergone rapid development within the last ten years. The result is a very limited database for the newest, radiation resistant materials. Therefore, a more detailed effort is recommended to be completed to enable the acceptance of $\mathrm{SiC}_{\mathrm{f}} / \mathrm{SiC}$ components by NGNP designers. The effort can be summarized in the six following areas:

1. Material optimization (i.e., selection of the optimum fiber, matrix and interface to match the design need)

2. Generation of a suitable database with the optimized material using ASTM test methods

3. Testing of prototype shapes (i.e., Can the same properties be obtained in a tubular geometry as compared to the flat plate geometry used for test samples?)

4. Design code selection and validation 


\section{Evaluation of material models \\ 6. Tribology and wear}

3.3.3.4.2 Composites Aged Properties Test Program - Prototype carbon-carboncomposite material components should be manufactured and tested for in-service conditions (i.e., service temperatures and environment). Properties data must be obtained for both carboncarbon-composite material and $\mathrm{SiC} / \mathrm{SiC}$ composites. Following the initial down select to two vendors (both $\mathrm{SiC} / \mathrm{SiC}$ and $\mathrm{C} / \mathrm{C}$ ), the candidate materials will be evaluated for the various inservice conditions. These may be unique to each component, so the architectures for each component may need to be individually tested at each condition (to be later specified by the designers). This activity will address both long-term corrosion due to helium impurities and short-term oxidation due to air ingress during accident conditions. These aged material tests will include:

- Oxidation

- Corrosion due to helium impurities

- Off normal events.

After each of the aging conditions is conducted, simple mechanical and thermal tests will be conducted to verify and quantify effects of the aging. These will include tensile strength and modulus, dimensional changes, and thermal conductivity.

The results of the aging studies will be used to characterize the kinetics (reaction rate) such that activation energies can be calculated. From these activation energies, we can develop aging/life prediction models for the degradation of the materials. These models will be crucial because it will be impossible to determine the effects after a 60 -year life without 60 years of testing. This accelerated life testing program will be used to reduce the time frame for gathering that data.

\subsection{Composites Irradiated Properties Test Program -}

3.3.3.4.3.1 $\quad C_{f} / C$ Irradiated Properties Test Program. Some illustrative components that could be manufactured from carbon-carbon composite material components of the NGNP are listed below:

- Control rod structural elements

- Control rod guide tubes

- Hot duct insulation cover sheets

- Lower core support insulation blocks

- Upper core restraint structure blocks

- Upper shroud insulation cover sheets

- Shutdown Cooling System entrance insulation.

The effects of neutron irradiation damage in carbon-carbon-composite materials have been studied because of their application in Tokamak fusion energy devices.

Sufficient information is available about the behavior of carbon-carbon-composite material's to guide selection of precursor carbon materials (fiber type, pregnant type, processing conditions, etc.). However, insufficient neutron irradiation data exists to qualify these materials for NGNP use. Composite architectures must be developed to 
meet design requirements for specific components, such as the prototype $\mathrm{C}_{\mathrm{f}} / \mathrm{C}$ control rods manufactured under the NP-GTMHR program in the 1990's.

It is important to note that existing data has shown that carbon-carbon components that are not located in the core of the reactor will not be exposed to sufficiently high radiation fluences to cause problems with strength, swelling, thermal conductivity, etc. Also, existing data has shown that $\mathrm{C}_{\mathrm{f}} / \mathrm{C}$ should easily withstand the neutron doses in all the components with the exception of the control rods. This data shows that carbon-carbon composite control rods will likely need to be changed at least twice.

3. 3.3.4.3.2 $\quad \mathrm{SiC}_{f} / \mathrm{SiC}$ Irradiated Properties Test Program. Initially, a survey irradiation study will need to be conducted to compare the differences between silicon carbide composites and carbon-carbon composites. Some recent compelling evidence shows that silicon carbide composites may be suitable as lifetime components (e.g., control rods); but, more after-irradiation property data is needed (as described in the next paragraph).

As the data in Figure 3-3 indicates, the latest $\mathrm{SiC}_{\mathrm{f}} / \mathrm{SiC}$ composites produced with Nicalon Type S and Tyranno SA fibers show little loss in strength up to $10 \mathrm{dpa}$. However, there are a number of variables that need to be evaluated before the optimum material can be chosen. Included in this list are fiber type (i.e., type $\mathrm{S}$ or Tyranno SA), interface structure (i.e., single carbon layer or multiple $\mathrm{SiC}_{\mathrm{f}} / \mathrm{C}$ layers and matrix type), chemical vapor infiltrated (CVI) SiC or crystallized pre-ceramic polymer matrices. Also, much of the available data is limited to thermal conductivity and 4-point bend strength. Therefore, a broad range of testing will be needed for properties such as thermal fatigue, mechanical fatigue, creep, environmental effects, etc. Scale-up of these materials must be evaluated because of geometric effects influencing the infiltration of the matrix into the fiber pre-form. A cylindrical geometry such as a control rod guide tube could result in different infiltration conditions and therefore properties than obtained with flat plates used to obtain the current database. It will also be necessary to develop a design code and test with the design shape. If the design shape is a control rod guide tube, this would be a cylindrical geometry. Tests such as burst strength and creep rate could be used to verify the design code. Also, material models could also be evaluated with the design shape. For example, strength, creep rate and environmental effects models exist but have not been developed for macroscopic test samples in complex geometries.

Following the initial irradiation survey of $\mathrm{C}-\mathrm{C}$ versus $\mathrm{SiC}-\mathrm{SiC}$ high-fluence performance, a decision will need to be made whether to carry the $\mathrm{SiC} / \mathrm{SiC}$ composite as an option for control rod materials. In either event, the data generation phase (Phase II) of the irradiation program will be to fully characterize the candidate materials with specific control rod architecture for the range of temperatures to be experienced in the reactor. In other words, the candidate materials selected based on the baseline materials program will need to be fabricated to meet the requirements of the design specification. These then need to be sectioned and irradiated to validate the effects of radiation on the specific geometry, architecture, materials selection, etc. It will be determined how many samples will be required to be tested at accident level temperatures at the beginning of this phase. One candidate $\mathrm{C} / \mathrm{C}$ material and 
one candidate $\mathrm{SiC} / \mathrm{SiC}$ material will be fully characterized to the fluence and temperature levels expected for the life of the reactor.

3.3.3.5 Intermediate Heat Exchanger and Piping Qualification Test. At present, a material qualification test plan for IHXs will focus on obtaining ASME B\&PV code approval in Section III for a metallic alloy to act as a pressure boundary at a nominal operating temperature of $1000^{\circ} \mathrm{C}$ with a design stress of approximately $10 \mathrm{MPa}$ operating in an impure helium environment. These conditions and the need for ASME code approval may change as the design of the heat exchanger and associated equipment evolves. The initial key element of a materials development and qualification plan will therefore be iteration of the design based on interaction of materials engineers with component designers. In particular, the issue of off-normal conditions must be addressed as soon as possible, since the temperature and stresses reached in off-normal conditions are a potential "show-stopper" for use of metallic alloys in the IHX.

Tests will be performed to sufficient times to permit the development of continuum damage models applicable to long times and complex loading conditions. The effect of fabrication methods on hightemperature performance will be included in the research. Again, Inconel 617 is of most interest but alloy 230 has comparable strength. Alloy X and alloy XR are worth consideration. Early research will be undertaken to determine if CCA617 and Inconel 740 maintain their strength advantage over the other alloys to $1000^{\circ} \mathrm{C}$. If so, these alloys will be strong candidates for consideration.

In parallel with the system design effort, available data regarding the behavior of candidate alloys in the conditions of interest will be gathered and evaluated. Of particular interest is experience with hightemperature alloys such as Hastelloy XR in the Japanese HTTR. Alloy vendors will also be further consulted to obtain the latest data.

Based on the information gained in this initial search and the better-defined operating conditions, three candidate alloys will be down selected for further, detailed evaluation and potential ASME code qualification.

The maximum temperature at which the properties must be provided is $50^{\circ} \mathrm{C}$ higher than the maximum expected use temperature. In addition, loss or change in mechanical properties caused by long-term environmental effects must be evaluated in included in the materials property database. For most of the alloys listed in Table 3-2, a significant amount of applicable mechanical property data likely already exists, however, there is little information regarding the effects of long-term impure helium exposure on these properties (Natesan, et al., NUREG/CR-6824, 2003). Determination of the effects of the helium environmental on mechanical properties will be a key element of material qualification for IHX use. In addition, the existing mechanical property database will have to be evaluated to determine its suitability for use in ASME code qualification.

Further down selection of one or two alloys will be made once initial helium exposure and mechanical property data is obtained. The alloy choice and requirements may also further change as the component design evolves.

The following represents a high-level outline of the qualification plan for IHX materials:

1. Initial testing of promising alloys will include exposure in impure, flowing helium, and stressrupture testing in impure helium (for comparison with air data). Ability to diffusion-bond into compact heat exchanger design must also be evaluated. 
2. In parallel, evaluate existing mechanical property data for use in code qualification case (i.e., does it meet ASME QA requirements?).

3. Further down-select one or two candidate alloys for code qualification.

4. Perform further mechanical property and impure helium exposure testing to complete code case requirements. Submit for code approval.

The baseline materials data generation program for the IHX will focus on the characterization of the material of construction as it is influenced by the specific fabrication procedures needed to produce the compact IHX configuration. It seems likely that, in the first year, the material performance requirements will be developed and a list of leading candidates will be identified. It will be necessary to decide if the fabrication processes should be selected to produce a material of optimum metallurgical condition or if an off-optimum material condition is satisfactory. At $1000^{\circ} \mathrm{C}$, most of the wrought nickel base alloys require relatively coarse grain size for good creep strength but fatigue resistance is best for fine grain size.

Early in the second year exploratory testing will be undertaken to establish the effect of fabrication variables on the subsequent creep and fatigue properties. Materials of comparable chemistry, grain size, and processing history will be used to produce data, which can then be used to model the performance of the IHX.

In the third year it will be determined if the metallurgical state of materials included in the testing program for the core supports and internals are suitable for the IHX. If so, a mechanical testing and aging work on materials for the IHX will not be needed. Efforts will be made to develop procedures for bench testing small models of the IHX.

In the fourth year, testing of models of the IHX will start and carry on into the fifth year. Metallugical evaluations will be undertaken. Beginning in the fifth year, aged materials will be examined for changes in microstructure and mechanical properties.

Tests of models of the IHX will continue in the sixth and seventh year to produce data that will add confidence to the life prediction methodology.

A part of the development of the fabrication technology for the IHX, the interfaces of the bonded plates will be metallugically and mechanically evaluated. This effort will begin in the second year and progress to the seventh year. The specific mechanical tests will be determined after completion of exploratory testing in the third year.

3.3.3.6 Metallic Reactor Internals Qualification Test. Initial qualification testing will be directed toward a better understanding of the strength, stability, and long-term performance of the preliminary candidate materials over the temperature range of their usefulness. Special emphasis is needed to understand the damage mechanisms operative in their service conditions, since the intended service, life (60 years) exceeds the experience database for most candidate materials. Damage assessment and life prediction are of paramount importance. These assessments will include consideration of factors that influence performance and are introduced in component fabrication. These factors include but are not limited to forming processes and joining processes. The testing will provide the elements needed for development or refinement of ASME code rules. At small level of effort, exploratory research on specialized materials will be included. These specialized materials are attractive from a crosscutting technology viewpoint and are likely to improve both performance and economics of high-temperature components for commercial-class, follow-on reactors of the NGNP type. Materials categories include ODS alloys, intermetallic alloys, refractory alloys, and grain-boundary engineered alloys. 
3.3.3.6.1 Reactor Internals Baseline Materials Test Program - Activities in the first year will begin with a detailed review of the available databases for the candidates identified in Table 3-2. The review will compile the sources for the data and lead to a draft "handbook" of representations for the data that will aide in the down select of candidates for more detailed evaluations. During this same period of review, an evaluation will be undertaken of available resources needed for the production of engineering design data. Test procedures and guidelines will be developed that will be consistent with the requirements of regulating bodies. Sources will be identified for the supply of the required products of candidate alloys. Limited testing of leading potential candidate materials in very high-temperature helium will be initiated to begin to provide data to select the more promising materials. Design modifications will be initiated on existing environmental testing equipment to enable obtaining the mechanical properties that will be required at very high temperatures. The materials will include archival alloys from earlier as-cooled reactor programs and products from a DOE-sponsored program on ultrasupercritical steam boilers.

In the second year, orders will be placed for representative products of candidate materials. Physical and mechanical testing will start to characterize the materials relative to the available databases. Tests needed to support the development of a design methodology will be started. Environmental creep-rupture testing will start. Techniques for fatigue, thermal-fatigue, creepfatigue, fatigue-crack growth, and creep-crack growth will be developed.

In the third year, testing of weldments will start. Fatigue and crack growth testing will start on the primary candidate alloys. Results will be compared to trends from the "handbook" document and the need for further testing will be assessed. A re-evaluation will be undertaken of the materials data requirements for use in the refinement of constitutive equations utilized in the design methodology research. Isochronous curves to 10,000 hours will be constructed. Complex stress and strain testing in helium will be started to evaluate parameters describing cumulative damage.

In the fourth and fifth years, results from testing in air and helium will be used to reformulate continuum damage models to accommodate aging, environmental, and cyclic loading effects. Creep rupture testing will continue. Results of testing on the chosen alloys will be compared with the expectations based on the historic data base and design codes developed in the United States, Germany, and Japan. The testing needs will be re-assessed in light of this evaluation. Emphasis will shift to alternate alloys if results indicate a favorable trend.

In the sixth and seventh years, testing will continue to produce more confidence in the predictive capability of the materials representations and models.

3.3.3.6.2 Reactor Internals Aged Material Test Program - Toward the end of the first year, testing of a limited number of archive materials will start. These will include materials aged for long times in helium. Typically, these materials will be Inconel 617 and alloy $\mathrm{X}$ aged at temperatures as high at $950^{\circ} \mathrm{C}$. Aged alloy $800 \mathrm{H}$ will be tested. Procedures for the evaluation of aged and "service-exposed" specimens will be developed.

In the second year, aging of potential candidate alloys will start. Some weldment samples will be included. Further evaluation of aged archive specimens will be undertaken. Microstructures will be evaluated and compared to predictions made by computational procedures such as Thermocalc. 
In the third year, mechanical testing and microstructural evaluations will be undertaken of candidate alloys aged 1000,3000, and 10,000 hours. These results will be provided to the computational modeling activity. Candidate alloys will be ranked on their performance.

Aging will continue during the fourth and fifth year until 25,000 of aging is accumulated on the leading candidate alloys. Subsequent mechanical properties will be undertaken to confirm the validity of predictions based on shorter time tests and results from archive specimen testing. Damage concepts utilized in the American Petroleum Institute-ASME post construction rules will be evaluated. Aging effects will be incorporated in continuum damage models for hightemperature life prediction.

Aging will continue during the sixth and seventh years, as required to establish confidence in the modeling of aging effects. Data will be provided to assist on the development of code rules for accounting for aging effects.

3.3.3.6.3 Reactor Internals Irradiated Materials Test - The fluences accumulated in the metallic core internal materials are expected to be low relative to the tolerances of the structural alloys. Nevertheless, some consideration of irradiated effects is thought to be prudent. In the first year, a review of the radiation effects on the metallic reactor internal components will be undertaken. The review will include a collection of data produced on austenitic alloys irradiated at high temperatures. This body of information will be characterized in terms of materials, exposure conditions, and testing conditions.

In the second year, data judged to be pertinent to the NGNP will be evaluated in some detail and provided to the modeling activities underway in the task areas. Also in the second year, consideration will be given to irradiation exposures. The selection of materials and exposure conditions will be undertaken. Working in collaboration with the task on the RPV materials, the design of experiments will be undertaken.

In the third year, fabrication of the irradiation capsules will be undertaken. It is anticipated that the irradiation and post-test evaluations will be undertaken in collaboration with other tasks on the NGNP materials project. The budget does not include the costs for actual exposures. Such exposures may occur in the fourth and fifth year. In the sixth year, evaluation of the irradiated materials will be undertaken. Included will be an evaluation of the radiation-induced changes in microstructure, hardness, and ductility.

3.3.3.6.4 Reactor Internals Joining Technology - In the first year, the status of the joining technology will be reviewed. The weld metal and weldment database will be collected for the candidate alloys. The technology behind the weld strength factors under development by the ASME and other international codes will be reviewed in collaboration with activities on design methodology. Welding consumables will be ordered toward the end of the first year.

In the second year, a major effort on joining technology will be developed and experimental work started. Weldments will be produced for mechanical testing, aging studies, and microstructural characterization. Creep-rupture and creep crack growth testing will be started.

In the third year, environmental testing and creep-fatigue will start on an exploratory basis. Computational models will be used to predict weld microstructures. Microstructural evaluations will be completed on materials aged 1000 and 3000 hours. Microstructural parameters will be quantified for use in damage prediction models. Preliminary estimates of weld strength reduction factors will be made. Candidate weld metals will be ranked on the 
performance. Data will be provided to the design methodology activity to explore the constitutive behavior of weld metal relative to base metal.

In the fourth and fifth years, longer time aging and testing will continue on the leading materials. Weldment test data required for the efforts on design methodology will be produced. Further development of weldment data for used in continuum damage models will be undertaken.

In the sixth and seventh years, testing of welds will continue to establish confidence the modeling efforts and the code rules developed from testing and modeling.

3.3.3.7 Hot Duct Liner and Insulations Qualification Test. Data on the performance of fibrous insulation are needed to ensure that the selected materials are capable of lasting for the life of the plant. The data include: physical properties (heat resistance, heat conductivity and heat capacity), long-term thermal and compositional stability, mechanical strength at temperature, resistance to pressure drop, vibrations and acoustic loads, radiation resistance, corrosion resistance to moisture and air-helium mixtures, stability to dust release and gas release, thermal creep, and manufacturing tolerances and mounting characteristics. The acquisition of these data requires testing of insulation specimens or small assemblies of thermal insulation panels and application of appropriate ASTM standards. This standards development work will be supported within this program. Moreover, application of current nondestructive evaluation techniques, especially in support of the monolithic insulators, is included within this test plan. Specific test rigs and facility requirements include helium flow, vibration, and acoustic test equipment as well as an irradiation facility and hot cell. Prototype assemblies testing is not planned to include neutron irradiation. However, this decision will be made following the neutron and gamma irradiation testing.

3.3.3.8 Intermediate Heat Exchanger Pressure Vessel Qualification Test. As before, a detailed assessment of the materials requirements for the heat exchanger designs will be undertaken prior to any experimental work. The leading potential candidate alloys will be identified in the course of this assessment. Most likely, these materials will be Inconel 617, alloy XR, and alloy X. New alloys such as CCA617, Inconel 740, and alloy 230 will be considered as alternates. An assessment will be undertaken of the potential of C-C composites for the compact IHX.

The research and development work for the compact IHX will require close collaboration with the developer of the compact counter-flow configuration. A research effort that helps to develop the fabrication technology will be undertaken. This effort will lead to the fabrication of a small "moduletype" unit. A testing plan will be developed to examine the performance of the configuration under various loading conditions. Included in the testing will be thermal transients.

A review will be undertaken of German and Japanese experiences with materials in "more conventional" IHX units for gas-cooled reactors. Any materials technology needed to advance the conventional units will be identified after this review.

\subsubsection{Power Conversion Turbine and Generator Qualification Test.}

3.3.3.9.1 Turbine and Generator Baseline Materials Test Program - Preparation of a materials test program in support of power conversion system (PCS) component materials requires knowledge and understanding of the materials requirements for those applications. For the turbine inlet shroud collar and the turbine shroud insulation package container/boundary, the property of greatest importance is very high-temperature creep strength. Further, it is extremely important that the creep behavior (strength and ductility) not be degraded by gas- 
metal interactions (reaction of the material with impurity gases in the primary coolant helium to cause carburization, decarburization, and/or internal oxidation) or by microstructural changes resulting from holding at elevated temperatures for long periods of time (thermal aging).

Early work should be initiated on the turbine shroud to assure that adequate long-term creep data is available in the temperature range $950^{\circ} \mathrm{C}$ to $1050^{\circ} \mathrm{C}$. Long-term in reference to the collar may be relatively short as the collar could be replaced at each 7-year maintenance period; however, it is likely that a much longer life is desired for the insulation package container. Environmental exposures (gas-metal interaction studies) should begin at the same time over the same temperature range and cover expected ranges of impurities in NGNP primary coolant helium. These should be designed primarily to elucidate the types of reactions that will occur and their kinetics.

The situation relative to the turbine blade material is essentially identical to that described above. Temperatures, environments, service periods, and many of the candidate materials are identical. In addition to the creep and environmental work it will be necessary to address questions relative to both low-cycle and high-cycle fatigue at very high temperatures and the effects of gas-metal interactions on fatigue behavior. Creep-fatigue interactions will also require study.

A large number of wrought Ni-base alloys are potentially appropriate to the turbine disk application. Of these, Hastelloy X and Hastelloy XR and Alloy 617 (also a candidate for the turbine inlet shroud collar) have been studied extensively in simulated gas-cooled reactor environments; all have received some attention. Creep and tensile strength data should be available for all candidate materials; further studies will likely be needed on fracture toughness and crack growth properties. Some confirmatory environmental exposures are desirable on the down-selected materials but effects at the temperature of application $\left(\sim 750^{\circ} \mathrm{C}\right)$ should be relatively minimal. Testing efforts aimed at the materials for the recuperator should be minimal. All needed mechanical property data are available; confirmatory environmental exposures are desirable but no adverse effects are expected. (See sections on Recuperator, Piping, and Valves.)

3.3.3.9.2 Turbine and Generator Aged Material Test Program - The most important aspect of this portion of the test program is to determine what effect long-term thermal exposures will have on the properties (strength, fatigue behavior, etc.) of the candidate materials. Any microstructural changes resulting from these exposures will have the potential to affect properties. Depending on the material composition and the temperature range, the material may soften or harden and embrittlement may become a concern. As example, sigmaphase (a potentially embrittling phase) will not form below about $950^{\circ} \mathrm{C}$ in cast Ni-base alloy IN-100 (candidate for the turbine inlet shroud collar) hardening is a maximum for Nimonic 80A at $650-700^{\circ} \mathrm{C}$. Superimposed on any thermal aging effects will be the effect of gas metal interactions. Materials will soften if decarburization occurs but will harden, and perhaps embrittle, if carburization is extensive. Internal oxidation, extending from the surface inward, can be detrimental to fatigue and crack growth properties. In general, concerns relative to gasmetal interactions will be greatest for those materials operating above $850^{\circ} \mathrm{C}$ and concerns relative to thermal aging will be greatest in the range $600-900^{\circ} \mathrm{C}$. However, the full range of temperatures associated with the component application will be investigated. Joining technology and inclusion of weld metal and heat-affected zones into the testing programs is needed. 
Other components of the PCS will or may require welding but there are no questions of feasibility with materials involved. However, it will be desirable to evaluate the properties (tensile, creep rupture, fatigue, fracture toughness, etc.) of representative weldments (see 2.2.10.5 below).

\subsection{Turbine and Generator Surface Engineering/Coatings Test Program -}

Thermal barrier coatings (TBC) have been developed for turbine blades in recent years to provide some thermal insulation between the operating fluid and the metal substrate. In both aircraft and stationary power generation turbines the TBC is a multi-layer system consisting of an insulating ceramic outer layer (typically $\mathrm{Y}_{2} \mathrm{O}_{3}$-stabilized $\mathrm{ZrO}_{2}$ ) on top of a metallic bond coat that is applied to the substrate material. The ceramic layer is deposited using either vapor deposition or thermal spray methods, and contains a carefully designed grain structure and level of porosity that act to decrease the thermal conductivity. Porosity in the ceramic layer allows transport of combustion gases to the bond coat. Bond coats have been developed to resist oxidation in the operating environment and have compositions designated as MCrAlY where $\mathrm{M}$ is one or more of the metals $\mathrm{Ni}, \mathrm{Co}$ or Fe. These compositions form tightly adherent $\mathrm{Al}$ or $\mathrm{Cr}$ scales that are protective at service temperatures.

Thermal barrier coatings are applied in existing turbine systems to allow operation above the nominal melting point of the turbine blade alloys in order to increase efficiency. At the expected outlet temperature of the NGNP it is not clear that a TBC will be necessary or desirable. A vast amount of data exists with vendors for turbine applications that will indicate if a TBC needs to be considered.

Should it be determined that a TBC is required, extensive testing and performance validation will be required. TBC systems have been developed for relatively short time service (thousands or tens of thousands of hours) in an oxidizing environment. Testing will be required to determine if the bond coat material will serve to protect the substrate under NGNP conditions where there may be insufficient oxygen partial pressure to maintain a protective scale. Continued performance of TBCs in service is assured by inspection during shut down of the turbine and coatings are refurbished as needed. Periods between service and inspection for the NGNP are likely to be longer; methods to apply more durable coatings or to inspect coatings in service may need to be developed.

3.3.3.10 Power Conversion Recuperators Qualification Test. The hot ducting and bellows operate at $600^{\circ} \mathrm{C}$ but could reach $700^{\circ} \mathrm{C}$ in event of an accident. Alloy $800 \mathrm{H}$ is the leading candidate. An enormous database exists for alloy $800 \mathrm{H}$. Work in the United States, Germany, and Japan includes a great deal of testing in helium environments. The Sect. III, Subsection NH allows the use of alloy $800 \mathrm{H}$ to $760^{\circ} \mathrm{C}$. Nevertheless, there have been several instances of early failures in bellows fabricated from alloy $800 \mathrm{H}$ and operating at temperatures in the range of 600 to $650^{\circ} \mathrm{C}$. These failures may be related to fabrication technology. Some testing will be undertaken to demonstrate that failures of $800 \mathrm{H}$ components in the refining and petrochemical industries are understood and can be avoided in the NGNP components. The testing will be largely confirmatory and will include aging effects and environmental effects studies under simple and complex loading conditions.

The helium circulator operates at $600^{\circ} \mathrm{C}$. There are no pressure stresses, but some concern exists in regard to high-cycle fatigue and creep-fatigue. Stainless steels may be considered for this application. However, ferritic steels, such as $21 / 4 \mathrm{Cr}-1 \mathrm{Mo}$ steel, and ferritic/martensitic steels, such as $9 \mathrm{Cr}-1 \mathrm{Mo}-\mathrm{V}$ steel, are potential candidates. The material selection will be based to some extent on the fatigue or creep-fatigue resistance of the candidate alloys. It is expected, for example, that the high yield strength of the ferritic/martensitic steels will produce favorable fatigue resistance in the absence of severely oxidizing 
environments. It is important that an assessment of the loading conditions be undertaken before the leading potential candidates are identified.

3.3.3.11 Valves, Bearings, and Seals Qualification Test. The qualification test program for these materials will be added with a later revision of this Program Plan. There is insufficient design information to support such a program at this time.

\subsubsection{Fabrication Infrastructure Development Program}

3.3.4.1 Pressure Vessel Fabrication Infrastructure. The issue of vessel fabricability is a major issue to be comprehensively evaluated. It is very unlikely that the manufacturing of the RPV would take place in the United States without a significant investment. Preliminary considerations and discussions indicate that Japan Steel Works is the most likely source of forgings of the required size. The physical size of even the largest required forging appears to be within their range of capability; however, the specific material selection is critical in that very large forgings of most of the potential candidate alloys listed above have not been manufactured, including the $9 \mathrm{Cr}-1 \mathrm{Mo}-\mathrm{V}$ alloy. The main issue in this regard is that of attainment of the required through-thickness properties of the higher-alloy steels in such thick sections. Additionally, weldability of the steels in thick sections is also an issue. Because of the relatively short lead-time available for ordering of components for the RPV system, fabricability and availability will be major considerations in the selection of materials. Besides the technical issues, transportation of the completed RPV or even the large ring forgings to the reactor site may be problematic. The diameter of the RPV is relatively well known from the design, but the thickness and, therefore, the weight is not as well known. It is possible that the RPV will require field fabrication, meaning welding of the ring forgings, heads, etc. onsite. In this case, the conduct of PWHT takes on more significance in that a PWHT is more difficult to conduct and control than that performed in the shop environment. Additionally, since the flange forging is likely to be the limiting forging component of the RPV, the option of eliminating the flanged closure and instead designing for cutting and rewelding the RPV if access is required may be a valid consideration. This issue has not been addressed at this point, but may be addressed in future revisions.

Fabrication and transportation for the RPV ring forgings are critical issues to be included within the literature review to be conducted during FY 2004. This review will enlist the assistance of consultants with expertise in large vessel fabrication, particularly with low alloy and medium level chromium ferritic steels. As mentioned earlier, there currently is no domestic manufacturer that can supply the very large ring forgings that are needed for the RPV. Japan Steel Works (JSW) appears to have the capacity to produce forgings of the needed size, but there may be other fabricators as well. Fabrication of the RPV with rolled and formed plates joined with axial welds will remain an option, but is not desirable because it results in a significant increase in weldments in the beltline region, the most highly irradiated region, of the RPV. Fabrication of the RPV is not considered to be a "show-stopper" for this reactor, but heavysection welding and PWHT development will require development if the high chrome low alloy steels are retained as the prime candidate materials. The production of such forgings with the potential candidate alloys will be evaluated during the literature review conducted in FY 2004. This evaluation will continue into FY 2006, with detailed assessments of the worldwide capabilities and experience with the preliminary candidate materials.

The assessment will also include transportation of individual ring forgings or a partially completed RPV to the United States, and a fully completed RPV to the construction site in Idaho. The assessment will include evaluation of domestic welding and heat-treating capabilities for the potential case of final fabrication of the RPV in the United States and transport of the completed RPV to the construction site. Transportation of other than a fully completed RPV to the construction site will also entail assessment of field fabrication issues and capabilities. Field fabrication of any part of the RPV involving welding will 
likely require development of a PWHT procedure and evaluation of the procedure and the weldments must be included in the testing program. Following identification of fabricators deemed to have the capability for manufacture of the required ring forgings, a fabricator will be chosen to fabricate a forging of sufficient size to represent the largest and thickest one required for the RPV. This forging would be evaluated with mechanical testing and microstructural characterization similar to that described in the Baseline Materials task. As a part of this task, a review of non-destructive examination (NDE) procedures for the preliminary candidate materials will be conducted. If the review indicates the need for development of procedures specific to those materials, NDE procedures will be developed with a view towards satisfying the requirements of the ASME Code and the Nuclear Regulatory Commission, to include incorporation of the procedures in the required in-service inspection program.

3.3.4.2 Reactor Core Graphite, Reflector and Supports Fabrication Infrastructure. There are no major graphite manufacturing and infrastructure issues. There is adequate manufacturing capacity in either the United States, Europe, or Japan to meet the requirements of the NGNP. However, one perennial concern with graphite manufacturing is that of coke source longevity. Manufacturers strive to select coke sources that are long-lived. Indeed, the selection of a coal tar derived coke by the SGL Company for their new nuclear grades was probably driven by this concern. However, one goal of the graphite materials qualification program is to identify the features of an ideal isotropic coke for nuclear grade graphite. The ability to specify the coke requirements precisely, and predict with confidence the behavior of the graphite made for the coke, will alleviate concerns regarding coke source longevity.

Appropriate NDE methods must be developed for large graphite billets and components. Such methods should be applied prior to accepting production billets for fuel element/component machining and will be useful for subsequent in-service inspection.

3.3.4.3 Control Rod and Composites Fabrication Infrastructure. Early involvement of manufacturers of ceramic composites will be crucial in providing test samples that closely represent components that will actually (eventually) be placed in the reactor. Material properties need to be statistically measured on test samples in the "as-received" condition and after being subjected to various levels of radiation damage at temperatures representative of their intended service. The following material properties should be measured: (1) Strength, (2) Poison's ratios, (3) gas permeability, (4) thermal expansion, (5) thermal conductivity, (6) acoustic response (modulus, etc.), (7) erosion resistance, and (8) slow crack growth and high-cycle fatigue resistance (thermal and mechanical).

3.3.4.3.1 $\mathrm{SiC}_{f} / \mathrm{SiC}$ Manufacturing Needs - The following potential components were identified as candidates to be manufactured using $\mathrm{SiCf} / \mathrm{SiC}$ Composites:

- Hot Duct Liners (see Section 3.3.4.6)

- Floor Block

- Upper core Restraint

- Upper Plenum Structure

- Control Rods

- Guide Tubes.

NOTE: The two largest manufacturers of $\mathrm{SiC}_{f} / \mathrm{SiC}$ composites contributed to this section.

There are several types of $\mathrm{SiC}_{\mathrm{f}} / \mathrm{SiC}$ composites currently being developed, although most are in the pre-production stage and are not available as "off the shelf" items. The fabrication methods include melt infiltration, chemical vapor infiltration and polymer pyrolysis. Each of these ceramic matrix composites has the ability to utilize a stoichiometric silicon carbide fiber, such as Hi-Nicalon Type S, as a reinforcement. To date, however, only the chemical vapor 
infiltration process, matched with either Type $\mathrm{S}$ or Tyranno SA fibers, has shown radiation resistance. The polymer route and melt infiltration route have not shown this stability; however, these processing routes have development potential since they have certain advantages (low porosity and high thermal conductivity for the melt infiltration process, and fabricability and low cost potential for the polymer impregnation pyrolysis process) and possibly could be fabricated with the requisite stoichiometric SiC fiber combined with a high purity $\mathrm{SiC}$ matrix composition and a non-boron nitride matrix/fiber interface. It will be necessary to scale up these CMC (ceramic matrix composite) processes to meet the size and shapes required to manufacture reactor parts. In some cases, these parts can be quite large and beyond the current size capability of the CMC suppliers. In order to meet these size requirements, manufacturers estimate it will require investment in new furnace capability at a cost of about $\$ 1 \mathrm{M} /$ furnace (with $>1 \mathrm{~m}^{3}$ capacity). Also, an increase in the capacity for producing the appropriate interface coatings on the reinforcing fiber will be required as well as other fabrication processes (e.g., "pre-pregging"). In addition, a moderate level of fabrication development activity will be required for each of the components being considered.

Significant effort will be required for the development of formal material and process specifications for candidate CMCs, along with rigorous process control and monitoring. It is feasible that fabrication of smaller sub-components can be fabricated and then assembled into a final structure using some form of joining/bonding. All of the CMC processes mentioned have demonstrated this capability. Assessment of the bond durability (compared to the bulk of the component) in the reactor environment needs to be investigated.

Most CMC materials are at a stage where fairly extensive property databases are currently being generated. This is usually carried out in funded programs where the material is being considered for a specific application. Frequently these are military or aerospace funded programs, and these databases may be company proprietary and have limited distribution. Most CMC materials are tested using available ASTM test methods, but many of these test methods are still being developed and not yet been formally released. Significant numbers of very specific property tests will be necessary, using sufficient number of samples as to be statistically meaningful. This will be very expensive and time consuming.

A leading manufacturer of $\mathrm{SiC}_{\mathrm{f}} / \mathrm{SiC}$ composites currently has three chemical vapor infiltration (CVI) reactors designed to produce $\mathrm{SiC}-\mathrm{SiC}$ composites. The equipment is capable of producing parts up to 55" in diameter and 84 " in length. This equipment is currently suitable for producing components such as segmented Control Rods, Guide Rods, floor blocks, upper plenum plates, and upper core restraints. The Hot duct at it's current diameter of 56" just exceeds the present reactor size and would require either purchase of new reactors or re-sizing of the duct diameter to $\sim 48$ ".

3.3.4.3.2 $C_{f} / C$ Manufacturing Needs - The following components were identified as candidates to be manufactured using $\mathrm{Cf} / \mathrm{C}$ Composites:

- Hot Duct Liners (see Section 3.3.4.6)

- Floor Block

- Upper core Restraint

- Upper Plenum Structure

- Control Rods

- Guide Tubes 
Currently the manufacturers of carbon-carbon composites fabricate very large rocket thrusters, nose caps, and leading edges for space vehicles. These can be up to several meters in diameter. However, the tooling required for these are expensive and requires modification for different shapes, architecture, and processing required for the carbon-carbon to be used in this NGNP program. The will be no "off the shelf" materials for testing, so the carbon-carbon will be designed specifically for the requirements of the application. However, since carbon-carbon is a relatively mature technology, this step will not be as complicated as that for scale-up of the $\mathrm{SiC} / \mathrm{SiC}$ composites.

The vendors selected for this project will need to demonstrate that they can fabricate the carbon-carbon in the sizes required and still meet the required materials properties. This will require interaction between the reactor designers and the vendors, as there may be some designs that the vendors cannot fabricate in large scale, and the designers may need to accommodate the fabrication limitations (i.e., they may not be able to fabricate a 9 meter carbon-carbon dome, but can make it in sections).

\subsection{Overall Structural Composite Manufacturing Program Needs - A}

Materials Qualification and Scale-up program for the structural composites for NGNP would consist of the following high-level elements:

1. Development of material database / qualification of material system suppliers

a. Evaluate existing vendor capability for manufacture

b. Assist in development of vendor QA Qualification

c. Purchase panels for coupon data

d. Purchase sub-elements for component data

i. Key features (e.g., flanges, unusual bends, etc.)

ii. Composite Structure (i.e., optimum ply lay-up etc.)

2. Demonstrate new technologies
a. Attachments
b. Joining

3. Full Scale Part Size Fabrication Trials
a. Equipment scale-up (as-needed)
i. Installation
ii. Validation
b. Demonstrate mfg. capability
c. Develop Process Control Document
d. Demonstrate Inspection techniques

\section{Production Tasks:}

1. First Part Qualification

a. Verification of $\mathrm{mfg}$. process and production equipment

2. First Lot Qualification

a. Verification of repeatable process 
3.3.4.4 Intermediate Heat Exchanger and Piping Fabrication Infrastructure. Manufacturing issues related to the compact counter-flow IHX will be addressed as part of the research and testing activities. It has yet to be demonstrated that such a unit can be manufactured from the high-temperatures alloys that are the leading candidates, so it is clear that the manufacturing of such a unit will produce several issues to be resolved. Issues include the production of a high-integrity diffusion bond between the sheets of metal used to build the module, the control of conditions that result in an optimum grain size in the metal ligament, the development of methods for nondestructive examination of the unit, and the design and fabrication of joints between the unit and the inlet and outlet piping systems.

3.3.4.5 Metallic Reactor Internals Fabrication Infrastructure. It is anticipated that the leading candidate alloys will be selected, in part, on the basis of their availability, fabricability, and cost. In this regard, the applicable manufacturing and inspection technology has been demonstrated for the product forms of the leading candidate alloys. The advanced (SOA) alloys, however, will require special consideration, since alloys with higher performance often experience problems with fabrication and joining. If ODS alloys or other specialized alloys are brought into the project, major efforts will be required to resolve manufacturing issues.

3.3.4.6 Hot Duct Liner and Insulations Fabrication Infrastructure. Commercial ceramic fibrous insulation materials, graphite and ceramic monolithic blocks, and metallic or carbon-carbon plates can be readily obtained from existing infrastructure in the U.S.A., Western Europe, and Russia. Only current commercially available materials are being considered in this test plan.

3.3.4.7 Intermediate Heat Exchange Pressure Vessel Fabrication Infrastructure. The infrastructure issues relating to a pressure vessel for the IHX are similar to those discussed in Section 3.3.3.1 with the exception that the size and wall thickness of this heat exchanger are currently undefined. No infrastructure development is expected as part of this program until initial preconceptual design information is provided to further define the requirements.

3.3.4.8 Power Conversion Turbine and Generator Fabrication Infrastructure. The manufacturing technology is an important issue for the bellows. Various fabrication routes are available for piping components and these will be carefully examined. Seam welded piping is generally avoided but there are several routes to produce seamless piping. The research leading to the data compilation will include consideration of the fabrication technology on high-temperature performance.

Confirmatory demonstrations of the manufacturing processes are needed for the forming and welding procedures required for the turbine inlet shroud collar and the shroud thermal insulation boundary/container.

3.3.4.9 Power Conversion Recuperators Fabrication Infrastructure. The applicable codes and standards need to be established early in the project. The materials data requirements will depend on whether these components are constructed to ASME Sect. III, NB, NC, or alternative sections of the pressure vessel and piping codes. Regardless of which construction rules apply, the codes require the designer to consider all likely modes of failure including those related to degradation from thermal aging or environmental attack.

Confirmatory demonstrations of the manufacturing processes are needed for the following:

- Commercial scale demonstration of capability to provide high-quality thin sheets $(\sim 0.35-\mathrm{mm})$ of 300 Series SS of size $\sim 2.2-\mathrm{m} \times 2.8-\mathrm{m}$ for producing recuperator corrugated heat exchange surfaces. 
- Forming and joining procedures required for the assembly of the recuperator. (See sections on Recuperators, Piping, and Valves.)

3.3.4.10 Valves, Bearings and Seals Fabrication Infrastructure. To be added with a later revision to this Program Plan.

\subsubsection{Codes and Standards Qualification Development}

3.3.5.1 Pressure Vessel Codes and Standards. The RPV system is part of the primary pressure boundary and, as such, must conform to ASME Section III, Division 1, and Subsection NB for Class 1 components. Section II, Part D, Properties, provides the maximum allowable stress values (design stress intensity values) with Tables $2 \mathrm{~A}$ and $2 \mathrm{~B}$ being applicable to ferrous materials and nonferrous materials, respectively, for Class 1 applications. Table 4 of Section II similarly provides maximum allowable stress values for Class 1 bolting. Detailed discussion of the bases for establishment of the design stress intensity values is beyond the scope of this report, but suffice it to note that they are nominally based on the lower of $1 / 3$ tensile strength or $2 / 3$ yield strength, with different criteria for wrought and cast alloys, and welded pipe or tube. Moreover, there are ratios applied to those basic criteria that are dependent on temperature dependent trends. Table $2 \mathrm{~A}$ covers temperatures to $371^{\circ} \mathrm{C}\left(700^{\circ} \mathrm{F}\right)$ for ferritic alloys and $426^{\circ} \mathrm{C}\left(800^{\circ} \mathrm{F}\right)$ for austenitic alloys, while the maximum temperature in Table $2 \mathrm{~B}$ is $426^{\circ} \mathrm{C}\left(800^{\circ} \mathrm{F}\right)$. Subsection $\mathrm{NH}$ to Section III permits construction to higher temperatures for a limited number of materials. These are 2 $1 / 4 \mathrm{Cr}-1 \mathrm{Mo}$ steel (Class 1$)$ to $649^{\circ} \mathrm{C}\left(1200^{\circ} \mathrm{F}\right)$, types $304 \mathrm{H}$ and $316 \mathrm{H}$ stainless steels to $816^{\circ} \mathrm{C}\left(1500^{\circ} \mathrm{F}\right)$, and alloy $800 \mathrm{H}$ to $760^{\circ} \mathrm{C}\left(1400^{\circ} \mathrm{F}\right)$. Those maximum temperatures are, however, somewhat deceiving in that they do not necessarily represent the approved temperatures for long-time operation $(300,000 \mathrm{~h})$. For example, the upper temperature limit for that long-time operation for the $21 / 4 \mathrm{Cr}-1 \mathrm{Mo}$ steel is $593^{\circ} \mathrm{C}$ $\left(1100^{\circ} \mathrm{F}\right)$. At the maximum allowable temperatures for long-time operation, the maximum allowable stress intensity values are extremely low; for the type 304 stainless steel, for example, it is four $\mathrm{MPa}(0.6$ $\mathrm{ksi})$. For the $21 / 4 \mathrm{Cr}-1 \mathrm{Mo}$ steel at $593^{\circ} \mathrm{C}$, the maximum allowable stress intensity is $19 \mathrm{MPa}(2.7 \mathrm{ksi})$. The extension of the required databases and ASME Code acceptance of the materials for NGNP RPV service will need to be closely coordinated with the high-temperature design methodology activities.

At the current time, $9 \mathrm{Cr}-1 \mathrm{Mo}-\mathrm{V}$ steel (grade 91) is approved to $593^{\circ} \mathrm{C}\left(1200^{\circ} \mathrm{F}\right)$ for Class 1 applications in Section III of the Code with the maximum allowable stress intensity at that temperature of $30 \mathrm{MPa}$ (4.3 ksi). However, at this time, grade 91 is in the final stages of acceptance into Subsection NH, with the proposal for its inclusion to $649^{\circ} \mathrm{C}\left(1200^{\circ} \mathrm{F}\right)$ and the same allowable stress.

A major issue for the RPV and CV materials is the conditions experienced under abnormal operating conditions. Currently, the estimated maximum temperature is $770^{\circ} \mathrm{C}\left(1418^{\circ} \mathrm{F}\right)$ with the potential for operation at that temperature for about $50 \mathrm{~h}$ and, more importantly, at full operating pressure or higher. This temperature is well beyond the aforementioned maximum that is currently proposed for Section III, Subsection NH. Moreover, that abnormal temperature is given as the mid-wall temperature; given an abnormal helium temperature of $1200^{\circ} \mathrm{C}$, this implies a temperature even higher than $770^{\circ} \mathrm{C}$ for the inner portion of the RPV wall. With increasing temperature, the allowable stress decreases and extrapolation of the trend curves used to obtain the stress of $30 \mathrm{MPa}$ at $649^{\circ} \mathrm{C}$ will result in a significantly lower maximum allowable stress at $770^{\circ} \mathrm{C}$. There are precedents in the ASME Code that allow for operation to temperatures beyond normal maximum under abnormal conditions. For example, Code Case N-499-1 allows SA533-B-1 and SA508-3 for Section III Class 1 components to be used to $427^{\circ} \mathrm{C}\left(800^{\circ} \mathrm{F}\right)$ for types $\mathrm{A}$ and $\mathrm{B}$ events for up to $3000 \mathrm{~h}$ cumulative, and to $538^{\circ} \mathrm{C}\left(1000^{\circ} \mathrm{F}\right)$ for types $\mathrm{C}$ and $\mathrm{D}$ events for up to $1000 \mathrm{hr}$ cumulative. Because the consideration of maximum allowable stress intensity is dependent on the time at temperature (creep dependent), the time for which the abnormal conditions would exist are very important in making judgments and recommendations regarding inclusion in the Code and for evaluating the efficacy of such type of operation. Strictly from an allowable stress viewpoint, for 
example, the $21 / 4 \mathrm{Cr}-1 \mathrm{Mo}$ steel has an allowable stress of $41 \mathrm{MPa}$ at $649^{\circ} \mathrm{C}$ for $100 \mathrm{~h}$, but only $19 \mathrm{MPa}$ $(2.7 \mathrm{ksi})$ at $593^{\circ} \mathrm{C}$ for $300,000 \mathrm{~h}$.

Thus, to extend application of $9 \mathrm{Cr}-1 \mathrm{Mo}-\mathrm{V}$ (grade 91) to these currently envisaged abnormal conditions will require reevaluation of the background data used to obtain the currently proposed allowable stresses for Subsection NH, the likely conduct of additional testing to obtain sufficient data at temperatures to $50^{\circ} \mathrm{C}$ beyond the highest envisaged abnormal temperature, reanalysis of all the data, and a proposed Code Case to obtain inclusion for such operation with that material within the ASME Code rules. As mentioned earlier, other variants of the same alloy class are grades 92 and 911 and, although they do not have the level of maturity of the grade 91, the databases are relatively good and they appear to offer the opportunity for much better high-temperature strength.

3.3.5.2 Reactor Core Graphite, Reflector and Supports Codes and Standards. Significant activity is required to bring the existing graphite codes and standards to an acceptable condition. The proposed section III, Division 2, Subsection CE of the ASME B\&PV Code (Design requirements for Graphite Core Supports) was issued for review and comment in 1992 and no action has been taken on this code since that date. There is activity underway currently (funded by the NRC) to reinitiate the "CE" code committee and begin the process of code case approval. However, significant revision of the code is required as well as expansion of the code to the higher temperatures envisioned for the NGNP.

Moreover, the NRC has indicated that the code should be revised to increase the neutron dose limits to levels appropriate to the PBMR.

Graphite test standards have been developed for nuclear grade graphites (ASTM C-781-02: Standard Practice for Testing Graphite and Boronated Graphite Components for High-temperature Gas-Cooled Nuclear Reactors). This ASTM Standard Practice is an umbrella standard that refers to a number of ASTM test methods to determine the following properties: bulk density, thermal expansion, thermal conductivity, compressive strength, tensile properties, Poisson's Ratio, flexural strength, Modulus of Elasticity, Relative Oxidation rate, surface area, catalytic impurities, ash, and Thermal Absorption Cross Section. ASTM C-781-02 must be further expanded to cover required test methods including, Fracture Toughness, XRD, Graphite Air Oxidation, Boron Equivalency. This activity is currently being led by ORNL but the pace will need to be accelerated to meet the needs of the NGNP. Moreover, the standard must address specimen size issues as they relate to the preparation of graphite irradiation specimens. ASTM is currently preparing a nuclear grade graphite material specification under the jurisdiction of Committee DO2-F.

3.3.5.3 Control Rod Composites Codes and Standards. There is no ASME codes or other existing industrial standards pertaining to the design requirements for $\mathrm{C}-\mathrm{C}$ or $\mathrm{SiC}-\mathrm{SiC}$ type composite materials for nuclear applications. Consequently, a new code and data from a full materials and component qualification test program will be required. This will constitute a major challenge to this materials program and also to the ASME technical community. Although such codification has not previously been attempted, there has been no need for the use of such materials in nuclear systems prior to this time.

3.3.5.4 Intermediate Heat Exchanger and Piping Codes and Standards. A review of the need for codes and standards will be undertaken. It seems likely that the IHX will be manufactured to meet ASME Sect. III for Class 2 or 3 components.

There is a clear need to qualify materials to 950 and $1000^{\circ} \mathrm{C}$ for construction of the primary-to- secondary piping. The applicable construction code has not been identified. However, the criteria for setting stresses for ASME Sect. III Class 2 and Class 3 components are similar to the criteria for ASME Sect. VIII, Division 1, B31.1, and B31.3. Here, the time-dependent allowable stresses are generally controlled 
by $67 \%$ (or less) of the average rupture strength at 100,000 hours. This stress is very low for all of the wrought alloys. The allowable for Inconel 617 , for example, is about $5 \mathrm{MPa}$ at $980^{\circ} \mathrm{C}$. A lower value applies to other code-approved alloys. Research is needed to collect the available data for these materials and develop a plan to supplement the data to address issues specific to the NGNP. In particular, it will be determined if the allowable stress must be further reduced to account for the 60 year design life. Creeprupture and fatigue behavior in helium are two additional categories where research will be required. Experience has shown that the creep behavior is greatly affected by the environment at the temperatures of interest, while creep-fatigue and thermal ratcheting are failure modes explicitly identified by the ASME code as operative in pressurized components in service above $815^{\circ} \mathrm{C}$.

The materials property database needed for ASME code qualification in high-temperature conditions includes the following, each as a function of temperature (from Shah, et al, NUREG/CR-6816, 2002):

1. Modulus of elasticity and Poisson's ratio

2. Yield and ultimate tensile strength

3. Stress-strain curves

4. Stress versus creep rupture time for base metals and their weldments

5. Stress versus time to $1 \%$ total strain

6. Stress versus time to onset of tertiary creep

7. Constitutive equations for conducting time- and temperature-dependent stress-strain analysis

8. Isochronous stress-strain curves

9. Continuously cycling fatigue life as a function of strain range at a fast strain rate

10. Creep-fatigue cyclic life involving cycles with various strain ranges and hold times.

Similar requirements will be imposed for the heat exchangers of the hydrogen plant. QA standards for the fabrication will be developed. Test methods will be developed for inspection and certification.

3.3.5.5 Metallic Reactor Internals Codes and Standards. For any new alloy, a significant effort will be needed to produce the information required for the development of ASTM and ASME materials specifications. Further efforts will be needed to resolve issues related to the acceptance of required materials into the applicable construction codes. If acceptance into Sect. III, Subsection NH is required, a major experimental program will be undertaken. Data to assist in the validation of design methodology will be produced when the need is identified. Special problems and issues will be resolved for the ODS and other specialized alloys. Some, but not all of the problems to be solved, include the requirements for material specifications, identification of criteria that can be used to set allowable stresses, and the assembly of data that can be used to set the stresses.

In the late 1980s, a draft code case was prepared for Inconel 617 for inclusion into ASME Sect. III with coverage to $980^{\circ} \mathrm{C}$. Most of the issues addressed in Subsection NH were covered in the draft code case, but there is a need for re-evaluation of the document in view of changes that have been introduced into the Code in the last 20 years. In particular, the need for coverage of Data has been developed on this alloy in German and Japanese programs but there is alack of understanding of weldment behavior in longterm exposure at high temperatures. In recent years, components fabricated from Inconel 617 have experienced failures in weldments. These failures may be due to corrosion or other factors, but it is clear that a weakness exists that needs exploration.

The controlled chemistry version of Inconel 617, CCA617, is quite new and years away from reaching code status. However, the potential use of this material for fossil-fired ultra supercritical steam boiler application assures that much of the data needed to gain approval for use of CCA617 in Class 2 and Class 3 construction may become available. Alloy 230 is incorporated in ASME Sect. II and is approved for construction in ASME Sect. VIII and Sect. I. The database is sufficient to obtain acceptance into Sect. III 
for Class 2 and Class 3 construction. More work is needed on weldments, creep-fatigue, helium effects and irradiation effects if the alloy is to be approved for Class 1 components. It is known that alloy 230 weldments have lower rupture strength than base metal, so some effort will be needed to establish weldment strength reduction factors for this material. The most challenging issue that needs resolution for service above $815^{\circ} \mathrm{C}$ is that of creep-fatigue interaction problem. Most experts concede that the current ASME Sect. III, Subsection NH approach to the problem is inadequate. A range of alternatives exists. These alternatives must be explored in a collaborative effort involving several disciplines. Testing is also needed to establish and defend exemption rules for creep-fatigue loadings.

Some work is needed to address the special problems and issues associated with the ODS and other specialized alloys. Some, but not all of the problems to be solved, include the requirements for material specifications, identification of criteria that can be used to set allowable stresses, and the assembly of data that can be used to set the stresses. Material specifications need to be developed that will cover the range of product forms and establish minimum property values at room temperature. Acceptable chemistry ranges and heat treatments will be needed. Joining processes must be identified. Once produced and subjected to high-temperature testing, it is not clear that the criteria set forth for establishing the allowable stress intensity values in ASME Sect. III, Subsection NH will apply to ODS alloys. These alloys are inherently more sensitive to defects and flaws, and consideration of this characteristic could affect the stress multiplier. Similar considerations could affect time-dependent allowables.

3.3.5.6 Hot Duct Liner and Insulations Codes and Standards. As with all ceramic products, no standard composition grades or material property standards necessary for inclusion in a NGNP are currently available to industry. Each company applies their own standards of manufacturing quality control to their various internal grades of product with some utilization of existing ASTM standards for selected property measurements. Therefore, significant work on ASTM standards development, along with improved methods for non-destructive evaluation of these systems, needs to be carried out. Priority, long lead-time items include thermal and mechanical fatigue testing of monolithic materials, creep of monolithic ceramics under compressive loading, and the related ASTM standards development. The neutron fluence to these materials is predicted to be quite low. However, it will be required to examine the stability (retaining thermal properties) of the higher temperature fibrous insulations (especially those containing silica) after exposure to a combination of high temperature and gamma flux over long time periods. Acoustic fatigue measurements on the various fibrous insulation materials will also required (early in the testing program).

\subsubsection{Intermediate Heat Exchange Pressure Vessel Codes and Standards. To be} determined and included in a later revision of this Program Plan.

3.3.5.8 Power Conversion Unit Codes and Standards. The applicable codes and standards need to be established early in the project. Bellows have been used at relatively high temperatures in nuclear facilities, and there is some coverage in the ASME Sect. III Code Case N-290. Nevertheless, further work on codes is likely to be needed. The materials data requirements will depend on whether these components are constructed to ASME Sect. III and the associated code cases or alternative sections of the pressure vessel and piping codes. Regardless of which construction rules apply, the codes require the designer to consider all likely modes of failure including those related to degradation from thermal aging or environmental attack. 


\subsection{Support for Codes and Standards Development}

\subsubsection{ASME Code Activities}

The NGNP Program must initiate a presence at the ASME Code meetings at the relevant committee and subcommittee level to be able to incorporate new materials or extend the application of materials presently in the Code. Steps to accomplish this are as follows:

- Develop a white paper that discusses NGNP concepts and illustrates Code boundaries (e.g., Class 1, Class 2, balance-of-plant Section VIII or B31, etc.)

- Contract with recognized ASME B\&PV Code experts to develop a prioritized action list

- Contact appropriate high-level ASME officials for an initial discussion of the NGNP Project needs and desired interaction

- Contact appropriate Subcommittee Chairs or Vice-Chairs to discuss NGNP Project needs and ways to help the effort

- Participate in Code development activities at the subcommittee and committee level.

\subsubsection{American Society for Testing Materials (ASTM) Standards Program}

The American Society for Testing and Materials International (ASTM International) is a voluntary standards developing organization. ASTM International defines a standard as follows: "As used in the ASTM, a standard is a document that has been developed and established within the consensus principles of the organization and which meets the requirements of ASTM procedures and regulations. Full consensus standards are developed with the participation of all parties who have a stake in the standard's development and use." The National Technology Transfer and Advancement Act (Public Law 104-113) require government agencies such as the DOE to use privately developed standards wherever possible. The ASME Code policy for acceptance of new materials (Section 2.5.2) requires that new materials be accepted into recognized national/international specifications such as ASTM before they can be considered for acceptance.

The ASTM Committee's that would be relevant to approval of new metallic materials for the NGNP are 1) Committee A01 on Steel, Stainless Steel and Related Alloys and 2) Committee B02 on Nonferrous Metals and Alloys. As described below, there are a number of metallic materials proposed for use in the NGNP that will require placement in an ASTM standard. The NGNP technical staff will have to draft a new or modified ASTM standard for the material and submit it to the appropriate subcommittee and follow the approval process through the subcommittee and committee stages.

\subsubsection{American Society of Mechanical Engineers Code Expansions/Additions}

3.4.3.1 Licensing/Code Work. Table 3-7 lists the ASME Code status and design allowable values for the candidate materials being considered for the reactor vessel and intermediate and high temperature components. As can be seen, there will be a lot of standards and code work required to have materials ready for the ASME Section III design process. For a list of potential candidate materials being considered for all internals, as well as the other high-temperature components likely to be constructed from metallic alloys, see Section 3.2.4.1, Table 3-2. 
Table 3-7. ASME Code Status and Design Allowable Values

\begin{tabular}{|c|c|c|c|c|}
\hline Material/UNS & ASME Code Status & $\begin{array}{c}\text { Code Maximum } \\
\text { Temperature }\left({ }^{\circ} \mathbf{F}\right)\end{array}$ & Product Form & Stress Value (ksi) \\
\hline $\begin{array}{l}800 \mathrm{H} / \mathrm{NO} 8810 \\
\text { (also ferritic } \\
\text { steels, 304, 316) }\end{array}$ & $\begin{array}{l}\text { Code Case N-201-4, } \\
\text { (Class CS Components } \\
\text { in Elevated Service, } \\
\text { Section III, Div. I) }\end{array}$ & $1400^{\circ} \mathrm{F}\left(760^{\circ} \mathrm{C}\right)$ & & \\
\hline 602CA/NO6025 & $\begin{array}{l}\text { Code Case 2359-1 } \\
\text { (Section I and } \\
\text { Section VIII, Div.1) }\end{array}$ & $1800^{\circ} \mathrm{F}\left(982^{\circ} \mathrm{C}\right)$ & $\begin{array}{l}\text { Forgings, bar, plate } \\
\text { sheet strip, welded } \\
\text { and seamless pipe } \\
\text { and tubing }\end{array}$ & $\begin{array}{l}0.32 \text { (Section VIII } \\
\text { only) }\end{array}$ \\
\hline 617/NO60617 & $\begin{array}{l}\text { Code Case 1982-1, } \\
\text { (Section VIII, Div.1) }\end{array}$ & $1800^{\circ} \mathrm{F}\left(982^{\circ} \mathrm{C}\right)$ & & $\begin{array}{l}0.73 \\
\text { (creep-fatigue, } \\
\text { thermal ratcheting } \\
\text { and environmental } \\
\text { effects must be } \\
\text { considered) }\end{array}$ \\
\hline 617/NO60617 & $\begin{array}{l}\text { Code Case 1946-7, } \\
\text { (Section VIII, Div.1) }\end{array}$ & $1650^{\circ} \mathrm{F}\left(899^{\circ} \mathrm{C}\right)$ & $\begin{array}{l}\text { Plate, rod, bar, } \\
\text { forgings and } \\
\text { seamless tube }\end{array}$ & $\begin{array}{l}1.7 \text { (creep-fatigue, } \\
\text { thermal ratcheting } \\
\text { and environmental } \\
\text { effects must be } \\
\text { considered) }\end{array}$ \\
\hline 617/NO60617 & $\begin{array}{l}\text { Draft Code Case, not } \\
\text { completed, (Section III, } \\
\text { Subsection NB, Class } 1 \\
\text { Components, } \\
\text { Subsection NH, Class } 1 \\
\text { Components in } \\
\text { Elevated Temperature } \\
\text { Service) }\end{array}$ & $1800^{\circ} \mathrm{F}\left(982^{\circ} \mathrm{C}\right)$ & & \\
\hline X/NO6002 & $\begin{array}{l}\text { Section II, Part D, } \\
\text { Table 1B, (Section I, } \\
\text { Section III, Class } 2 \text { and } \\
\text { 3, Section VIII, Div. 1) }\end{array}$ & $\begin{array}{l}1650^{\circ} \mathrm{F}\left(899^{\circ} \mathrm{C}\right) \\
\text { (not all product } \\
\text { forms-fittings, } \\
\text { pipe, tube, plate, } \\
\text { rod) }\end{array}$ & $\begin{array}{l}\text { Forgings, bar, plate } \\
\text { sheet strip, welded } \\
\text { and seamless pipe, } \\
\text { tubing, and fittings }\end{array}$ & 1.2 \\
\hline $\begin{array}{l}\text { XR-Mitsubishi } \\
\text { Materials }\end{array}$ & Unknown & Unknown & Unknown & Unknown \\
\hline 230/NO6230 & $\begin{array}{l}\text { Code Case } 2384 \\
\text { (Section VIII, Div. 1) }\end{array}$ & $1800^{\circ} \mathrm{F}\left(982^{\circ} \mathrm{C}\right)$ & $\begin{array}{l}\text { Strip, plate, bar, } \\
\text { welded pipe and } \\
\text { tube, seamless pipe, } \\
\text { tube, and fittings, } \\
\text { forgings }\end{array}$ & 0.45 \\
\hline HR-120/NO8120 & $\begin{array}{l}\text { Code Case 2315, } \\
\text { (Section VIII, Div. 1) }\end{array}$ & $1650^{\circ} \mathrm{F}\left(899^{\circ} \mathrm{C}\right)$ & $\begin{array}{l}\text { Strip, plate, bar, } \\
\text { welded pipe and } \\
\text { tube, seamless pipe, } \\
\text { tube, and fittings, } \\
\text { forgings }\end{array}$ & 1.4 \\
\hline $\begin{array}{l}\text { 9Cr-1MoVNb, } \\
\text { Grade } 91\end{array}$ & Section III, Class 1 & $593^{\circ} \mathrm{C}$ & Plate & 4.3 \\
\hline
\end{tabular}


3.4.3.2 ASME Code Section III, Subsection NH and Associated Cases. The current Subsection NH criteria and material coverage originate largely from the liquid-metal reactor (LMR) program of the late 1960s, '70s, and early '80s. In the late 1960s the Atomic Energy Commission initiated a Materials and Structures Technology program and simultaneously asked the ASME B\&PV Code Committee to charge an expanded Subgroup on Elevated Temperature Design with developing the design rules that eventually provided the basis for Subsection NH. That Subgroup was staffed largely with LMR program participants. A High-Temperature Structural Design Technology task within the nationwide Materials and Structures Technology program supported the development and experimental confirmation of design criteria to guard against creep, creep-fatigue, and ratcheting failures. The Mechanical Properties Design Data task provided the uniaxial data for design and quantification of the criteria. In companion efforts, the High-Temperature Structural Design Technology task provided recommended constitutive equations for the required inelastic design analyses, and the Design Data task provided the uniaxial stress-strain and creep data needed for designers to implement the equations. All of this work was based on experimental data from common heats of materials, so that the resulting design methods, criteria, and data were as consistent as possible. A recent Argonne National Laboratory report, prepared for the Nuclear Regulatory Commission (NRC) provides a good overview of Subsection NH and its associated cases and their shortcomings for HTGR components [31].

The design rules of Subsection NH for Class 1 elevated-temperature components consist of: (1) loadcontrolled (primary) stress limits, and (2) strain, deformation, and fatigue limits (Appendix T). The loadcontrolled stress limits are in the form of time-dependent allowable stresses based on both short-time tensile test results and long-term creep test results. Allowable stress reduction factors for weldments are given, as are reduction factors to account for the degrading effects of prior service. Only elastic analysis results are required to satisfy the primary stress limits. The second category of design rules - strain, deformation, and fatigue limits - are much more problematic. These rules deal with the complex behavior, described in the previous section, resulting from primary plus cyclic secondary and peak stresses. They are aimed at preventing failures due to excessive deformation, creep-fatigue damage, and inelastic buckling, and they generally require inelastic design analysis results for their satisfaction. The rules include strain accumulation limits, creep-fatigue criteria ${ }^{c}$, buckling limits, and special limits for welds.

The materials that are currently covered, allowable life times, and maximum allowable temperatures are limited in Subsection NH, as shown in Table 3-8. Only the temperature limits for Alloy $800 \mathrm{H}$ come close to those required for the NGNP vessels. Coverage for none of the materials is adequate for the very hightemperature NGNP components.

\footnotetext{
${ }^{\mathrm{c}}$ As currently formulated in Subsection NH, the creep-fatigue rules are based on a linear damage accumulation rule, an interaction diagram to account for the synergistic effects (and for environmental effects in the case of ferritic steels), and multiaxial strength theories for both fatigue and creep rupture.
} 
Table 3-8. Current Subsection NH materials and maximum allowable times and temperatures

\begin{tabular}{|c|c|c|}
\hline \multirow{2}{*}{ Material } & \multicolumn{2}{|c|}{ Temperature $\left({ }^{\circ} \mathrm{C}\right)$} \\
\hline & $\begin{array}{c}\text { Primary stress limits and } \\
\text { ratcheting rules }\end{array}$ & Fatigue curves \\
\hline 304 stainless steel & 816 & 704 \\
\hline 316 stainless steel & 816 & 704 \\
\hline $21 / 4 \mathrm{Cr}-1 \mathrm{Mo}$ steel & $593^{\mathrm{b}}$ & 593 \\
\hline Alloy $800 \mathrm{H}$ & 760 & 760 \\
\hline Modified $9 \mathrm{Cr}-1$ Mo steel (Grade 91) & $593^{\mathrm{b}}$ & 538 \\
\hline
\end{tabular}

${ }^{a}$ Allowable stresses extend to $300,000 \mathrm{~h}$ (34 years) unless otherwise noted.

${ }^{\mathrm{b}}$ Temperatures up to $649^{\circ} \mathrm{C}$ are allowed for not more than $1000 \mathrm{~h}$.

Aside from the fact that most preliminary candidate NGNP materials are not included in Subsection NH, there are several generic shortcomings that will require resolution. First, the maximum temperatures permitted will have to be significantly increased. Second, allowable time-dependent stresses will have to be extended beyond the current $300,000 \mathrm{~h}$ maximum to $600,000 \mathrm{~h}$. Third, environmental effects (impure helium) need to be incorporated into the failure criteria, particularly creep-fatigue. Finally, it is generally recognized, by both Code developers and researchers worldwide, that the current linear damage accumulation rule for creep-fatigue is incorrect, inadequate, particularly at higher temperatures, and longer times. Various improvements, such as those based on ductility exhaustion and damage rate, have been proposed, but sufficient R\&D to allow their adoption, as a replacement for linear damage in Subsection NH has backed none. These several shortcomings will have to be remedied for NGNP.

Two other generic shortcomings in the high-temperature structural design methodology were identified in the licensing process for the Clinch River Breeder Reactor Plant (CRBRP) and will likewise have to remedy for NGNP. The first relates to the treatment of weldments. Most high-temperature structural failures occur at weldments. Welded pipe, for example, has failed in high-temperature fossil plants after many years of operation. Reliably guarding against weldment failures is particularly challenging at hightemperatures, where variations in inelastic response of the constituent parts of the weldment (i.e., weld metal, heat-affected zone, and base metal) can result in a strong metallurgical discontinuity. In the hearings for a construction permit for CRBRP, NRC as the foremost structural integrity concern identified early weldment cracking. It was felt that designers should have a better understanding of the metallurgical interactions that take place in weldments and their effects on weldment life. The CRBRP project committed to a five-year development program to address these issues prior to issuance of a plantoperating license. The program was never carried out because of the subsequent demise of the project. Since the issues will almost certainly resurface with NGNP, they will need to be addressed within the High-Temperature Structural Design Technology task.

Like metallurgical discontinuities, geometric discontinuities (i.e., notches and other local structural discontinuities) are sources of component failure initiation. The adequacy of the methodology to handle such discontinuities is reliability and licensing issue, particularly when heat-to-heat variability, strain hardening/softening, and cyclic loadings are considered. This was the number two unresolved issue (after weldments) in the CRBRP licensing hearings, and again NRC required a development program.

Reviewers felt that he effects of stress gradients were not reflected in creep-fatigue design limits and that general notch weakening and loss of ductility under long-term cyclic loadings were not well understood. Notches will receive particular attention in the development of the required high-temperature structural design technology for NGNP. 
Four current Code cases and a draft Code case are relevant. Case N-499 was developed for HTGRs. It permits Class 1 components fabricated from SA-533, Grade B steel to exceed the normal $371^{\circ} \mathrm{C}$ lowtemperature design limit for short periods for Levels B, C, and D events. A similar case might be developed for the NGNP vessel material under off-normal conditions. Case N-201 provides rules for construction of core support structures made of ferritic steels, austenitic stainless steels, and high-nickel alloys, and having metal temperatures not exceeding those in Section II, Part D, of the ASME Code. This Case, with modifications, might be useful for the metallic core internals of NGNP. The basis for the Case is the same high-temperature structural design methodology as that on which Subsection NH is based. Code case N-253 provides rules for Class 2 and 3 components for elevated temperature service. Unless exemption rules are met, the case essentially defaults to the criteria of Subsection NH. Code case N-290, which covers expansion joints in Class 1 liquid-metal piping, can serve as a starting point for criteria and design methods for the NGNP bellows.

A draft Code case developed in the 1980 s for design of nickel Inconel 617 to $982^{\circ} \mathrm{C}$ is directly pertinent to NGNP [32]. The original request for the case came from DOE and General Electric. The specific gascooled reactor component of primary interest was a steam-methane reformer, which was to be part of the reactor primary pressure boundary. Materials of potential interest included nickel alloys $800 \mathrm{H}, \mathrm{X}$, and 617. Inconel 617 was chosen for the case because it was a leading choice of designers, and a reasonable database of material properties existed. The case was developed by an ad hoc group of the Code Subgroup on Elevated Temperatures Design (SG-ETD). The case was subsequently approved by SGETD and submitted to its parent group, the Subcommittee on Design, for approval. However, further action on the case was suspended when the DOE project was canceled.

The case is of value to NGNP because it can serve as a springboard for establishing NGNP Code rules. It was the result of a five-year effort of experienced high-temperature materials and structures engineers, as well as gas-cooled reactor project participants. It also had the participation and input of researchers from JAERI in Japan and KFA in Germany. The draft case, while having the same framework as Subsection $\mathrm{NH}$, has several unique features that are ramifications of the very-high-temperature material behavior. This behavior includes (1) the lack of clear distinction between time-independent and time-dependent behavior, (2) the high dependence of flow stress on strain rate, and (3) softening with time, temperature and strain. Therefore, the design rules of Subsection NH that are based on the separation of time- and rate-independent response, or on strain-hardening idealizations of material behavior required careful reconsideration in the case. For example, the case specifies that inelastic design analyses for temperatures above $649^{\circ} \mathrm{C}$ must be based on unified constitutive equations, which do not distinguish between timeindependent plasticity and time-dependent creep. ${ }^{\mathrm{d}}$ The draft case also recognizes that significant environmental effects on Inconel 617 could exist, and it recognizes that extended exposure at elevated temperature may cause a significant reduction in fracture toughness of Inconel 617, thus introducing an additional failure mode - brittle fracture - to be considered. Finally, because of the uncertainties in data extrapolation and the lack of experience in designing to such high temperatures, where allowable stresses are very low, the draft case is limited to design lives of just $100,000 \mathrm{~h}$ or less.

In addition to inheriting the known shortcomings of Subsection $\mathrm{NH}$, the draft case has a number of gaps and shortcomings that would have to be overcome before it could be satisfactorily and reliably applied. These were identified as the case was being developed. They are tabulated below because of their relevance to this plan.

\footnotetext{
${ }^{\mathrm{d}}$ This is also the case for the high-alloy ferritics (e.g., $9 \mathrm{Cr}-1 \mathrm{Mo}$ steel) at the upper end of their useful temperature range.
} 


\section{Actions Required to Complete Case:}

- Inconel 617 must be added to the low-temperature rules of Section III.

- Weldment stress rupture factors must be added.

- Thermal expansion coefficients must be added.

- Additional isochronous stress-strain curves covering temperatures below $649^{\circ} \mathrm{C}$ and above $950^{\circ} \mathrm{C}$ must be added.

\section{Material Data Needs:}

- Weldment fatigue data are needed.

- A more complete creep-fatigue database is needed.

- The synergistic effects of aging, environment, loading, and temperature should be better understood.

- The effects of aging on toughness must be characterized.

\section{Structural Design Technology Needs:}

- A validated uniaxial constitutive model must be developed.

Some very-high-temperature, time-dependent tests of simple Inconel 617 structural models are needed to

1. Provide a better understanding of structural behavior and failure modes,

2. Validate inelastic analysis methods,

3. Provide application feedback for the case.

Simplified ratcheting evaluation procedures need to be developed for temperatures above $649^{\circ} \mathrm{C}$.

The use of linear damage fractions as the basis of creep-fatigue rules is probably the biggest shortcoming of the draft case. A basic effort is needed to identify and experimentally validate a more suitable damage theory. Since development of the draft case, much more applicable data on Inconel 617 were generated in Germany. In addition, improved restricted-chemistry versions of Inconel 617 are being pursued.

\subsubsection{New ASME Code Section on Composites, Ceramics, and Graphite. The NRC} utilizes codes and standards for nuclear technology that are developed by the NRC, but also accepts codes from the ASME (particularly relevant is the ASME B\&PV Code that includes nuclear power systems). Section II (Materials) of this ASME code currently has specification for ferrous metals (Part A), nonferrous metals (Part B), and welding materials (Part C), but it does not include ceramic materials. ASME will normally accept specifications approved by the ASTM if they grant ASME permission to reprint the specification. This is because the ASTM is considered by ASME to be a source of "consensus" test standards and specifications for evaluating and confirming the composition, microstructure, and properties of a wide range of metals, ceramics, polymers, and composites. As a consensus source, ASTM standards are often cited in ASME codes as a standard for material qualification and acceptance.

Graphite, carbon-carbon (C-C) composites, ceramic matrix composites (CMC), monolithic ceramics, and ceramic insulating systems (e.g., ceramic fiber blankets) are material systems that offer great potential to provide various internal components with structural durability and long life at the very high temperatures that will be encountered within the NGNP reactor. Particular grades of graphite (e.g., grade H-451, 
previous manufactured by SGL Carbon, which is no longer available) were used extensively in previous nuclear reactors (e.g., Fort St. Vrain Reactor). Monolithic ceramics and ceramic insulating systems have not been commonly used, and the new $\mathrm{C}-\mathrm{C}$ and $\mathrm{CMC}$ materials being developed for aerospace and military applications have not been used. As a result, there previously has been no reason for $\mathrm{C}-\mathrm{C}$ and $\mathrm{CMC}$ materials to be licensed by the NRC. Therefore, extensive work will have to be accomplished to assess, refine, qualify, and license existing "ceramic" materials (including new grades of graphite that have been developed by manufacturers and $\mathrm{C}-\mathrm{C}$ and $\mathrm{CMC}$ ) for official approval and licensed use.

One of the difficult challenges in the NGNP program is to plan and pursue a strategy for the early and concurrent development and acceptance of codes and standards for C-C composites, CMCs, graphite(s), monolithic ceramics and ceramic insulation at the three levels: ASTM, ASME, and NRC. Failure to develop those codes and standards in a timely and comprehensive manner will delay or block the regulatory and licensing process that has to be completed for design and operational approval of the reactor. It is essential that the NGNP program include a well-planned, comprehensive, and sufficiently funded effort (from the start of the program) to develop and promote approved codes and standards for C$\mathrm{C}, \mathrm{CMC}$ composites, graphite, monolithic ceramics, and ceramic insulating systems to be used within the reactor. Code and standard work should take advantage of the most relevant ASTM Committee or Subcommittee. Examples of probable committees are: C28 (Advanced Ceramics), E08 (Fatigue and Fracture), E10 (Nuclear Technology and Applications), E28 (Mechanical Testing), D02 (Petroleum Products and Lubricants).

Subcommittee D02.FO (Manufactured Carbon and Graphite Products) already has at least 20 standard test methods under its jurisdiction related to the measurement of mechanical, physical, and chemical properties of nuclear-grade graphite. Two examples are: C625-95 (2000) Standard Practice for Reporting Irradiation Results on Graphite and C781-02 Standard Practice for Testing Graphite and Boronated Graphite Components for High-Temperature Gas-Cooled Nuclear Reactors. Therefore, ASTM subcommittee D02.FO is a likely choice for development of codes and standards for graphite.

ASTM Committee C28 (Advanced Ceramics), including Subcommittee C28.07 (Ceramic Matrix Composites) already has 13 standard test methods for measuring physical and mechanical properties of CMCs. This committee has expressed a willingness to work with the NGNP Materials Program to expand their codes and standards to include the structure and chemistry of ceramic matrix composites (both $\mathrm{SiC}_{\mathrm{f}} / \mathrm{SiC}$ and $\mathrm{C}_{\mathrm{f}} / \mathrm{C}$ ) for nuclear applications. Therefore, ASTM Committee $\mathrm{C} 28$ and subcommittee C28.07 are likely choices for development of codes and standards for ceramic-matrix composites (CMCs), monolithic ceramics, and ceramic insulating systems. The following paragraphs detail the example of working through ASTM Committee C28; it is assumed that work could proceed through other ASTM committees in a similar fashion.

It is recommended that the Qualification of codes and standards effort should be pursued in 4 phases, as discussed below. This effort should begin as soon as possible because it is recognized that it will take many years before the effort can be completed. The 4 phases were developed with input from the leaders of the ASTM Committee C28 on Advanced Ceramics. The Chairman, Vice Chairman, and Recording Secretary of ASTM Committee C28 were all contacted. The consensus from this leadership was that it would be possible to use $\mathrm{C} 28$ to work towards standardization of chemistry, structure, and properties of ceramic composites. They also noted the process was not fast, and would require very strong involvement from the "stakeholders" as well as experts in the field. The committee is voluntary and the standards go through a series of iterations by a voting procedure among the members. A subcommittee of experts has to be established where the $\mathrm{C} 28$ committee serves as a forum for the subcommittee members to work towards achieving solid consensus as needed for ceramics and composite materials. Several subcommittees already exist: C28.01 Properties and Performance, C28.02 Design and Evaluation, C28.05 Characterization and Processing, C28.07 Ceramic Matrix Composites. Other subcommittees can be 
created if the existing ones are not sufficient to meet our specific needs. Since its inception in 1988, the ASTM C28 Committee has created 42 standard test methods for ceramics. These primarily have addressed the standardization and specification of testing methods to provide physical property data. Representative standards for monolithic ceramics are: C 1161 Flexure Strength (Room Temp.), C 1211 Flexure Strength (High Temp.), C 1273 Tension Strength (Room Temp.), C 1322 Fractography, C 1326 Vicker Hardness, C 1259 Elastic Moduli - Impulse Exitation. Representative standards for continuous fiber reinforced ceramics are: C 1275 Tension Strength (Room Temp.), C 1337 Creep, Creep Rupture, C 1292 shear Strength, C 1341 CFCC Flexure Strength. A review of tests standards Developed by ASTM sub-committee C28.07 for Continuous Fiber Reinforced Ceramic Composites (CFCCs; a subcategory of CMC) was written by Lara-Curzio [33].

In addition to standardized tests to measure material property, it will be necessary to develop standard grades of ceramic materials (especially $\mathrm{C}-\mathrm{Cs}$ and $\mathrm{CMCs}$ ) where the physical properties can depend upon many factors: chemical impurities, particular reinforcement pattern/design ("lay-up"), processing/fabrication method and temperatures, porosity, bonding of fibers to the matrix (including coating layers deposited upon the outside of the fibers prior to fabrication), size of the reinforcing fibers, etc. These factors vary from ceramic manufacturer " $A$ " to manufacturer " $B$ " such that no standardized grades exist for ceramic materials. The overall qualification process is essentially the same for a ceramic as it is for a new metal alloy. For a new metal alloy, you start with the proper ASTM Committee that will assign a UNS \# (Unified Numbering System). After approval by ASTM, the qualification moves on to the proper ASME section.

\subsection{Phase 1: Organization and Planning (O/P phase - 12 months) -}

1. Organize an action group for high-temperature composites with participation from the composite producers (manufacturers), the reactor engineering and design companies, the ASTM Advanced Materials committees, the ASME Nuclear Engineering Division, and the NRC Materials and Chemical Engineering Branch in the Engineering Division of the Office of Nuclear Reactor Regulation

2. Assess the projected requirements for ceramics (e.g., C-C and CMC) codes and standards, survey the currently available codes and standards, and identify and prioritize in detail the need for new codes and standards at the three levels: ASTM, ASME, and NRC.

3. Develop a detailed strategy and prioritized action plan for researching, writing, coordinating, and approving the prioritized codes and standards with schedules and resource requirements.

\section{Critical Issues:}

- This effort will depend on the voluntary participation of all the interested parties, but there has to be a designated leader with funded time and resources to champion and drive the initial $\mathrm{O} / \mathrm{P}$ effort.

- Early and continuing participation by NRC, ASME, and ASTM committee members is essential.

- There also has to be strong support from senior DOE and NGNP project leadership to encourage full participation from all parties. 
- Two organizational meetings should be held the first year to energize and focus the standards effort -- a kick-off meeting and a closing meeting.

- The team leader should have a continuing responsibility and funding over the life of the project to organize and coordinate the effort, to report semiannually to program leadership on status and progress, and to foster awareness of and participation in the project within the nuclear community.

\subsection{Phase 2: Writing the Priority 1 Codes and Standards (P1 phase - 36 months) -}

- Select the top five) codes and standards based on priority needs and technical maturity with the goal of producing five standards in 36 months.

- Organize five work teams to research, draft and refine the selected codes and standards in close coordination with ASTM, ASME, and NRC.

- Lay out detailed action plans for each selected code and standard with tasks, schedules, and resource requirements.

- Research and write the drafts and submit to the appropriate regulatory/standards committee for review and approval.

- Refine and resubmit the codes and standards in response to the regulatory/standards committee actions and suggestions.

- Assess the writing and approval process and the team organizations and modify as necessary to meet product, schedule, and cost targets in Phase 3.

\section{Critical Issues}

- Effective, efficient, and timely writing of a given code or standard cannot be guaranteed with the $100 \%$ use of volunteers whose time and energy are already prioritized against job priorities and family obligations. The most effective approach is to fund one person to act as lead author for each code/standard and use the volunteer action team to support his effort with referrals, source material, reviewing, and editing.

- Volunteer participation on the work teams can be encouraged by offering travel funding to attend the pertinent ASTM, ASME, and NRC committee meetings that review and accept the codes and standards.

\subsection{Phase 3: Writing the Priority 2 Codes and Standards (P2 phase - 60 months) -}

1. Select the next ten priority codes and standards and organize action teams to research, draft and refine the selected codes and standards in close coordination with ASTM, ASME, and NRC.

2. Lay out detailed execution plans for each selected code and standard with tasks, schedules, and resources. 
3. Research and write the drafts and submit to the appropriate regulatory committee for review and approval.

4. Refine and resubmit the codes and standards in response to the regulatory/standards committee actions and suggestions.

\section{$\underline{\text { Critical Issue }}$}

The time required for research, writing, review, and approval of a given standard will depend on four factors:

- The depth, breadth, and detail required for a given code or standard

- The technical maturity of a given material system and/or test methods. New material systems may require extensive research and characterization to develop performance specifications and material property databases.

- The time and effort that the action team can apply during the writing and review process, based on funding levels and volunteer dedication and availability.

- The cycle time for review and comment by the designated regulatory/standards committee - ASTM, ASME, NRC.

Some codes and standards will be developed quickly and easily, because the technology is known and there are reference standards available. Others will require extensive effort and time to write and move through the approval process.

\subsection{Phase 4: Writing the Priority 3 Codes and Standards (P3 phase - 48 months)}

1. Select the next ten priority codes and standards and organize action teams to research, draft and refine the selected codes and standards in close coordination with ASTM, ASME, and NRC.

2. Lay out detailed execution plans for each selected code and standard with tasks, schedules, and resources.

3. Research and write the drafts and submit to the appropriate regulatory committee for review and approval.

4. Refine and resubmit the codes and standards in response to the regulatory/standards committee actions and suggestions.

\subsubsection{High-temperature Design Methodology}

Time-dependent failure modes and time- and rate-dependent deformation response to time-varying thermal and mechanical loadings characterize the design of NGNP metallic components operating at high-temperatures. The primary role of the High-Temperature Structural Design Methodology task is two-fold. First it will provide the data and models required by ASME Code groups to formulate timedependent failure criteria that will assure adequate life for components fabricated from the selected 
NGNP materials. ${ }^{e}$ Second, it will provide the experimentally-based constitutive models that are the foundation of the inelastic design analyses specifically required by Subsection NH of Section III of the ASME B\&PV Code, which governs design of elevated-temperature Class 1 nuclear components. This task is thus a key part of the codification and utilization of the selected NGNP structural materials.

A secondary role of the task deals with regulatory acceptance. Safety assessments, required by NRC, will depend on time-dependent flaw growth and the resulting leak rates from postulated pressure-boundary breaks. This requires a flaw assessment procedure capable of reliably predicting crack-induced failures as well as the size and growth of the resulting opening in the pressure boundary. Identification of an overall proven procedure is a part of this task.

The challenges and requirements for designing high-temperature NGNP components, especially when operating temperatures are at the upper end of the usable range for the chosen materials, as will likely be the case for NGNP components, are explained, as background, in the next section. The current scope and coverage of Subsection NH of the ASME Code and its associated Code cases are then outlined in Sect. 2. Identified shortcomings and limitations, as they apply to NGNP, are described. Against this backdrop, and the projected NGNP schedule, the requirements for codification and design with the selected NGNP high-temperature metallic materials are next discussed in Sect. 3. Finally, the scope and schedule for the required High-Temperature Structural Design Methodology task is summarized in Sect. 4.

3.4.4.1 NGNP Requirements. The deliverables for the High-Temperature Structural Design Methodology task need to be keyed to the projected NGNP schedule and the required materials selection dates.

This means that prior to the completion of preliminary design, sufficient data must be collected on each pair of component materials to allow a first cut at design criteria and allowable. The feasibility of the design and the likely adequacy a minimum of two materials will be established by the preliminary design effort. By the beginning of final design, draft Code rules and allowable would have been available for a minimum of two materials selected per component. Soon thereafter, the Code development would focus on the final chosen material for each component, and the High-Temperature Structural Design Technology task would focus on supporting that effort and on resolving application and licensing issues.

Reflecting the overall materials program, the High-Temperature Structural Design Technology task will have two thrusts: (1) pressure boundary metals (pressure vessels) and (2) very-high-temperature metals for internal components. The pressure vessels will certainly be designed to Subsection NH. The highertemperature internal structures, while not strictly pressure boundaries, will likely be designed at least to the intent of Subsection NH since NRL will likely consider a failure of these components as an accident initiator. For purposes of this plan, it is assumed that both pressure boundary and very-high-temperature materials will be included in the rules of Subsection $\mathrm{NH}$ or its associated Code cases.

3.4.4.2 High-temperature Design Work Plan. The following overall strategy will be used to establish the required NGNP High-Temperature Structural Design Methodology, consisting of unified constitutive equations for design analyses, design criteria (creep-fatigue, etc.) and simplified methods for meeting the criteria where possible. Because of the very short time available, immediate attention will be focused on (1) completing work on the draft Code case for Inconel 617, or a variant thereof, for veryhigh-temperature components and (2) adapting the criteria and design methods for modified $9 \mathrm{Cr}-1 \mathrm{Mo}$

\footnotetext{
${ }^{\mathrm{e}}$ A clear distinction should be made between the development of criteria (e.g., the damage accumulation rule and multiaxial strength criterion needed to guard against creep rupture) and the design data needed to quantify the criteria (e.g., uniaxial creeprupture data). The former are largely the purview of the High-Temperature Structural Design Technology task; the latter are the responsibility of the design data generation tasks.
} 
steel (Grade 91) to cover Grade 92 for pressure boundary components. While these materials are leading contenders for NGNP use, even if they are not chosen, their early consideration will allow the design methodology development to build on the considerable previous experience and provide a framework for including subsequent material candidates. The effort will be expanded as material down selection occurs.

Much of this effort provides required technological support and recommendations to the ASME Code Subgroup on Elevated Temperature Design, which is the group responsible for the development of the Subsection NH rules and for inserting new materials into the Subsection. To that extent, the pace and direction of the activities will be dictated by the deliberations and decisions of the Subgroup. It is imperative that key participants in the High-Temperature Structural Design Methodology Development task, as well as those in the materials data tasks, be actively involved in the Subgroup on Elevated Temperature Design.

The planned High-Temperature Structural Design Methodology task activities are outlined in the following subsections. Timelines and key milestones are given at the end. The timing of the various activities reflects their interdependencies, the effort required, and the overall NGNP tentative schedule.

3.4.4.2.1 High-temperature Design Work Plan — The planning effort will focus on three activities:

- Conduct a detailed review of German data and criteria development for high-temperature alloys

- Request, through DOE and the project, that active work on the draft existing code case be reinitiated within the Code groups, and establish, jointly with the metallic materials data tasks, an advisory panel of key Code and Pressure Vessel Research Council participants

- Develop a detailed strategy and program plan for codification of selected NGNP materials, development of the supporting detailed and simplified analysis methods, and experimental validation of the resulting overall methodology.

3.4.4.2.2 High-temperature Design Analysis Methods - Constitutive models, or equations, are the key ingredients of inelastic design analysis methods, which are required by Subsection NH. These equations describe the inelastic flow response of a material to complex time-varying, multiaxial, loadings. Their development must be based on results of a body of exploratory uniaxial and multiaxial tests in which specimens are subjected to a variety of relevant thermal and mechanical loading histories. Experimentally based constitutive equations must be developed for each pair of NGNP materials. Clearly, the constitutive equation development effort must be carried out in close coordination with the materials data tasks.

When the selected pair of structural materials for each component becomes known, the constitutive equation development effort will transition to them. Two of the materials will likely be in the two classes discussed above, so that the earlier efforts will be applicable. Equations for the pairs of pressure boundary and very-high-temperature component materials will be provided in FY-08 in time for final design use. One more iteration on the equations for the final NGNP materials will be issued early in the final design phase. This final iteration will correct shortcomings identified from the results of structural tests and from design analysis experience.

An integral part of constitutive equation development, particularly in the case of unified theories, is the incorporation of the models into computational tools for parameter studies, 
behavioral predictions, and analyses of structural tests. A finite element program that provides assess to the constitutive modeling subroutines will be used for this purpose. Ultimately, the subtask will work with commercial program developers to assure that the needed equations are correctly incorporated into the computer codes to be used for NGNP component design analyses.

\subsection{High-temperature Design Failure Models for Design Criteria — Failure} models normally consist of two ingredients: (1) a damage accumulation model describing failure resulting from the accumulation of damage under varying thermal and mechanical loadings, and (2) a strength criterion relating failures under multiaxial stresses to uniaxial failure data. At the relatively low-temperatures presently covered by Subsection NH, the allimportant area of creep-fatigue failures is handled by separating damage into creep and fatigue components and providing an interaction diagram. Creep damage is characterized by time fractions, and fatigue, by cycle fractions. Von Mises equivalent strain is used for the fatigue strength theory; a special equivalent stress quantity, which must be quantified for each material on the basis of multiaxial creep-rupture test results, is used for the creep-rupture strength theory.

As has been emphasized previously the linear-damage creep-fatigue damage accumulation rule used in Subsection NH is the major shortcoming of the high-temperature rules, and it will likely be an even greater shortcoming at very high temperatures. The key objective of this subtask is thus to develop, in close cooperation with the materials data tasks, a defensible damage accumulation rule and associated strength theories for the NGNP materials. The subtask will include a major consideration of weldments.

Damage models that have been proposed and studied in the past include ductility exhaustion, damage rate, and strain-range partitioning. Their proponents have reported improvements for each over linear damage. To the extent possible, this subtask will take a new fundamental approach to the problem. Exploratory tests will focus on understanding the damage mechanisms, which for NGNP will include environmental effects.

3.4.4.2.4 Simplified Methods for High-temperature Design - While the underlying premise of Subsection NH is that, the variation of stresses and strains with time in a hightemperature component will be predicted by detailed inelastic design analysis, the wide use of such analyses for preliminary design and for every region and loading condition of a component would prove impracticable. Thus, simplified rules for satisfying the strain limits (ratcheting) and creep-fatigue criteria were developed and are provided in Subsection $\mathrm{NH}$. Those simplified methods, which are necessarily considerable more conservative than would be an evaluation based on inelastic analysis, are based on simplifying descriptions of the inelastic material behavior. Unfortunately, as temperatures increase and material behavior becomes more rate-dependent and time-dependent, the bases for the simplified methods become more tenuous. This was recognized in the draft Inconel 617 Code case where application of the simplified ratcheting rules was limited to temperatures of $649^{\circ} \mathrm{C}$ and below.

New, more generally applicable simplified rules will be developed and analytically and experimentally validated for each NGNP structural material. To some extent, this effort must lag behind the development of constitutive equations and improved creep-fatigue criteria. Validated methods for the four NGNP materials - two for pressure vessels and two for veryhigh-temperature components - will be made available. 
The approach to the development of simplified methods will start with an understanding of material behavior and simple models for describing and bounding that behavior. Validation of the methods will come from comparisons with detailed inelastic analysis of representative structural configurations and loadings. Confirmation of the inelastic analysis results will, in turn, come from the structural tests described in the next subsection.

Exemption rules are a form of simplified methods that are also covered in this subtask. They may exempt a component or loading from high-temperature evaluation if, for example, certain time-temperature limits are satisfied or if the number of cyclic loadings is limited. Exemption rules are used in both Code cases N-201 and N-253. Their appropriateness for NGNP components will have to be evaluated with the Code Subgroup on Elevated Temperature Structural Design. Where exemption rules are appropriate, their development can draw on the body of information generated in the High-Temperature Structural Design Methodology task.

3.4.4.2.5 High-temperature Design Confirmatory Structural Tests - Confirmatory time-dependent structural tests have, in the case of most of the current Subsection NH materials and design methodology, provided data that either validated the high-temperature design methodology (inelastic design analysis methods and criteria) or led to changes in inelastic design analysis guidelines or Code rules. The role of structural tests will be even more important for the NGNP materials because of the lack of long-term service experience. The need for very-high-temperature, time-dependent tests of structural models was identified to (1) provide a better understanding of structural behavior and failure modes, (2) validate inelastic analysis methods, and (3) provide some applications feedback to the Code.

It should be emphasized that the structural tests to be performed under this subtask are not tests of NGNP component structures. Rather they are tests of carefully chosen, simple, but representative, geometrical and metallurgical features subjected to time-varying thermal and mechanical loadings. The tests are contrived to explore key features or problem areas of the methodology. Past examples include beams, plates; thick-walled cylinders subjected to thermal gradients, capped cylindrical shells, and nozzle attachments. Cylinders and plates with notchlike discontinuities and with axial or circumferential welds were included. The latter two types of tests will be particularly important to NGNP because of the two major NRC concerns discussed earlier.

3.4.4.2.6 High-temperature Design Safety/Reliability Assessments - While not strictly a part of the design methodology, the safety assessments required for licensing depend on much of the same materials and structures database. A particular need is for a flaw assessment procedure capable of reliably predicting crack-induced failures as well as the size and growth of the resulting opening in the pressure boundary. High-temperature flaw assessment guides have been developed in France, Japan, and the United Kingdom, and work on elements of a procedure is currently underway in the United States under Pressure Vessel Research Council sponsorship. An overall proven procedure, which will require inelastic analysis of flawed components, characterization of sub-critical creep and fatigue crack growth, and a structural failure criterion, does not exist however. These will be developed for the NGNP materials.

\subsection{High-temperature Design Resolution of Identified Shortcomings,} Issues, and Regulatory Concerns - Experience has shown that once detailed design assessments are undertaken, shortcomings and issues with the design methodology and criteria will arise, requiring additional $R \& D$ for their resolution. In addition, the licensing process will likely result in the identification of further R\&D requirements, as it did in the case of the 
CRBRP project. Thus, it is anticipated that the High-Temperature Structural Design Methodology development project will continue throughout the design effort to resolve the shortcomings, issues, and regulatory concerns.

\subsubsection{Component Material Life Prediction Modeling}

The usable lifetime of materials in service are determined by the combination of initial quality, normal service conditions, and the cumulative effect of off-normal and/or accident conditions encountered. For essential components, an optimum materials selection will have a test data set that provides data on time dependent failure mechanisms such as corrosion and creep that bound the expected product lifetime. However, obtaining such a data set is generally impractical. The desired design life for most components for the NGNP have been set at a nominal 60 years and that is generally longer than most needed reactor system materials have been available.

To make defensible design and regulatory arguments for the viability of materials beyond their existing test data set involves the combined use of test data and modeling that accurately predicts the effects of relevant time-dependent failure mechanisms. A standardized and structured approach to prediction of long-term behavior in materials has been documented in ASTM C-1174, 1997, Prediction of the LongTerm Behavior of Materials, Including Waste Forms, Used in Engineered Barrier Systems (EBS) for Geological Disposal of High Level Radioactive Waste.

This standard requires use of problem definition, testing, modeling, and model confirmation to predict long-term behavior. Testing typically involves attribute tests, characterization tests, accelerated effects tests, service condition tests, confirmation tests, and analog tests or analyses. This standard or a similar, approved standard shall be used to guide life prediction modeling activities. 


\section{$4 \quad$ MATERIALS SELECTION AND QUALIFICATION DOCUMENTS}

\subsection{Documentation of Materials Selections}

\subsubsection{Preliminary Selection Documentation}

The process for preliminary selection of candidate materials is discussed in Section 3.1. A complete, independently reviewed and approved preliminary selection document is expected to be the first product of the Materials Program. It is expected to provide the specific basis and justification for initiating qualification testing in a given component set. At this time, ten preliminary selection documents are considered essential, although more could be added if necessary:

- Pressure Vessels, Fixtures, and Connectors

- Graphite Fuel Blocks, Reflectors, and Separators

- Control Rod System Components

- Primary Loop IHX and Piping

- Reactor Internal Metallic Components

- Hot Duct Liner and Thermal Insulating Materials

- IHX Pressure Vessel

- Power Conversion Unit Turbine and Generator Components

- PCU Recuperators

- Valves, Bearings, and Seals.

These documents will reflect the database reviews, existing data qualification, and expected usability of materials options (i.e., technical acceptability, manufacturability, regulatory acceptability, cost, longevity, schedule). The documents will also lay out a detailed qualification sequence including scoping tests to further narrow the selection and qualification tests specifically for use as design inputs and codification support.

Where design tradeoff studies are necessary to complete the preliminary selection, the documentation of the preliminary selection will be held until the tradeoff study is completed so that the results of the tradeoff analysis can be included in the selection document. Tradeoff studies will also be documented separately as engineering design files with their own document number and independent reviews/approvals.

\subsubsection{Component Final Material Selection Report}

The Component Final Material Selection Report is a product of the NGNP system developer and the materials qualification and selection process and is intended to summarize all existing and newlygenerated materials data, code status, and manufacturability work demonstrating the qualification of the material selected for an essential reactor component. The data presented in the final selection report must be fully referenced to show its source and that it was previously qualified or generated under appropriately controlled testing efforts such that it is fully usable as design input data under the reactor project QA requirements set.

\subsection{Qualification Program Topical Reports}

The documentation of qualification testing and analysis will be managed by generation of topical reports covering logical divisions of the qualification test program. These interim reports will act as the permanent QA records documenting the results of specific tests and analyses performed within the 
materials program. The qualification program topical reports will generally be designed to cover specific testing or analytical efforts that can be performed within a calendar year and can be used as the deliverables for easily definable blocks of work. Where a specific test program (i.e., creep testing of pressure vessel steel) spans more than one year, an interim topical report may be used to document work completed through a given fiscal year or funding cycle. As the formal record of work completed, the reports will require document numbers, 


\section{COLLABORATION ON MATERIALS PROGRAMS}

\subsection{Collaboration with Other U.S. Materials Developments}

To ensure that materials qualification efforts are not duplicated, a dialogue and collaboration between the NGNP materials effort, other Generation IV programs, and other significant U.S. materials efforts is appropriate. Materials development and qualification activities are underway on several other major DOE programs in the United States at this time - the Yucca Mountain Spent Nuclear fuel Disposal Project, the Advanced Fuel Cycle Initiative, the Office of Fissile Energy's materials research program, the DOE Fusion Energy Sciences (FES) program, the FES Fusion Materials Development subprogram, and the DOE Office of Science's Materials Sciences and Engineering subprogram.

- The Yucca Mountain Project has developed welding procedures including pre and post-heat treatment requirements for heavy section welding of ASTM A 516, Gr. 70 carbon steel. This technology could be applied to the fabrication of the RPV. They are also working on thick section welding of Alloy 22. The knowledge gained here could be applied to alloys such as Inconel 617. These programs include development of new welding control and inspection technologies.

- The Advanced Fuel Cycle Initiative is looking at transmutation materials and may be able to provide significant information on materials irradiation behavior that is applicable to reactor components.

- The DOE Office of Fossil Energy's materials research program includes research on developing high-temperature, corrosion-resistant structural ceramic composites and alloys, and materials that perform specific functions in advanced fossil energy systems. Some of the areas of interest to the NGNP materials program would be advanced materials research in high-temperature alloys and refractories and the development of advanced carbon products.

- The FES Fusion Materials Development subprogram directly supports DOE's efforts to advance plasma science, fusion science, and fusion technology - the knowledge base needed for an economically and environmentally attractive fusion energy source. Materials developed and evaluated within the Fusion Materials Development subprogram for their highly challenging irradiation, temperature, and chemical environments will be highly pertinent to the NGNP.

- The DOE Office of Science Materials Sciences and Engineering subprogram supports research to extend the frontiers of materials sciences and engineering to expand the scientific foundations for the development of materials that improve the efficiency, economy, environmental acceptability, and safety in energy generation, conversion, transmission, and use. The subprogram supports basic research to understand the atomistic basis of materials properties and behavior and how to make materials perform better at acceptable cost through new methods of synthesis and processing.

\subsection{International Nuclear Program Collaboration}

Major efforts are in progress to develop gas reactor technology in a variety of locations throughout the world. The Generation IV program involves collaboration with a number of member countries on a regular basis. The Generation IV materials crosscut program is expected to provide the collaborative interface between the NGNP materials program and foreign interests. 
Of particular interest and importance to the NGNP materials program are activities being conducted in Japan, France, Switzerland, and South Africa. The Japanese High-temperature Test Reactor (HTTR) represents a reactor currently in operation that is closer to the proposed NGNP concepts than any other in the world at this time. A wealth of information on graphite and other reactor materials could be very helpful to the U.S. program. France is not currently building an NGNP-type reactor, but is actively pursuing materials and fuels development activities. Existing French facilities for high-temperature helium loop studies and French thick section welding development may be directly applicable to the NGNP materials efforts. The Swiss Paul Shearer Institute for nuclear studies may provide an additional location for materials irradiations and collaboration on a variety of materials issues that they are currently working on.

Funding is provided in the NGNP materials program (see Section 6.2) to support the travel and negotiations with these international entities to come to agreement on the collaborative work efforts to be performed. 


\section{PROGRAM SCHEDULE \& COST ESTIMATES}

\subsection{Program Schedule}

\subsubsection{NGNP Program Schedule}

The NGNP summary program schedule is shown in Figure 6-1 with an assumed start of October 2003. A detailed schedule of program tasks is provided in Appendix $\mathrm{C}$ for those interested in the full schedule logic and task interrelationships.

\subsubsection{Schedule Basis}

The materials selection and qualification program is designed to achieve materials qualification on a schedule that will support the NGNP design process. Final materials design data and the final material selection reports are essential early in the final design to support the initiation of long-lead component procurements.

The NGNP schedule is dependent on the funding profile and a variety of other factors beyond the purview of the materials program; however, most current planning efforts have been focused on completing an NGNP reactor to begin operation somewhere between 2015 and 2017. The schedule provided in this document is designed to complete the materials selection and qualification activities necessary to support the NGNP design consistent with a year 2015 reactor startup.

\subsubsection{Schedule Logic}

The NGNP schedule provides time estimates for all major activities to be performed in the materials program. A baseline logic path is followed throughout the materials program to try to minimize the overall time required to complete the materials efforts. This logic involves the following sequential actions:

- Preliminary selection of materials to enter the qualification process based on existing data

- Design of needed irradiation test plans and fixtures to support irradiation testing

- Scoping tests (if needed) to further narrow the scope of the qualification program

- Early manufacturability determinations to verify feasibility of obtaining desired materials in desired configurations, sizes, etc.

- Purchase of representative qualification test sample materials to be used throughout the materials qualification testing sequence

- Testing of representative qualification test materials to obtain needed properties information for reactor design and support needed licensing activities

- Final selection based on the full set of existing data, manufacturability determinations, qualification testing, and code acceptability. 


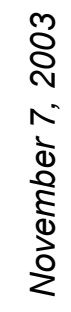

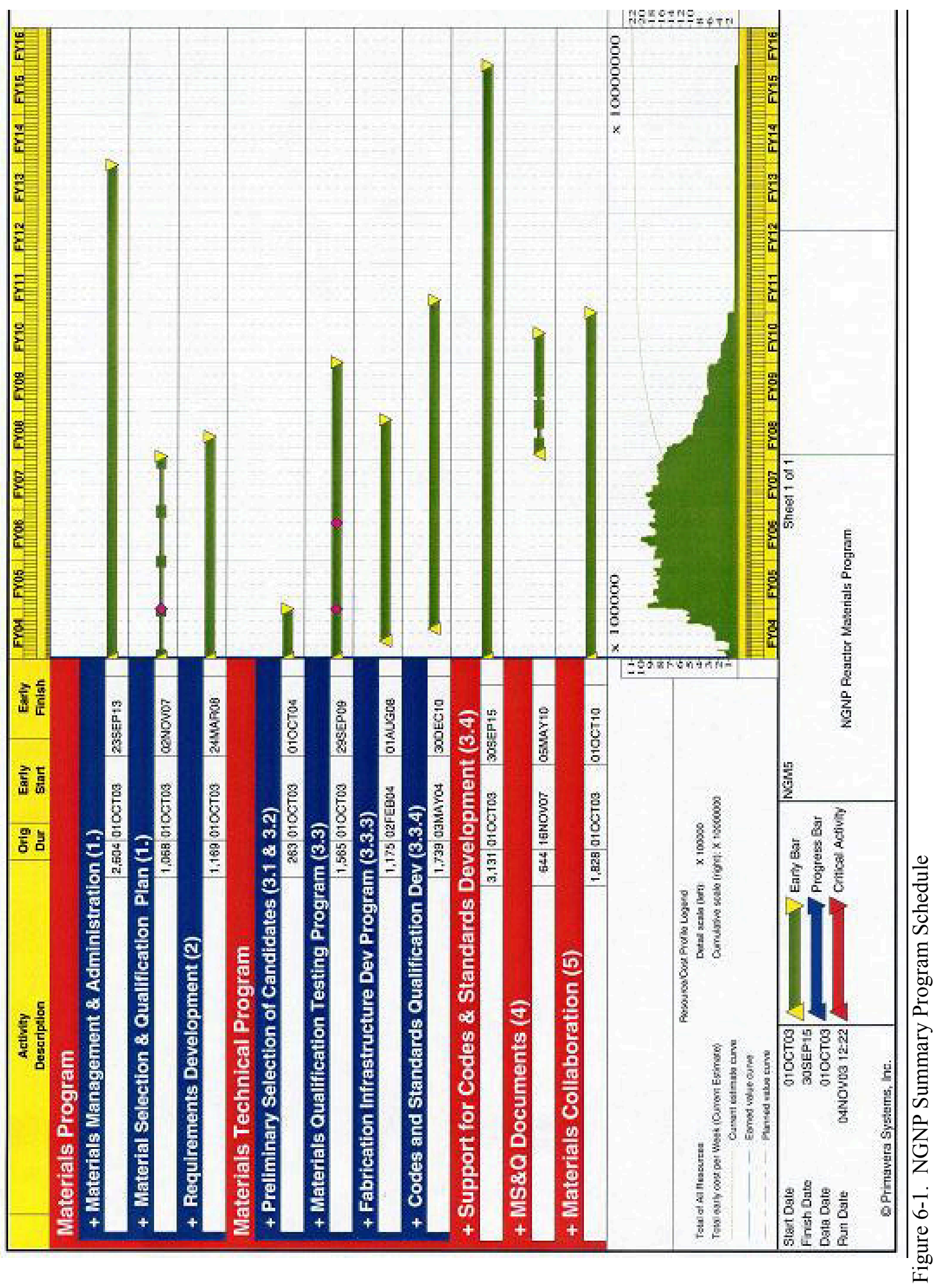




\subsection{Cost and Resources Estimates}

\subsubsection{Cost Estimate}

The overall cost for the NGNP materials program was estimated at $\$ 241.5 \mathrm{M}$. The cost estimate for the program was computed by resource loading the specific tasks in the program schedule with the scientific, technician, and support manpower, and materials and subcontract costs. The schedule program computes the distribution of the resources over the duration of the specific tasks to provide costs and resource loading as a function of time. Costs are estimated in FY-03 dollars. No cost escalation factors have been added.

The following manpower rates were used in calculating the costs shown in the tables:

- M\&O Scientific and Metallurgical Engineering Manpower.

$\$ 300 \mathrm{~K} / \mathrm{MY}$

- M\&O Technicians, Crafts, and Support Personnel.........................................\$228K/MY

- National Technical Director (NTD) Manpower............................................\$350K/MY

The total estimate is calculated as follows:

Calculated costs from Schedule loading: $\$ 219.6 \mathrm{M}$

Contingency and Escalation (10\%): $\$ 21.9 \mathrm{M}$

Total Program Estimate:

The calculated cost, broken down by Fiscal year and program element (without contingency), is shown in Table 6-1.

\subsubsection{Resource Breakdown}

The following breakdown between manpower, materials, and subcontract resources for performing this program was calculated:

Scientific and Engineering Manpower (326 MY) $\$ 108.5 \mathrm{M}$

Technician, Crafts, and Support Manpower (144.4 MY) $\$ 45.4 \mathrm{M}$

Materials and Equipment $\$ 40.1 \mathrm{M}$

Subcontracts $\$ 25.6 \mathrm{M}$ 


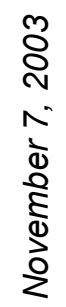

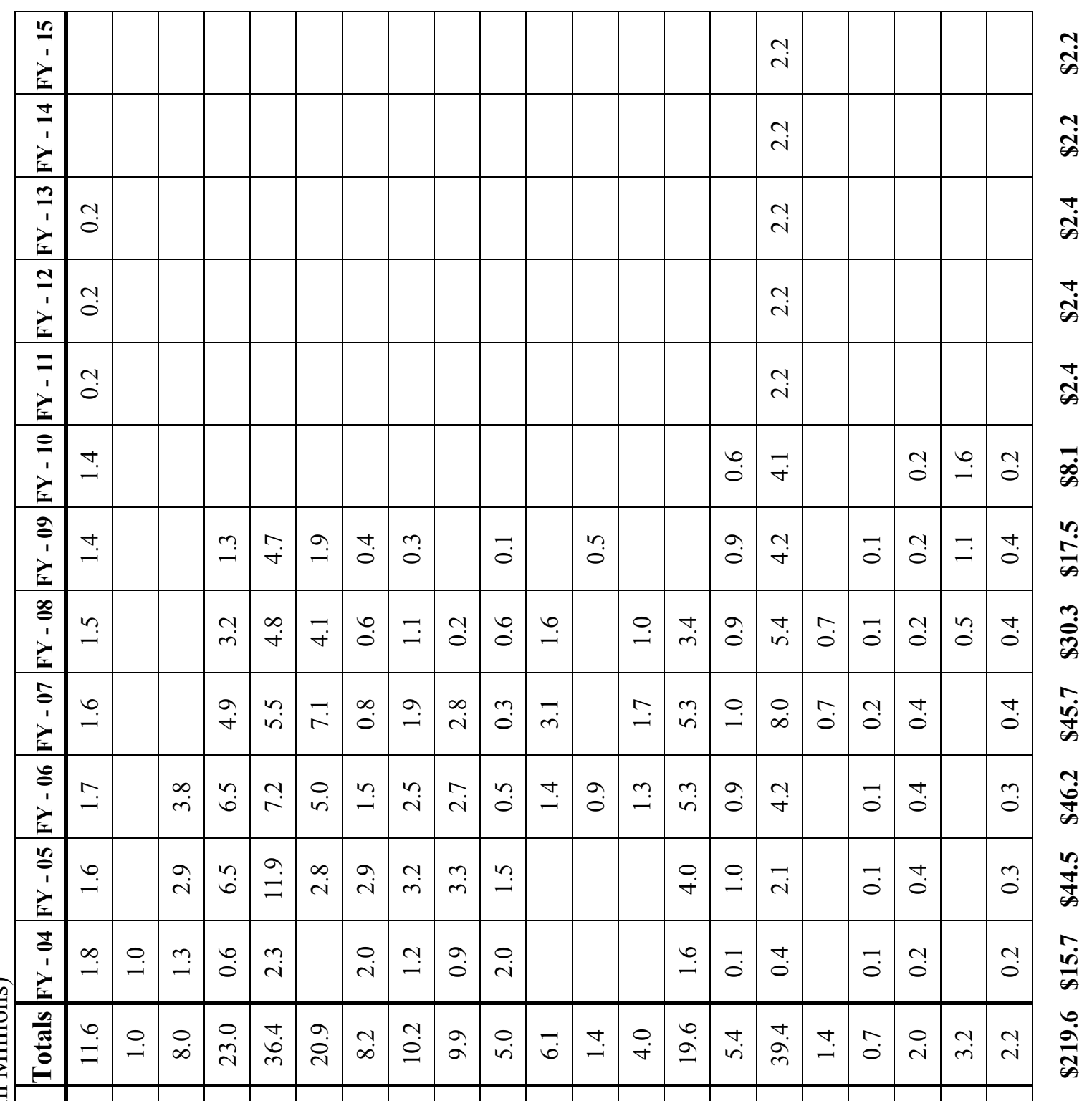



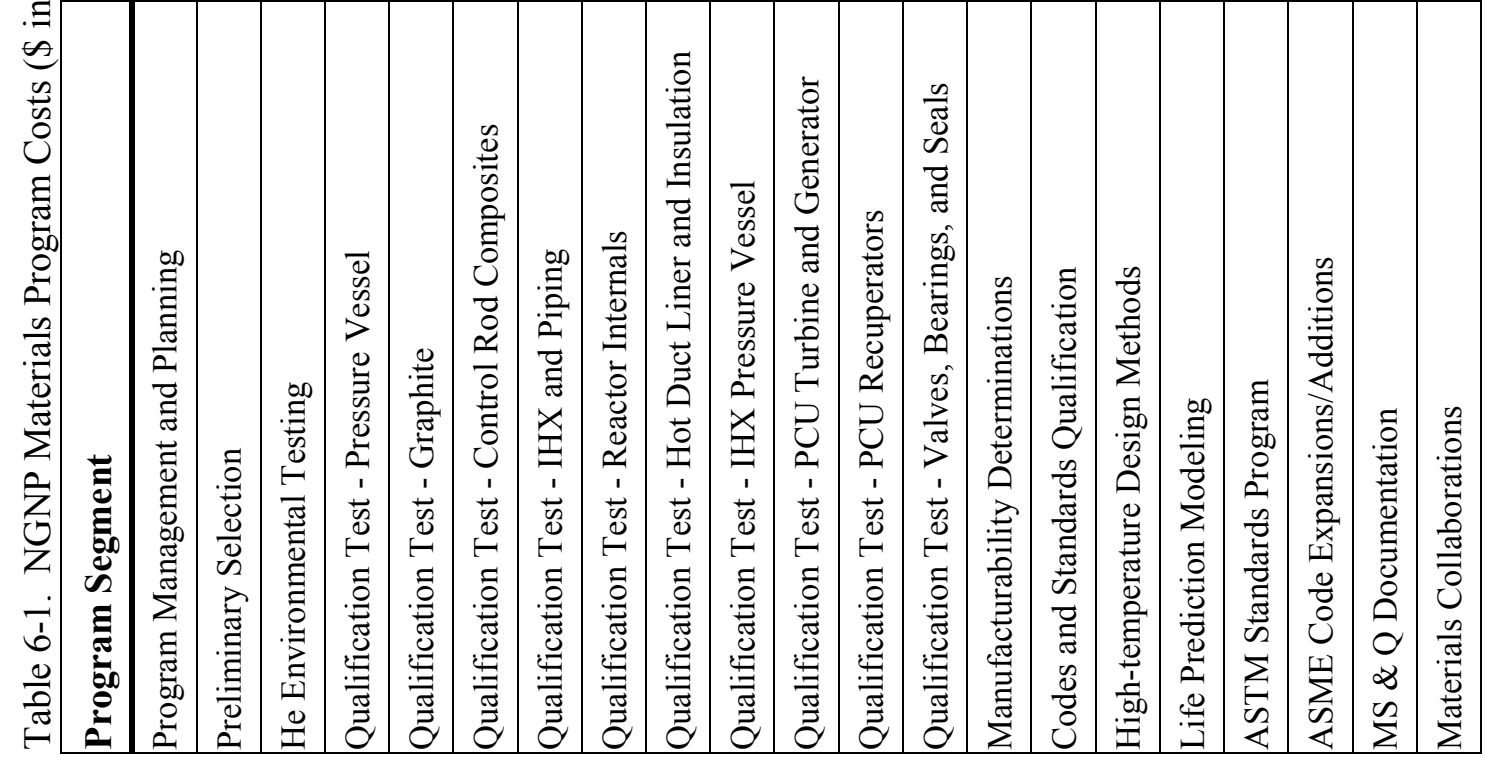


This page intentionally left blank. 


\section{Appendix A - July 8-9, 2003, Meeting Attendees}

\section{Argonne National Laboratory - West}

Todd R. Allen

\section{ATK-COI Ceramics, Inc}

Andrew Szweda

\section{BWXT Services Inc.}

William A. McInteer

\section{U.S. Department of Energy - Headquarters}

Sue Lesica

\section{U.S. DOE Idaho Operations Office}

Cliff Fineman

Gordon McClellan

John Yankeelov

\section{Gateway}

Stephen Gonczy

\section{GE Power Systems, Power Systems Composites, LLC}

Dennis Landini

\section{General Atomics}

Malcom P. LaBar

Russ Vollman

Idaho National Engineering and

Environmental Laboratory

George Beitel

Lori Braase

Rob Bratton

Dennis Harrell

George Hayner

Ron Mizia

D. K. Morton

W. K. Sowder

Kim Stein

Dave Swank

Terry Totemeier
Will Windes

Richard Wright

\section{Los Alamos National Laboratory}

Stuart A. Maloy

Ralph H. Moeller

Kurt E. Sickafus

\section{Oak Ridge National Laboratory}

Bill Corwin

James Klett

Randy Nanstad

Lance Snead

Roger Earl Stoller

Robert W. Swindeman

Dane Wilson

Marina Ruggles-Wrenn

Steve Zinkle

George E. Kulynych - BWXT

Philip L. Rittenhouse - Consultant

Pacific Northwest National Laboratory

Steve Bruemmer

David S. Gelles

Roger Johnson

Russell H. Jones

Sandia National Laboratory

Rion Causey - CA

John Stephens

\section{Savannah River Site}

Dennis F. Bickford

Paul Korinko

McIntyre R. Louthan, Jr.

\section{Ultramet}

Theodore J. Norbut

Westinghouse

Thomas Mager 
This page intentionally left blank. 


\section{Appendix B - Next Generation Nuclear Plant (NGNP) Materials Review Committee Charter}

Purpose: The Idaho National Engineering and Environmental Lab (INEEL) created a Materials Review Committee (MRC) to provide the NGNP Materials Program Manager with a collegial review and an independent assessment of the wide range of materials-related issues required to successfully design and construct the NGNP. The MRC will provide advice solely to the NGNP Materials Program and the INEEL as the NGNP reactor integrator and design authority for DOE-NE. MRC advice can be accepted or rejected and it is not binding. The MRC is an INEEL-sponsored committee and does not fall under the Federal Advisory Committee Act.

1. Scope

1.1 Provide (as requested) an independent review, objective technical materials guidance, and recommendations related to:

1.1.1 Materials program plan documents, reports, contracts, vendor submittals, testing plans, etc.

1.1.2 Materials requirements as a function of overall system and component needs.

1.1.3 Materials research, development, and qualification program information.

1.1.4 Other related materials issues as directed by the NGNP Materials Program Manager.

1.2 Report all reviews, advice, actions or recommendations collectively in MRC meeting minutes.

\section{MRC Independence/Conflict of Interest}

2.1 Personnel having a direct part or decision-making role in the NGNP Materials Program cannot serve as a member of the MRC.

2.2 The experts on the MRC must be independent from actual testing and $\mathrm{R} \& \mathrm{D}$ work that is performed.

2.3 MRC members may not personally lead NGNP associated activities.3. Operating

Principles

3.1 The MRC will operate within the guidelines of an approved Charter.

3.2 The MRC will not receive or review proprietary information.

3.3 The INEEL NGNP Materials Program Manager will be the primary interface with the MRC Chair.

3.4 MRC Members and participants will act in a confidential, ethical, and scientifically responsible manner in association with all MRC activities. 
3.5 The NGNP Materials Program will fund travel and per diem expenses of the MRC Members.

3.6 The NGNP Materials Program will provide reports of MRC activity to the Generation IV Materials NTD and other affected NGNP Program participants.3.7 Any actions taken as a result of MRC recommendations will be under the control of the NGNP QA Program.4. Membership

4.1 Members must agree with and abide by this Charter. Primary organizations that employ Members must agree with their employee participation and membership on the MRC.

4.2 The MRC consists of an open number of Members, including the Chair. Membership may include representatives from industry, the DOE-NE contractor organizations, academia, or other related sources.

4.3 MRC Members are selected based on their materials expertise and independence.

4.4 Non-members may present or attend MRC meetings as participants at the request of the NGNP Materials Program Manager or the MRC Chair.

4.5 A Member may delegate their role to an alternate acceptable to the MRC Chair in the event of a conflict with a scheduled meeting.

\section{Roles and Responsibilities}

5.1 Chair - Authority to conduct the meetings and responsibility to interface with the NGNP Materials Program Manager. Retains full MRC membership with all associated roles and responsibilities.

5.2 Members - Participate in the meetings and decision-making process to accomplish the stated goals. Remain current with meeting materials and communications. Complete requested actions.

5.3 Participants - Participate in meeting discussions and provide information/input and presentations as requested. Does not have voting or decision-making rights regarding issues discussed by the MRC.

5.4 Facilitator/Secretary - Works with the Chair to develop and distribute the Agenda approximately two weeks prior to a meeting. Helps MRC maintain focus on the Agenda topics. Facilitates discussion topics as requested by the Chair. Ensures appropriate information is captured during the meetings. Produces a draft summary of the meeting approximately two weeks after the conclusion; issues the final meeting summary with concurrence of the Chair approximately one month after the meeting. The Facilitator is not a voting member of the MRC.

5.5 NGNP Materials Program Manager - Interfaces with the Chair, MRC Members, DOENE, other DOE contractor personnel, and the Facilitator/Secretary as appropriate to develop the program and reconcile issues or recommendations made by the MRC. Documents any clarifications, assignments, or reconciliations made as an attachment to the MRC minutes. Participates in MRC meeting preparation and coordination activities, but is not a voting member of the MRC. Appoints MRC Members and the Chair based 
on relevant expertise, program requirements, and independence. Rotates Members based on program considerations or resignations from Members.

\section{Meeting Management}

6.1 Schedule - Meetings will generally be held quarterly, but can be scheduled based on need. Sufficient notice will be provided to the Members regarding date, location, and purpose.

6.2 Meeting Rules - The Chair will establish the rules and guidelines for the meeting.

6.3 Recommendations - Recommendations will be made based on consensus of the MRC Members. Consensus is defined as general agreement with no strong objection. In the event of not reaching consensus, recommendations will be made based on majority vote with documentation of minority opinion.

6.4 Quorum - A quorum of two-thirds of the membership, including the Chair, is required to conduct a meeting.

6.5 Document Control - Actions and issues will be tracked to resolution. Recommendations will be documented and maintained as part of the NGNP document control system.

6.6 Approval of Minutes - The MRC Members will approve the MRC meeting summary as final at the next MRC meeting.

\section{Charter Modification}

7.1 The MRC Charter can be revised at any time by the NGNP Materials Program Manager based on program considerations. 


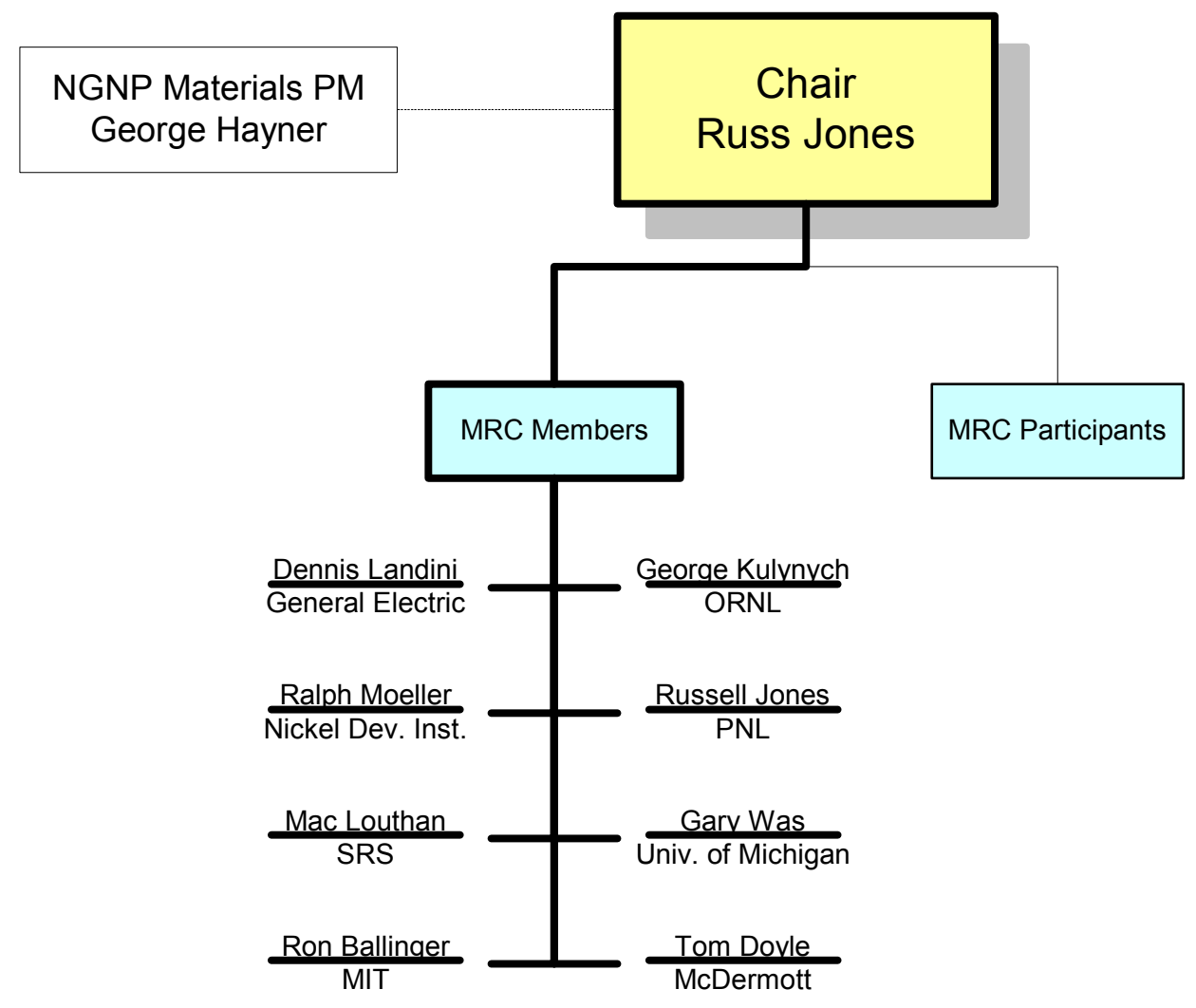

Figure B-1. NGNP Materials Review Committee, 2003 


\section{Appendix C - Guidance on Qualification of Existing Data}

\section{C-1 GENERAL}

This provides non-mandatory guidance on the qualification of existing data, including data of indeterminate quality, for use in activities specified in Part I of NQA-1. The data qualification process includes data qualification planning, a controlled process for evaluating and establishing data quality, and documentation of the results of this process. This guidance may be used in conjunction with guidance on the Control of Scientific Investigations.

Existing data is defined as data determined to be necessary for activities specified in Part I, NQA-1, but developed prior to the implementation or outside of Part I NQA-1; or data published in scientific publications. Existing data does not include information, which is accepted by the scientific and engineering community as established fact (e.g., engineering handbooks, density tables, gravitational laws, etc.).

\section{C-2 SELECTING DATA SETS FOR QUALIFICATION}

The identification of data sets to be recommended for qualification should be based on its end use and a consideration of the potential impact on risk, safety, or mission.

\section{C-3 DATA QUALIFICATION PROCESS}

\section{C-3.1 Data Qualification Planning}

Data qualification planning includes:

1. The reason(s) for qualifying the data

2. The selected qualification method(s)

3. The rationale for selecting the methods

4. The evaluation criteria planned for use in qualifying the data set including specific information such as size of sample to be tested, statistical method to be used, and identification of computer codes to be used.

5. A description of the required technical disciplines and subject matter discipline experts pertaining to the data

6. The identification of individuals performing the data qualification effort and their requisite qualifications

7. A schedule for completing the work.

\section{C-3.2 Data Qualification Preparation}

Before initiating a data qualification effort, background information on the subject data set should be collected, including pertinent records concerning any available procedures or documentation of data acquisition or development methodology, and prior reviews of data. 


\section{C-3.3 Data Qualification Attributes}

Attributes to consider in the qualification process include:

1. The technical adequacy of equipment and procedures used to collect and analyze the data

2. The extent to which the data demonstrate the properties and ranges of interest (e.g., physical, chemical, geological, mechanical)

3. The environmental conditions under which the data were obtained (if germane to the quality of the data)

4. The quality and reliability of the measurement control program under which the data were generated

5. The extent to which conditions under which the data were generated may generally meet the requirements and guidance of NQA-1

6. Prior range of uses of the data and associated verification processes

7. Prior peer or other professional reviews of the data and their results

8. Extent and reliability of the documentation associated with the data

9. Extent and quality of corroborating data or confirmatory test results

10. The degree to which independent audits of the process that generated the data was conducted.

\section{C-4 QUALIFICATION METHODS}

One or more of the following methods should be used to qualify data: (1) Quality Assurance Program Equivalency, (2) Data Corroboration, (3) Confirmatory Testing, and (4) Peer Review.

\section{C-4.1 Quality Assurance Program Equivalency Method}

The Quality Assurance Program Equivalency method may be used to determine if the acquisition, development, or processing of data have been performed in accordance with sound technical, administrative practices or procedures that can be demonstrated to generally meet the applicable requirements and guidance of NQA-1. The employed practices or procedures must demonstrate industryacceptable scientific, engineering, or administrative practices or processes with appropriate compliance documentation as defined in data qualification planning. Examples of conditions for which the Quality Assurance Program Equivalency method may be useful include: (a) data acquisition, collection, or development records, including equipment calibration documentation, and personnel qualification records are available; and (b) documentation of the technical or administrative practices or procedures used to process the data are available.

\section{C-4.2 Data Corroboration Method}

The Data Corroboration method may be used in order to determine if subject matter data comparisons can be shown to substantiate or confirm parameter values. This method may include comparisons of the data 
to both other sources of qualified data, as well as to sources of other existing data, as defined in data qualification planning. Examples of conditions for which the Data Corroboration method may be useful include: (a) a sufficient quantity of corroborating data are available to permit valid statistical comparison with the unqualified data set(s); and (b) inferences drawn to corroborate the existing data can be clearly identified, justified, and documented.

\section{C-4.3 Confirmatory Testing Method}

The Confirmatory Testing method may be used when tests can be designed and performed to establish the quality of existing or indeterminate data. Confirmatory Testing also may be used when previous test results are not verifiable because of questionable testing methodology or a lack of applicable documentation. Confirmatory test results should demonstrate direct correlation to previous test results, if feasible. However, data extrapolation is acceptable within the limits defined in data qualification planning. Examples of conditions for which the Confirmatory Testing method may be useful include: (a) similar test conditions are prescribed, and (b) test result correlation or extrapolations are applicable.

\section{C-4.4 Peer Review Method}

The Peer Review Method is used to independently evaluate data to determine if the employed methodology is acceptable; confidence is warranted in the data acquisition or developmental results; or the data have been used in a similar range of applications. Use of the Peer Review method for this purpose should include an evaluation of the data acquisition and development approach, including test plans, to determine the acceptability of the uncertainties associated with the employed data acquisition or development methodology, the adequacy and appropriateness of the interpretations derived from the data, and the extent to which the uncertainties affect the interpretations, conclusions, and overall validity of the data. If the evaluation indicates the uncertainties are unacceptable or the data interpretations are inappropriate, this result should be fully documented. A report documenting the peer review activity should be prepared as defined during data qualification planning and provide for the inclusion of any dissenting conclusions and comments by individual peer reviewers.

\section{C-5 DOCUMENTATION OF RESULTS}

Results of the data qualification task should be documented in a report that includes:

1. The scope of the task

2. The data set(s) for qualification

3. The expertise of the individuals performing the data qualification effort

4. The method(s) of qualification and rationale for the selected option(s)

5. The rationale for abandoning any of the qualification methods, if appropriate

6. Evaluation criteria

7. Qualification criteria

8. Data generated by the evaluation (if applicable)

9. The results of the evaluation

10. A recommendation for/against changing the qualification status of the data.

Management should evaluate the recommendation and disposition the data appropriately (i.e., if the data set(s) is determined to be "qualified", update the data qualification status from "existing" to "qualified," OR if the data set(s) is determined to be "not qualified", a decision should be made and documented regarding the need to collect more data.) 
This page intentionally left blank. 


\section{Appendix D - Detailed NGNP Program Schedule}

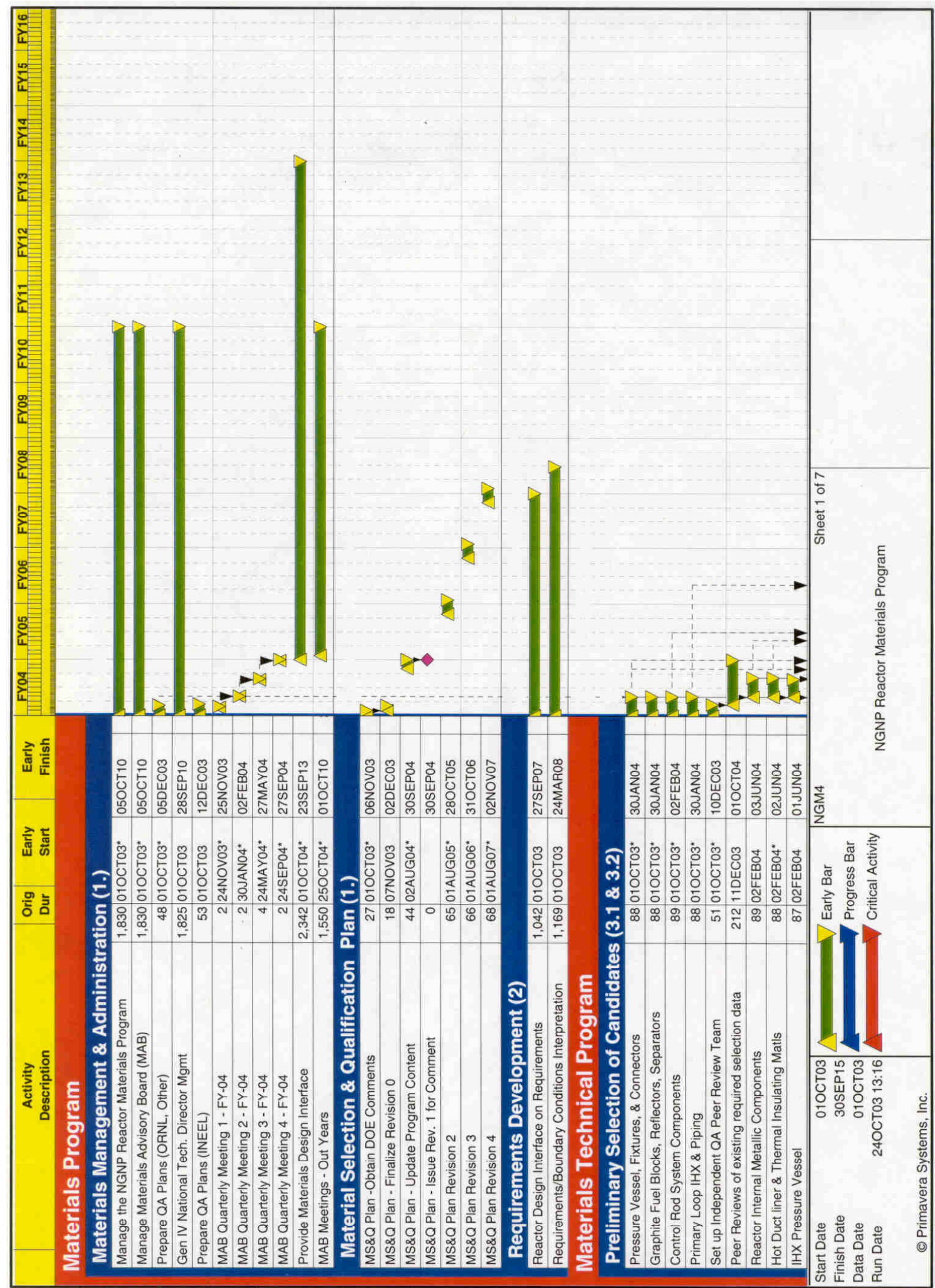




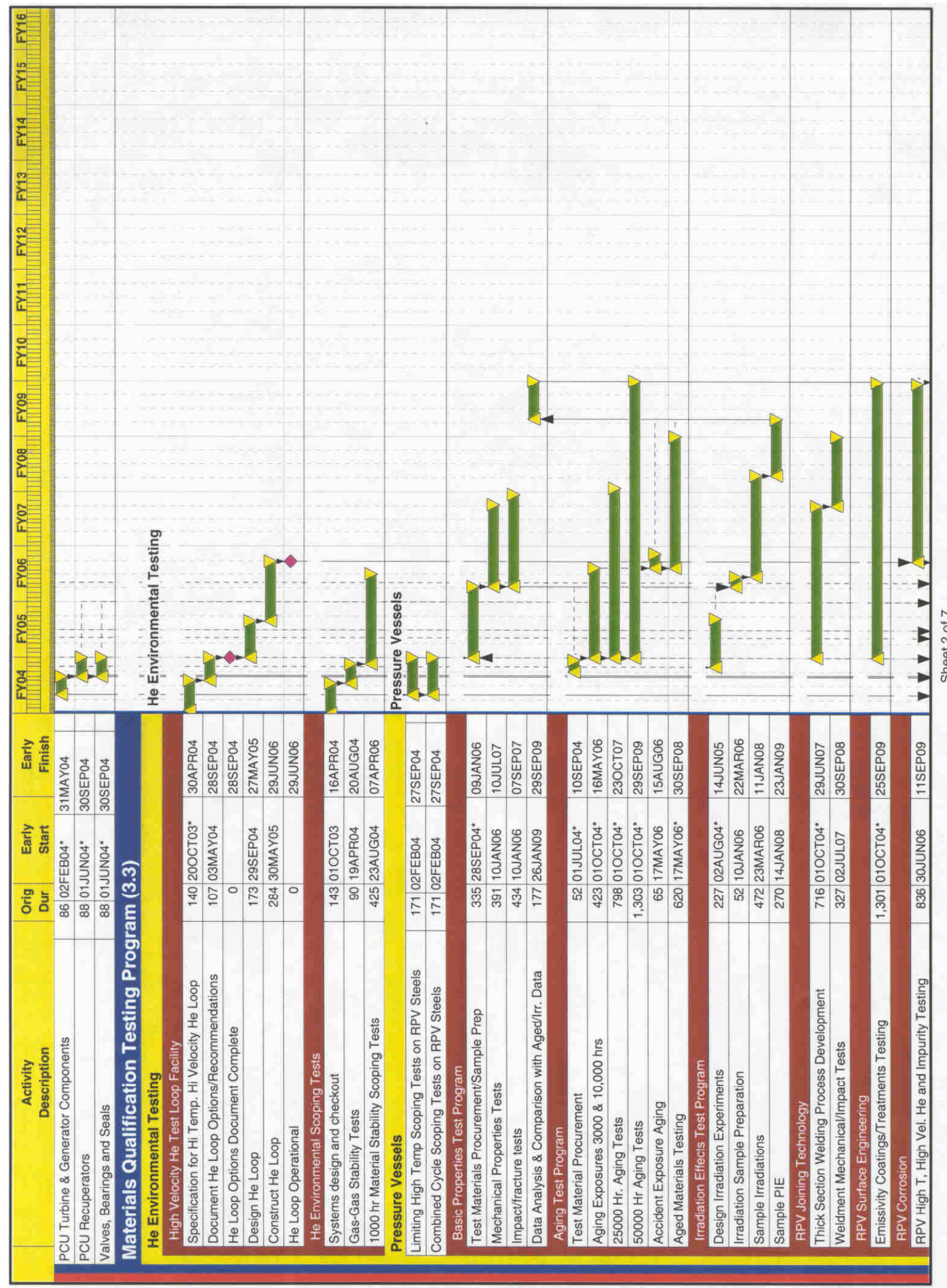




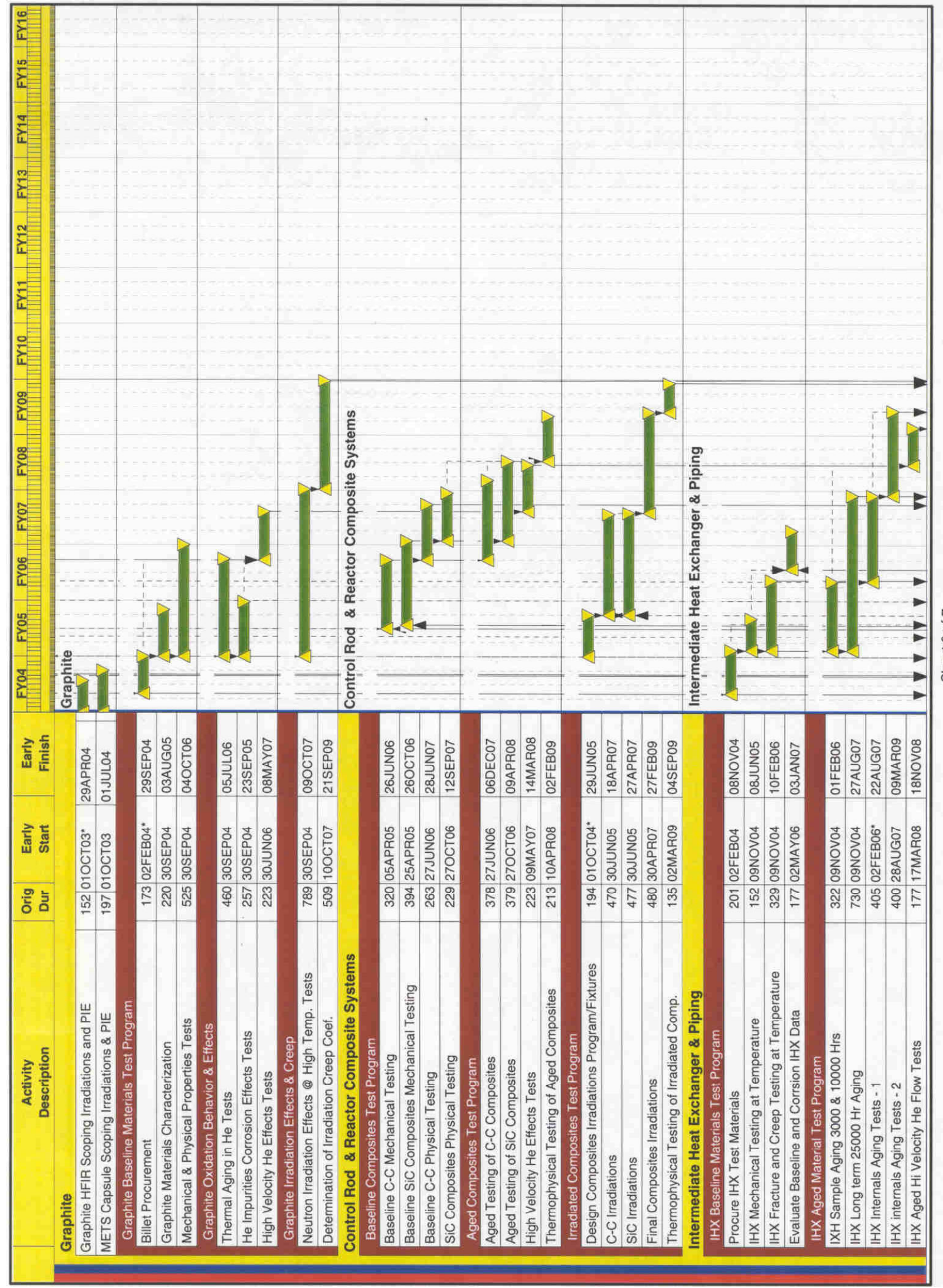




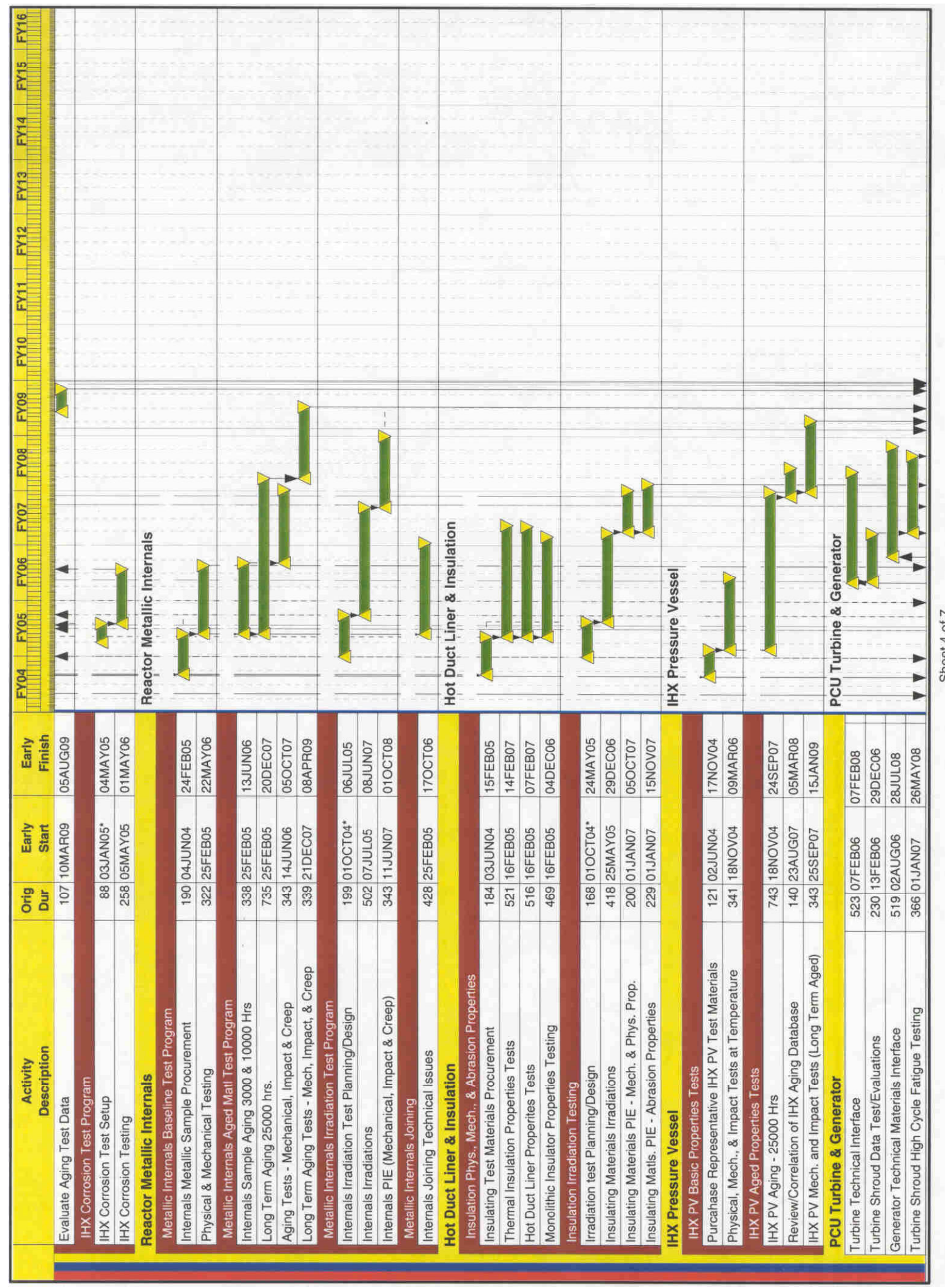




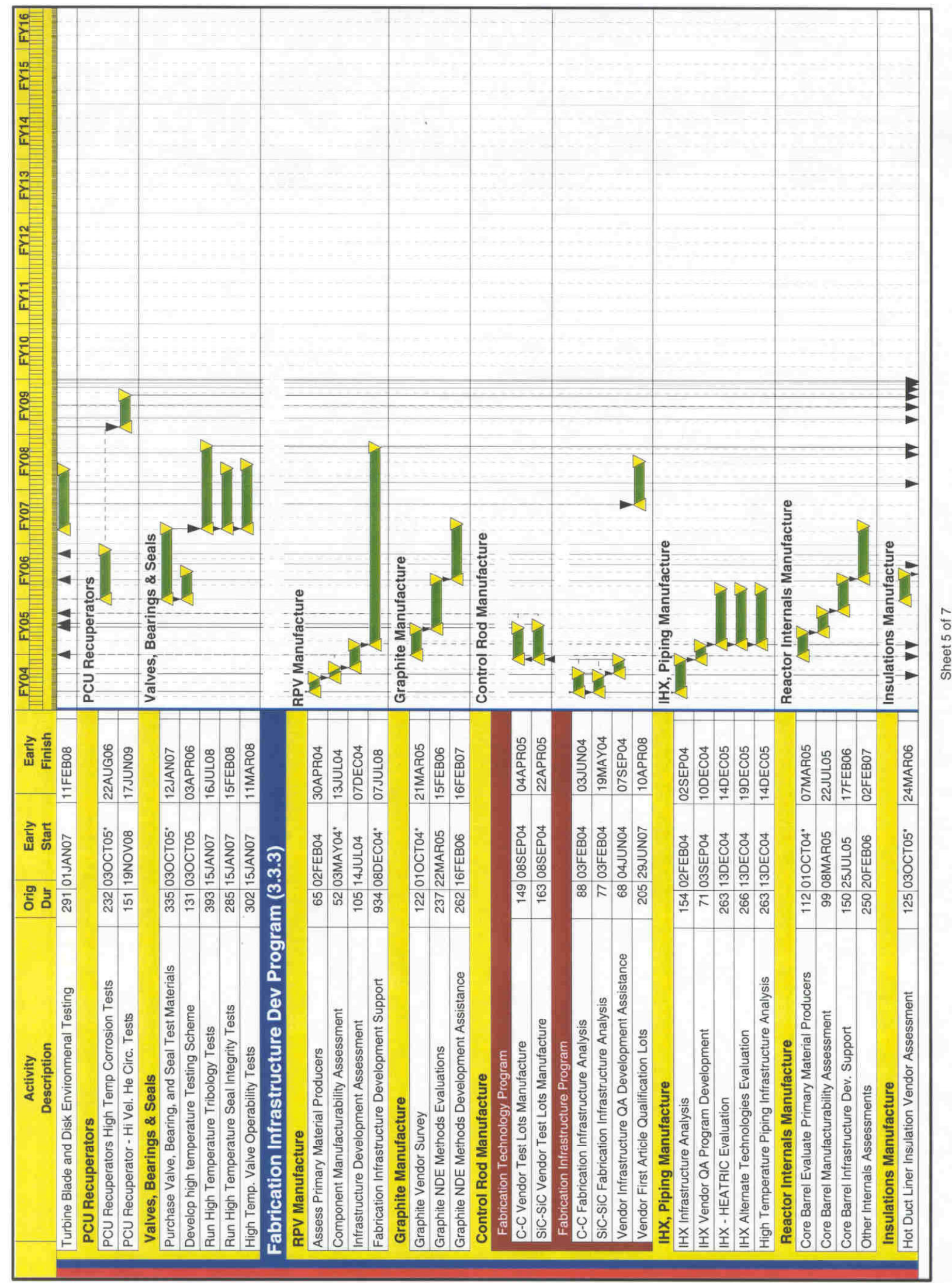




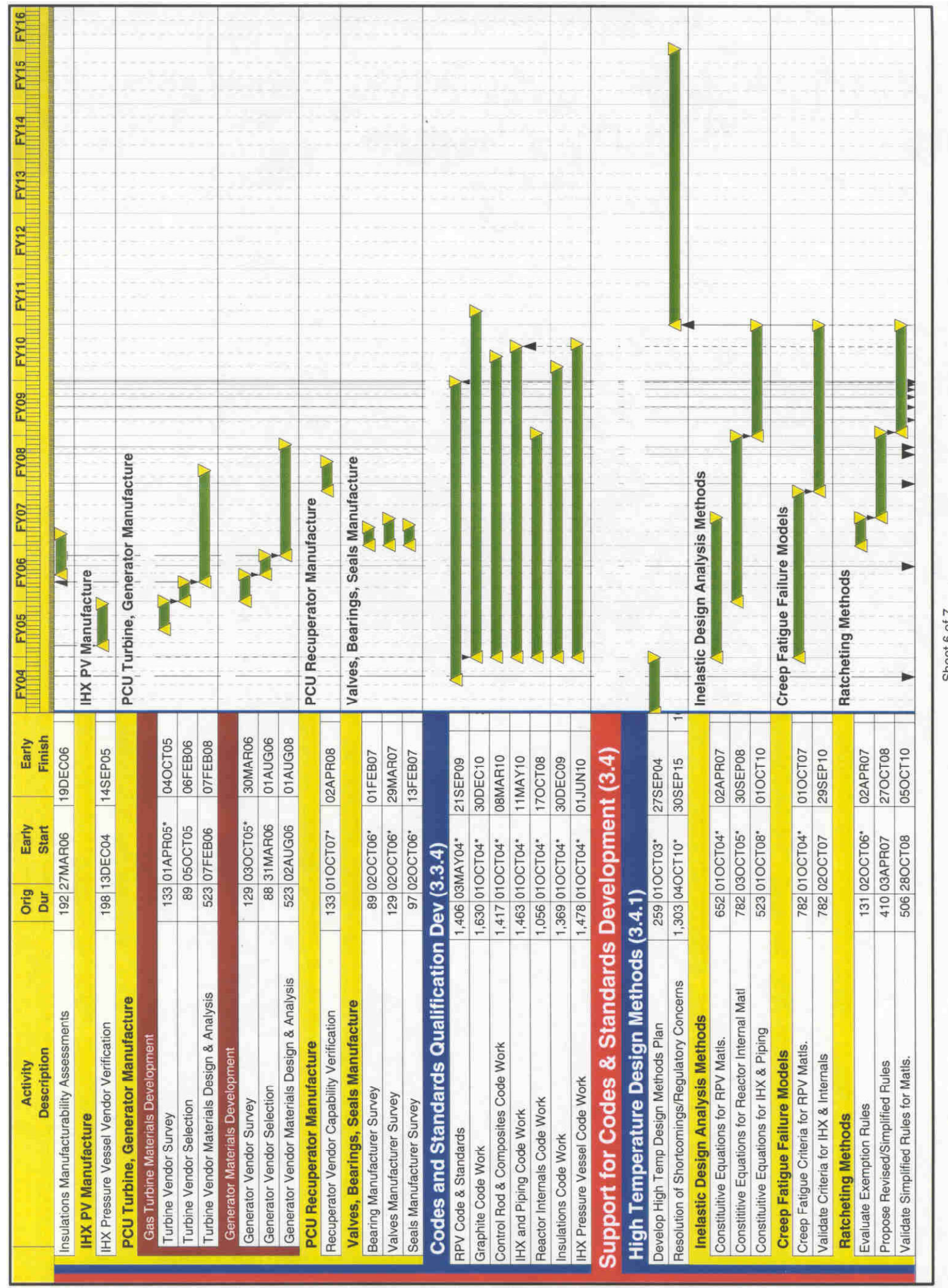




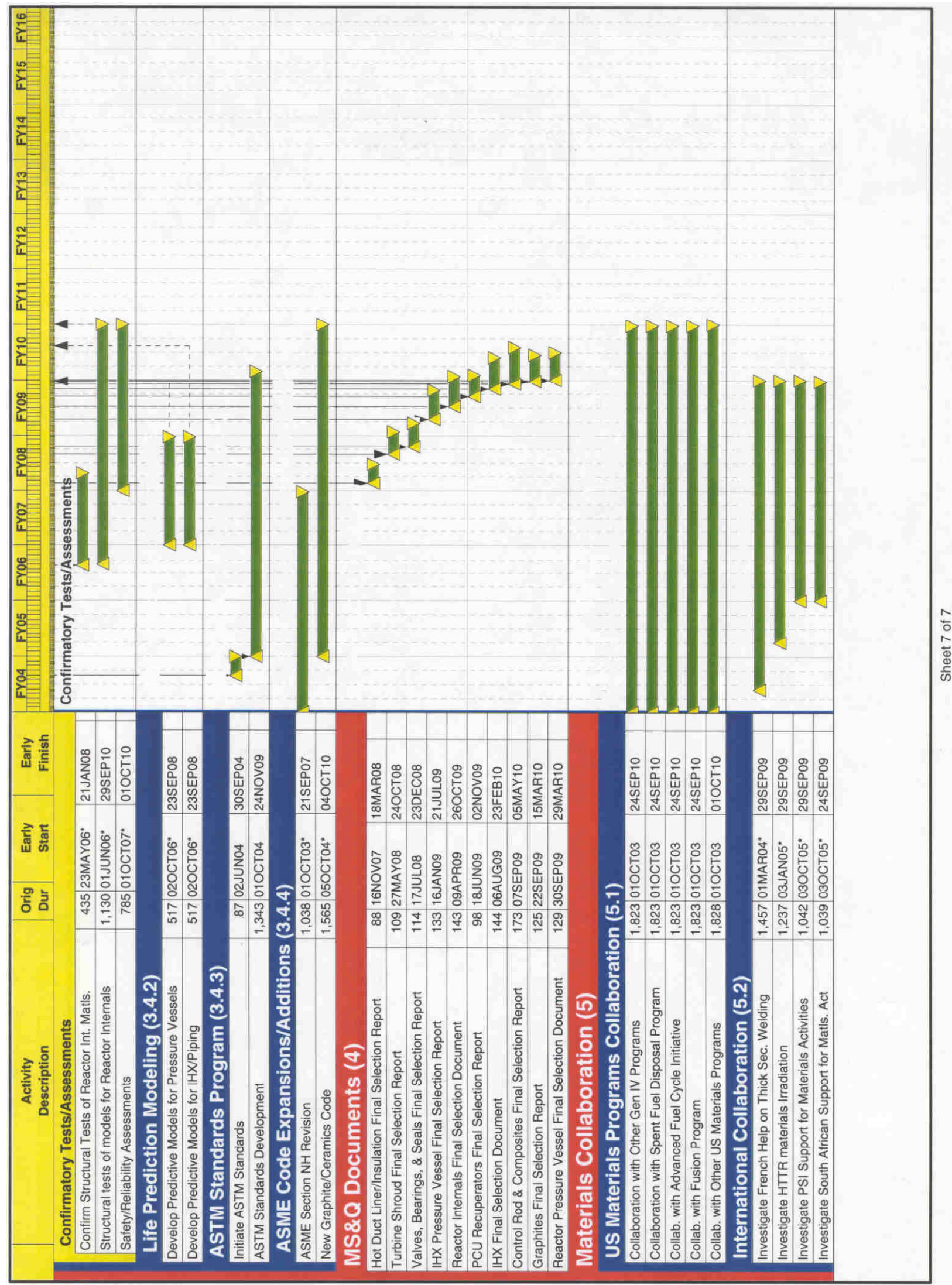


This page intentionally left blank. 


\section{Appendix E - References}

1 Baccaglini, G. et.al, Very High Temperature Reactor (VHTR) Survey of Materials Research and Development needs to Support Early Deployment, INEEL/EXT-03-00141, January 31, 2003.

2 Conversation with Russ Vollman of General Atomics

3 Email from Jim Sterbentz 7/2/03 "Flux-Fluence-dpa data for prismatic VHTR"

4 Table 6.2-1 in General Atomics Gas Turbine-Modular Helium Reactor (GT-MHR) Conceptual Design Description Report, \# 910720 Rev. 1, July 1996.

5 ANS 2003 Gas Reactor Technology Course, Arkal Shenoy's presentation in slide titled "High Temperature Materials"

6 Inagaki, Y, et al., Nuclear Engineering and Design, Vol. 185, 1998, pp. 141-151.

7 L. L. Snead, Journal of Nuclear Materials, 283-287, (2000) 551-555.

8 T. Hinoki, et al, Journal of Nuclear Materials, Vol. 307-311, Part B [2003], pp. 1157-1162

9 R. H. Jones, G. E. Youngblood, C. H. Henager, Jr., M. L. Hamilton, H. L. Heinisch, and C. A. Lewinsohn, "Progress in the Development of SiCf/SiC Composites for Fusion Energy Applications", in Proceedings of the $1^{\text {st }}$ IEA International Workshop on SiCf /SiC Ceramic Composites for Fusion Structural Applications, October 19-28, 1996, Ispra, Italy, p. 1.

10 L. L. Snead, M. Osborne, and K. L. More, Journal of Materials Research, Vol. 10 [3], 1995, pp. 736-747.

11 T. Nozawa, Proceedings of the $10^{\text {th }}$ International Conference on Fusion Reactor Materials, BadenBaden, Germany, October 2001, Journal of Nuclear Materials, in press.

12 R. J. Price, et al., Journal of Nuclear Materials, 108-109, (1982), 732-738.

13 R. J. Price, et al., Journal of Nuclear Materials, 33, (1969), 17-22.

14 L. L. Snead, Proceedings of the 10 International Conference on Fusion Reactor Materials, BadenBaden, Germany, October 2001, Journal of Nuclear Materials, in press.

15 D. A. G. Bruggeman, "Dielectric Constant And Conductivity Of Mixtures Of Isotropic Materials", Annal. Physik 24 (1935) 636.

16 S. Nomura and T. W. Chou, "Bounds Of Effective Thermal Conductivities Of Short-Fiber Composites”, J. Comp. Mater. 14 (1980) 120.

17 J. J. Brennan, L. D. Bentsen, and D. P. H. Hasselman, "Determination Of The Thermal Conductivity And Diffusivity Of Thin Fibers By The Composite Method”, J. Mater. Sci. 17 (1982) 2337. 
18 H. Tawil, Larry D. Bentsen, S. Baskaran, and D. P. H. Hasselman, "Thermal conductivity of chemically vapor deposited silicon carbide reinforced with silicon carbide or carbon fibers," $J$. Mater. Sci. 20 (1985) 3201.

19 D. P. H. Hasselman, L. F. Johnson, R. Syed, Mark P. Taylor, and K. Chyung, "Heat conduction characteristics of a carbon fiber-reinforced lithia-aluminosilicate ceramic," J. Mater. Sci. 22 (1987) 701.

20 D. P. H. Hasselman, A. Venkateswaran, M. Yu, and H. Tawil, "Role of interfacial debonding and matrix cracking in the effective thermal diffusivity of SiC fiber-reinforced chemically vapor deposited SiC matrix composite," J. Mater. Sci. Lett. 10 (1991) 1037.

21 Hemanshu Bhatt, Kimberly Y. Donaldson, and D. P. H. Hasselman, "Role of interfacial carbon layer in the thermal diffusivity/conductivity of silicon carbide fiber-reinforced reaction bonded silicon nitride matrix composites," J. Am. Ceram. Soc. 75[2] (1992) 334.

22 D. P. H. Hasselman and Lloyd F. Johnson, "Effective thermal conductivity of composites with interfacial thermal barrier resistance," J. Comp. Mater. 21 (1987) 508

23 W. R. Cannon and T. G. Langdon, "Review of Creep of ceramics - Part 1 Mechanical Characterstics", Journal of Materials Science 18 (1983) pp. 1-50.

24 P. A. Lessing and R. S. Gordon, "Creep of polycrystalline alumina, pure and doped with transition metal impurities”, Journal of Materials Science 12 (1977) pp. 2291-2302.

25 P. A. Lessing, R. S. Gordon and K. S. Mazdiyasni, "Creep of Polycrystalline Mullite", J. Am. Cer. Soc. 58 [3-4] 149 (1975).

26 Grafoil is a registered trademark of UCAR Carbon Company, Inc., P.O. Box 218, Columbia, TN 38402-0218. Phone: 931-380-4360.

27 Kaowool is a registered trademark of Thermal Ceramics (Division of Morgan Refractories), Old Savannah Rd., P.O. Box 923, Augusta, GA 30903. Phone: 706-796-4323.

28 Calcarb, 110 Indel Ave., P.O. Box 477, Rancocas, NJ 08073. Phone : 800-732-5432.

29 O. F. Kimball and D. E. Plumblee, Gas/Metal Interaction Studies in Simulated HTGR Helium, HTGR -85-064, General Electric Company, Schenectady, New York, June 1985.

30 R. E. Pawel, D. L. McElroy, R. S. Graves, J. J. Campbell, The Emittance of an Oxidized 304 Stainless Steel, ORNL/TM-9858, Oak Ridge National Laboratory, 1986.

31 V. N. Shah, S. Majumdar, and K. Natesan, Review and Assessment of Codes and Procedures for HTGR Components, NUREG/CR-6816 (ANL-02/36), Argonne National Laboratory, June 2003.

32 J. M. Corum and J. J. Blass, "Rules for Design of Alloy 617 Nuclear Components to Very High Temperatures," pp. 147-153, PVP-Vol. 215, Fatigue, Fracture, and Risk, Am. Soc. of Mechanical Engineers, 1991. 
33 Edgar Lara-Curzio, "Development of Test Standards for Continuous Fiber Ceramic Composites in the United States" in Advanced SiC/SiC Ceramic Composites: Developments and Applications in Energy Systems, Eds. Akira Kohyama, Mrityunjay Singh, Hua-Tay Lin, and Yutai Katoh, Ceramic Transactions, Vol. 144, The American Ceramic Society, May 20-22, 2002, Kyoto, Japan, pp. 191 206. 